\title{
High Efficiency, Low Emission Refrigeration System
}

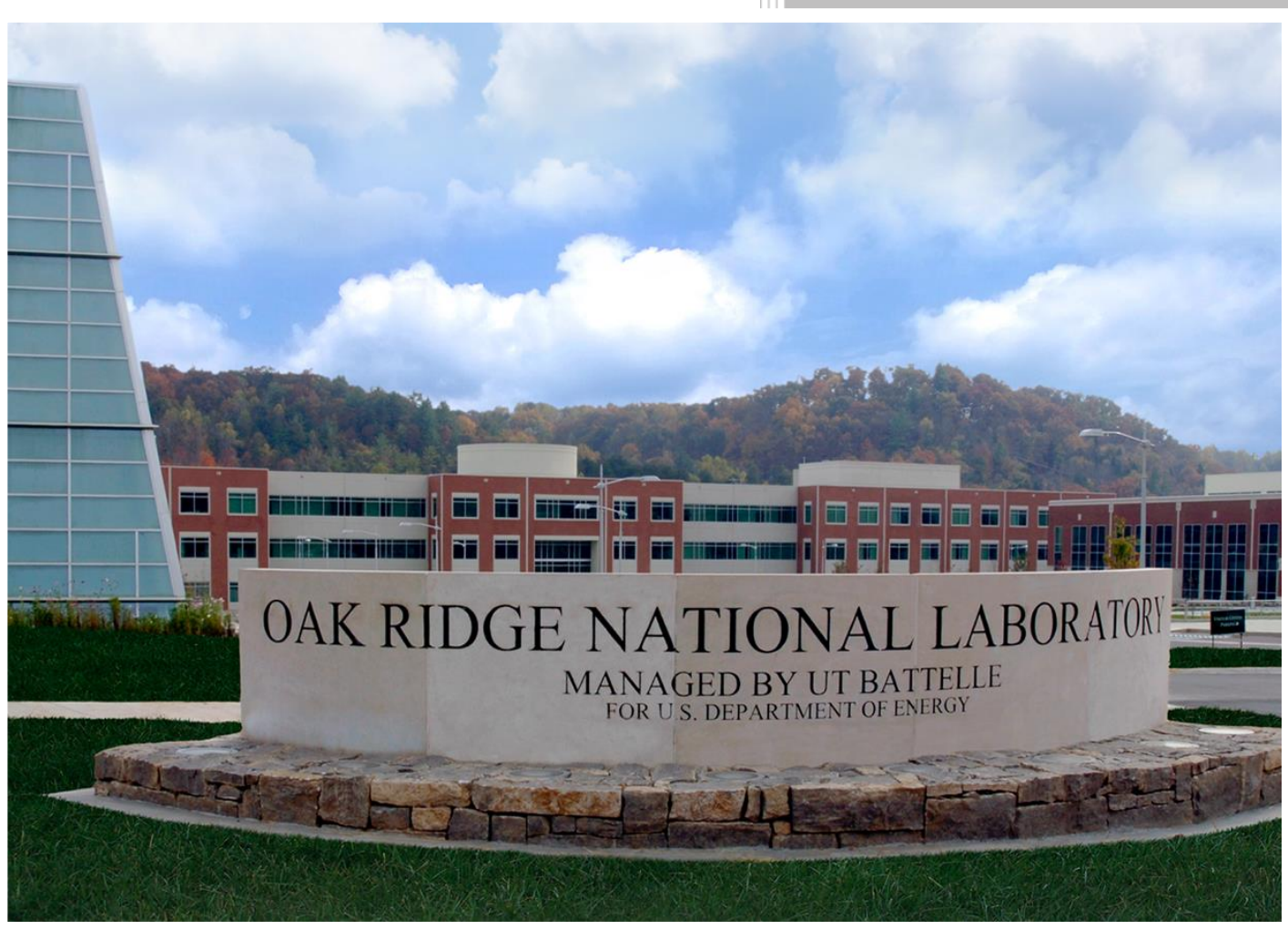

Approved for public release. Distribution is unlimited.

Brian A. Fricke

Vishaldeep Sharma

August 2016 


\section{DOCUMENT AVAILABILITY}

Reports produced after January 1, 1996, are generally available free via US Department of Energy (DOE) SciTech Connect.

Website http://www.osti.gov/scitech/

Reports produced before January 1, 1996, may be purchased by members of the public from the following source:

National Technical Information Service

5285 Port Royal Road

Springfield, VA 22161

Telephone 703-605-6000 (1-800-553-6847)

TDD 703-487-4639

Fax 703-605-6900

E-mail info@ntis.gov

Website http://www.ntis.gov/help/ordermethods.aspx

Reports are available to DOE employees, DOE contractors, Energy Technology Data Exchange representatives, and International Nuclear Information System representatives from the following source:

Office of Scientific and Technical Information

PO Box 62

Oak Ridge, TN 37831

Telephone 865-576-8401

Fax 865-576-5728

E-mail reports@osti.gov

Website http://www.osti.gov/contact.html

This report was prepared as an account of work sponsored by an agency of the United States Government. Neither the United States Government nor any agency thereof, nor any of their employees, makes any warranty, express or implied, or assumes any legal liability or responsibility for the accuracy, completeness, or usefulness of any information, apparatus, product, or process disclosed, or represents that its use would not infringe privately owned rights. Reference herein to any specific commercial product, process, or service by trade name, trademark, manufacturer, or otherwise, does not necessarily constitute or imply its endorsement, recommendation, or favoring by the United States Government or any agency thereof. The views and opinions of authors expressed herein do not necessarily state or reflect those of the United States Government or any agency thereof. 
ORNL/TM-2016/363

CRADA/NFE-11-03296

Building Technologies Research and Integration Center

\title{
HIGH EFFICIENCY, LOW EMISSION REFRIGERATION SYSTEM
}

\author{
Brian A. Fricke \\ Vishaldeep Sharma
}

Date Published: August 2016

\author{
Prepared by \\ OAK RIDGE NATIONAL LABORATORY \\ Oak Ridge, Tennessee 37831-6283 \\ managed by \\ UT-BATTELLE, LLC \\ for the \\ US DEPARTMENT OF ENERGY \\ under contract DE-AC05-00OR22725
}

Approved for Public Release 



\section{CONTENTS}

CONTENTS...

2. ANALYSIS OF REFRIGERATION SYSTEMS AND REFRIGERANT OPTIONS …………......... 5

2.1 LIFE CYCLE CLIMATE PERFORMANCE (LCCP) ……………………………............5

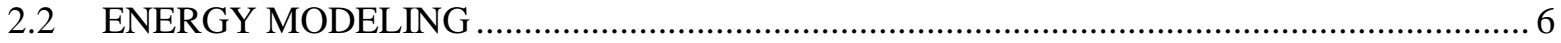

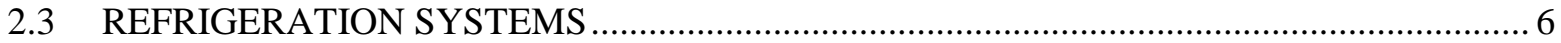

2.3.1 Refrigerated Display Cases and Walk-Ins ……………………………………..... 7

2.3.2 Refrigeration Systems ……………………………........................................ 8

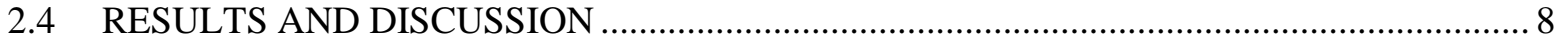

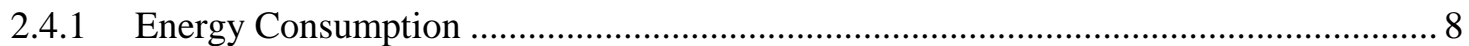

2.4.2 Life Cycle Climate Performance......................................................................... 10

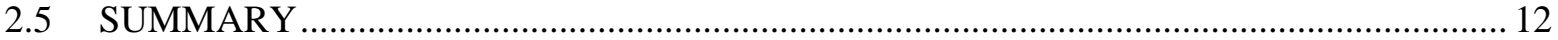

3. FURTHER ANALYSIS OF $\mathrm{CO}_{2}$ BASED REFRIGERATION SYSTEMS .................................13

3.1 DESCRIPTION OF $\mathrm{CO}_{2}$ BASED REFRIGERATION SYSTEMS ……………………….... 13

3.1.1 Secondary Loop and Cascade Systems …………………......................................... 13

3.1.2 Transcritical $\mathrm{CO}_{2}$ Booster Systems ..................................................................... 17

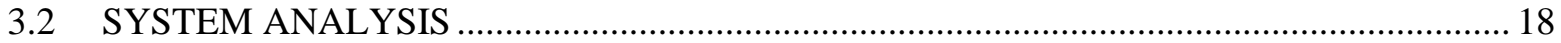

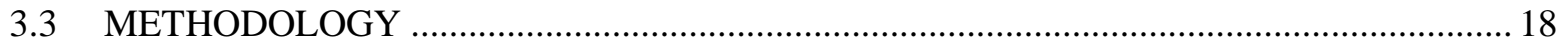

3.3.1 Baseline Parameters ......................................................................................... 18

3.3.2 System Operating Assumptions ........................................................................... 19

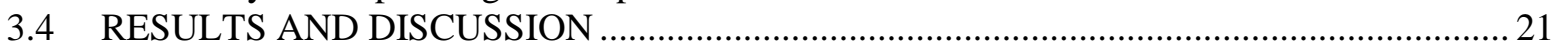

3.4.1 Cascade and Secondary Loop Systems …………………………………………... 21

3.4.2 Transcritical Booster Systems..........................................................................2 23

3.4.3 Comparison of $\mathrm{CO}_{2}$-based Refrigeration Systems with the Baseline System...............25

3.4.4 Climate Zones ……………………………………………………………. 25

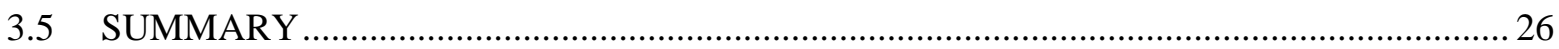

4. LABORATORY-SCALE HIGH-EFFICIENCY, LOW-EMISSION REFRIGERATION

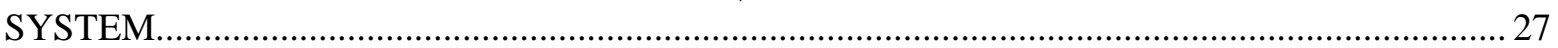

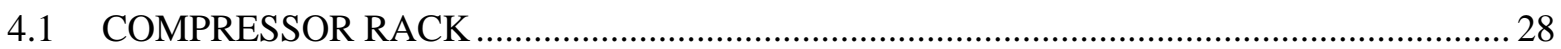

4.2 REFRIGERATED DISPLAY CASES AND FALSE LOADS ………………………….....2 28

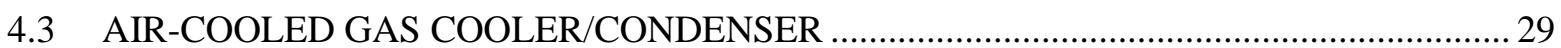

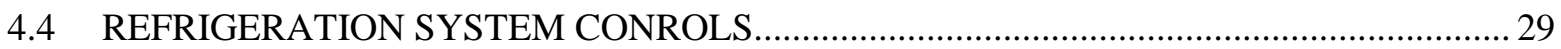

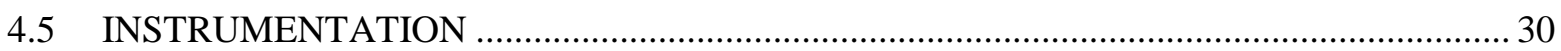

5. EVALUATION OF HIGH EFFICIENCY, LOW EMISSION REFRIGERATION SYSTEM ........... 31

5.1 LABORATORY PERFORMANCE DATA.................................................................. 31

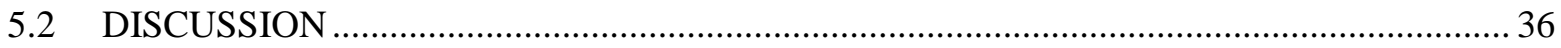

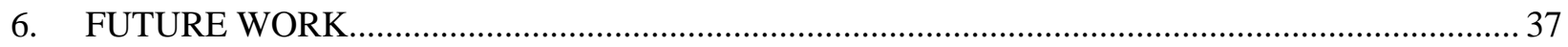




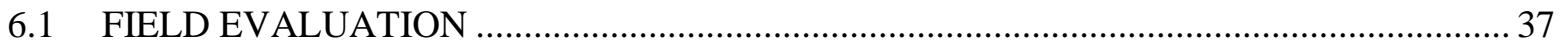

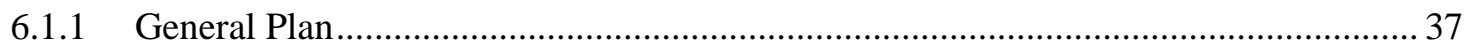

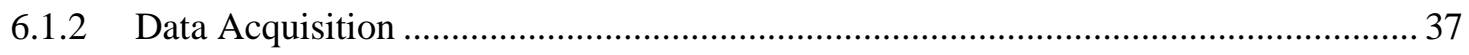

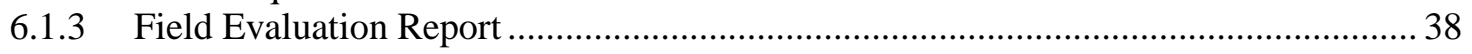

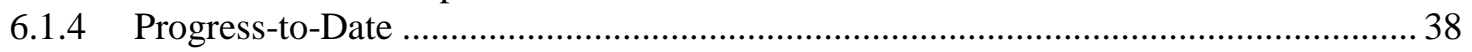

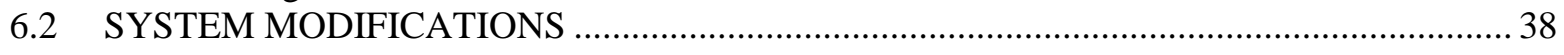

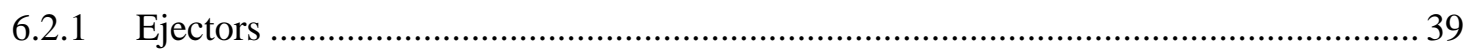

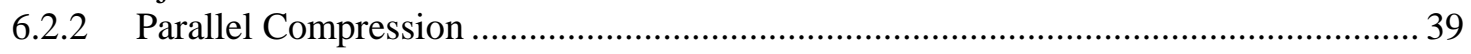

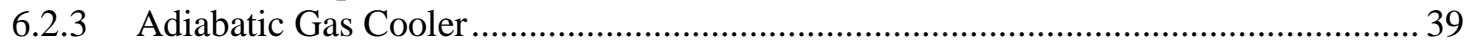

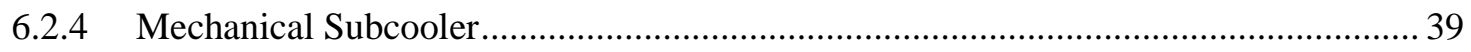

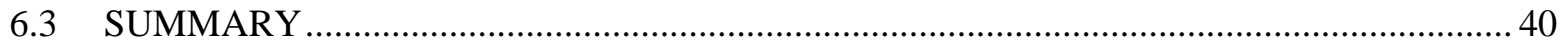

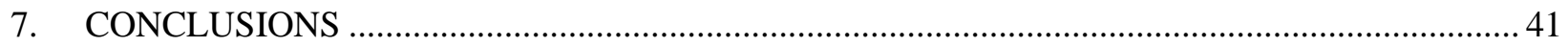

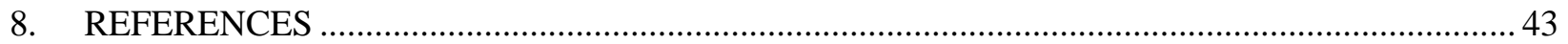

APPENDIX A. MEASUREMENT POINTS FOR LABORATORY-SCALE TRANSCRITICAL

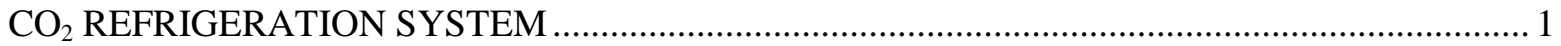
APPENDIX A. MEASUREMENT POINTS FOR LABORATORY-SCALE TRANSCRITICAL

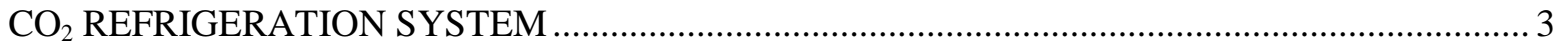




\section{LIST OF FIGURES}

Figure

Page

Figure 1. Schematic of multiplex direct expansion (DX) supermarket refrigeration system. 1

Figure. 2. Annual electrical energy consumption of the various refrigeration systems in the seven climate zones of the continental United States, relative to the baseline R-404A DX system in Miami, FL.

Figure 3. Carbon dioxide equivalent emissions of the various refrigeration systems in the seven climate zones of the continental United States, relative to the baseline R-404A DX system in Miami, FL.

Figure 4. Average direct and indirect carbon dioxide equivalent emissions for the various refrigeration systems.

Figure 5. Cycle schematic and pressure-enthalpy (p-h) diagram for the baseline multiplex direct expansion (DX) refrigeration system.

Figure 6. Cycle schematic and pressure-enthalpy (p-h) diagram for the $\mathrm{CO}_{2}$ secondary coolant (SC) refrigeration system.

Figure 7. Cycle schematic and pressure-enthalpy $(p-h)$ diagram for the $\mathrm{CO}_{2}$ direct expansion cascade (DEC) refrigeration system.

Figure 8. Cycle schematic and pressure-enthalpy $(p-h)$ diagram for the combined $\mathrm{CO}_{2}$ secondary/cascade (CSC) refrigeration system.

Figure 9. Cycle schematic and pressure-enthalpy $(p-h)$ diagram for the combined glycol secondary $/ \mathrm{CO}_{2}$ Cascade (CSC-G) refrigeration system.

Figure 10. Cycle schematic and pressure-enthalpy $(p-h)$ diagram for the standard transcritical $\mathrm{CO}_{2}$ booster refrigeration system (STBS).

Figure 11. Cycle schematic and pressure-enthalpy $(p-h)$ diagram for the transcritical $\mathrm{CO}_{2}$ booster refrigeration system with bypass compressor (TBS-BC).

Figure 12. COP and work ratio vs. ambient temperature with $\mathrm{CR}=1.5$ for Combined System 1...........2 21

Figure 13. COP vs. ambient temperature with $\Delta T_{L T}=9 \mathrm{R}(5 \mathrm{~K})$ for the CSC system (System 4)........... 22

Figure 14. Performance of the STBS system (System 6) for $\varepsilon_{\mathrm{SLHX}}=0.4$ and $\Delta T=9 \mathrm{R}(5 \mathrm{~K})$.

(a) System COP and work ratios, (b) Mass flow ratio................................................... 23

Figure 15. Mass flow ratio vs. ambient temperature with $\Delta T=9 \mathrm{R}(5 \mathrm{~K})$ for the STBS (System 6)........ 24

Figure 16. System COP vs. ambient temperature at $\varepsilon_{\mathrm{SLHX}}=0.4, \Delta T=9 \mathrm{R}(5 \mathrm{~K})$ and $C R=1.5$.

(a) Transcritical booster systems, (b) Cascade/secondary systems. ................................... 25

Figure 17. Schematic of the laboratory-scale transcritical $\mathrm{CO}_{2}$ booster refrigeration system.................. 27

Figure 18. Average medium-temperature (MT) and low-temperature (LT) refrigeration loads for the

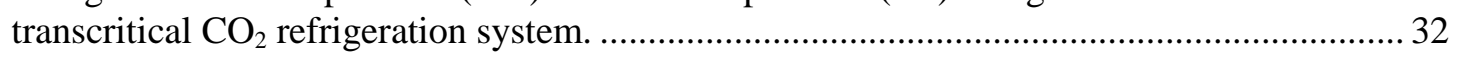

Figure 19. Average total compressor power for the transcritical $\mathrm{CO}_{2}$ refrigeration system.................... 33

Figure 20. Coefficient of performance (COP) for the transcritical $\mathrm{CO}_{2}$ refrigeration system.................. 33

Figure 21. Gas cooler inlet pressure for the transcritical $\mathrm{CO}_{2}$ refrigeration system. .............................. 34

Figure 22. Medium-temperature (MT) compressor discharge temperature, and gas cooler inlet and

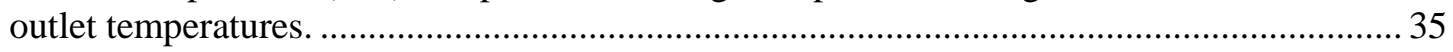

Figure 23. Comparison of COP for R-404A multiplex DX and transcritical $\mathrm{CO}_{2}$ booster refrigeration systems. 



\section{LIST OF TABLES}

Table

Page

Table 1. U.S. climate zones and cities used in energy simulations.................................................... 6

Table 2. Rated load of standard- and high-efficiency refrigerated display cases ................................... 7

Table 3. Global warming potential (GWP) values for selected refrigerants (ASHRAE, 2009; Spatz

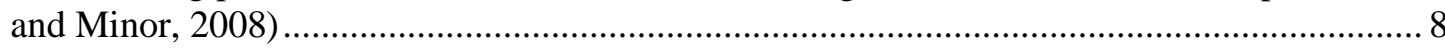

Table 4. Average percent reduction in $\mathrm{CO}_{2 \mathrm{eq}}$ emissions relative to the baseline standard-efficiency

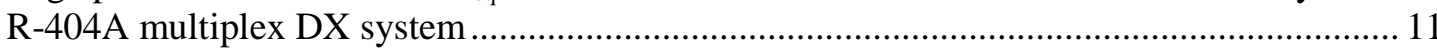

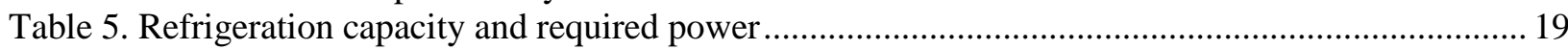

Table 6. Parameters and their ranges ............................................................................................ 19

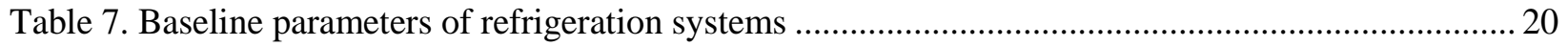

Table 8. U.S. climate zones, cities and annual average $\mathrm{COP}$ for several $\mathrm{CO}_{2}$-based refrigeration

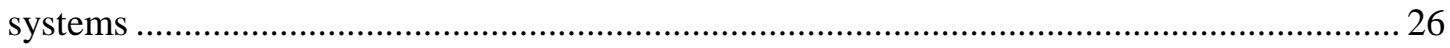

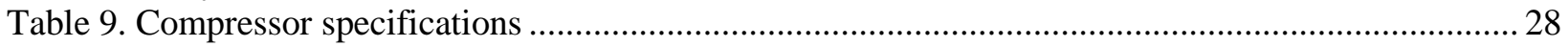

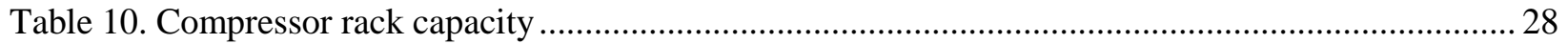

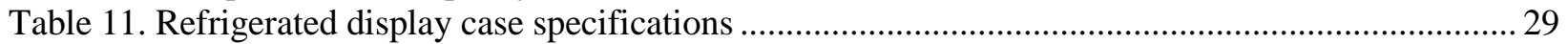

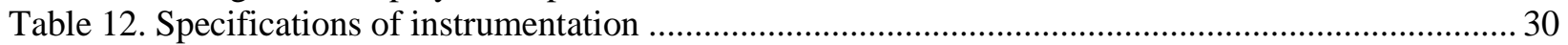

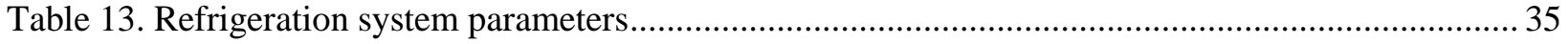





\section{ACRONYMS}

$\begin{array}{ll}\text { ACRONYMS } & \\ \text { BTO } & \text { U.S. Department of Energy Building Technolgies Office } \\ \text { CFC } & \text { clorofluorocarbon } \\ \text { COP } & \text { coefficient of performance } \\ \text { CR } & \text { circulation ratio } \\ \text { CRADA } & \text { cooperative research and development agreement } \\ \text { CSC } & \text { combined } \text { CO }_{2} \text { secondary/cascade system } \\ \text { CSC-G } & \text { combined glycol secondary/CO }{ }_{2} \text { cascade system } \\ \text { DEC } & \text { direct expansion cascade system } \\ \text { DOE } & \text { U.S. Department of Energy } \\ \text { DX } & \text { direct expansion } \\ \text { EC } & \text { electronically commutated } \\ \text { EEV } & \text { electronic expansion valve } \\ \text { EPA } & \text { U.S. Environmental Protection Agency } \\ \text { GC } & \text { gas cooler } \\ \text { GWP } & \text { global warming potential } \\ \text { HC } & \text { hydrocarbon } \\ \text { HCFC } & \text { hydroclorofluorocarbon } \\ \text { HFC } & \text { hydrofluorocarbon } \\ \text { HVAC } & \text { heating, ventilating and air-conditioning } \\ \text { LCCP } & \text { life cycle climate performance } \\ \text { LED } & \text { light emitting diode } \\ \text { LT } & \text { low temperature } \\ \text { MT } & \text { medium temperature } \\ \text { ODP } & \text { ozone depletion potential } \\ \text { ORNL } & \text { Oak Ridge National Laboratory } \\ \text { PNNL } & \text { Pacific Northwest National Laboratory } \\ \text { PSC } & \text { permanent split capacitor } \\ \text { RH } & \text { relative humidity } \\ \text { SC } & \text { secondary coolant system } \\ \text { SLHX } & \text { suction line heat exchanger } \\ \text { STBS } & \text { standard transcritical booster system } \\ \text { TBS-BC } & \text { transcritical booster system with bypass compressor } \\ \text { TBS-UX } & \text { transcritical booster system with upstream expansion valve } \\ & \end{array}$

\section{VARIABLES}

$\begin{array}{ll}h & \text { enthalpy } \\ E & \text { carbon dioxide equivalent emissions } \\ \dot{m} & \text { mass flow rate } \\ M R & \text { refrigerant mass flow ratio } \\ P & \text { pressure } \\ \dot{Q} & \text { rate of heat transfer } \\ T & \text { temperature } \\ \Delta T & \text { evaporator superheat } \\ \dot{W} & \text { power } \\ W R & \text { compressor work ratio }\end{array}$




\section{Greek Symbols}

$\varepsilon$

Subscripts
amb
app
BP
circ
comp
cond
direct
energy
EOL
GC
HP
indirect
int
leakage
LP
LT
manuf
MT
pump
recycle
ref
service
STBS
TBS-BC
TBS-UX
total

heat exchanger effectiveness

ambient

approach

bypass

refrigerant circuit

compressor

condensing

direct emissions

emissions associated with production and distribution of electricity

emissions associated with refrigerant release at end-of-life

gas cooler

high-pressure

indirect emissions

intermediate

emissions due to refrigerant leakage

low-pressure

low temperature

emissions associated with the manufacture of refrigerants and refrigeration systems medium temperature

pump

emissions associated with the energy to recycle refrigeration systems at end-of-life refrigerating capacity

emissions associated with refrigerant release during service events

standard transcritical booster system

transcritical booster system with bypass compressor

transcritical booster system with upstream expansion valve

sum around refrigeration cycle 


\section{ACKNOWLEDGMENTS}

This report and the work described were sponsored by the Emerging Technologies Program within the Building Technologies Office (BTO) of the US Department of Energy (DOE) Office of Energy Efficiency and Renewable Energy. The authors wish to acknowledge the support of Antonio Bouza in guiding this work. A special debt of gratitude is due to Shitong Zha and Jeff Newel of Hillphoenix, for without their major contributions, this project would not have been a success. In addition, the authors would like to recognize the generous contributions of Danfoss, who provided refrigeration system controls and Luvata, who provided the gas cooler for the prototype transcritical $\mathrm{CO}_{2}$ refrigeration system evaluated in this project. Finally, this work would not have been possible without the excellent technical support provided by Dewayne Beeler, Randy Linkous, Geoffrey Ormston, and Jeffrey Taylor. 



\begin{abstract}
Supermarket refrigeration systems account for approximately $50 \%$ of supermarket energy use, placing this class of equipment among the highest energy consumers in the commercial building domain. In addition, the commonly used refrigeration system in supermarket applications is the multiplex direct expansion (DX) system, which is prone to refrigerant leaks due to its long lengths of refrigerant piping. This leakage reduces the efficiency of the system and increases the impact of the system on the environment. The high Global Warming Potential (GWP) of the hydrofluorocarbon (HFC) refrigerants commonly used in these systems, coupled with the large refrigerant charge and the high refrigerant leakage rates leads to significant direct emissions of greenhouse gases into the atmosphere. Methods for reducing refrigerant leakage and energy consumption are available, but underutilized. Further work needs to be done to reduce costs of advanced system designs to improve market utilization. In addition, refrigeration system retrofits that result in reduced energy consumption are needed since the majority of applications address retrofits rather than new stores. The retrofit market is also of most concern since it involves large-volume refrigerant systems with high leak rates. Finally, alternative refrigerants for new and retrofit applications are needed to reduce emissions and reduce the impact on the environment.

The objective of this Collaborative Research and Development Agreement (CRADA) between the Oak Ridge National Laboratory and Hill Phoenix is to develop a supermarket refrigeration system that reduces greenhouse gas emissions and has 25 to 30 percent lower energy consumption than existing systems. The outcomes of this project will include the design of a low emission, high efficiency commercial refrigeration system suitable for use in current U.S. supermarkets. In addition, a prototype low emission, high efficiency supermarket refrigeration system will be produced for laboratory and field testing. Laboratory and field testing will demonstrate the high energy efficiency and low environmental impact of the refrigeration system developed in this project.

Energy and life cycle climate performance (LCCP) analyses were performed for a variety of refrigeration system designs and refrigerant options, with the goal of identifying a system configuration and a refrigerant option which reduces both energy consumption and carbon dioxide equivalent emissions. Based on this analysis, a transcritical $\mathrm{CO}_{2}$ booster refrigeration system was identified as having the potential to reduce energy consumption and emissions as compared to the baseline multiplex DX system using R-404A. The analysis showed that a transcritical $\mathrm{CO}_{2}$ booster refrigeration system, coupled with high-efficiency display cases and walk-ins, can achieve average energy reductions of 39\% compared to the standard-efficiency R-404A multiplex DX system, with $76 \%$ lower emissions and hence is a potential low emission, high-efficiency alternative to the current baseline R-404A multiplex DX systems in use.

Based on the results of the energy and emissions analyses, a laboratory-scale transcritical $\mathrm{CO}_{2}$ booster refrigeration system was fabricated and installed in the environmental test chambers at the Oak Ridge National Laboratory (ORNL). This system consisted of a transcritical $\mathrm{CO}_{2}$ compressor rack, an aircooled gas cooler/condenser, medium-temperature (MT) and low-temperature (LT) refrigerated display cases, and MT and LT "false" loads. The laboratory-scale refrigeration system has a low-temperature cooling capacity of approximately 2.5 tons at a saturated evaporating temperature of $-22^{\circ} \mathrm{F}(9.1 \mathrm{~kW}$ at $-30^{\circ} \mathrm{C}$ ) and a medium-temperature cooling capacity of approximately 9.6 tons at a saturated evaporating temperature of $20^{\circ} \mathrm{F}\left(34 \mathrm{~kW}\right.$ at $\left.-6.7^{\circ} \mathrm{C}\right)$. The air-cooled gas cooler/condenser was installed in a temperature and humidity controlled "outdoor" environmental chamber while the compressor rack and refrigerated display cases were installed in a separate temperature and humidity controlled "indoor" environmental chamber.

The performance of the transcritical $\mathrm{CO}_{2}$ booster refrigeration system was determined at four outdoor ambient temperature conditions, nominally $60^{\circ} \mathrm{F}\left(16^{\circ} \mathrm{C}\right), 70^{\circ} \mathrm{F}\left(21^{\circ} \mathrm{C}\right), 80^{\circ} \mathrm{F}\left(27^{\circ} \mathrm{C}\right)$ and $90^{\circ} \mathrm{F}\left(32^{\circ} \mathrm{C}\right)$. Over the outdoor ambient temperature range of $60^{\circ} \mathrm{F}$ to $90^{\circ} \mathrm{F}\left(16^{\circ} \mathrm{C}\right.$ to $\left.32^{\circ} \mathrm{C}\right)$, the total load on the system was found to remain relatively constant. In addition, the compressor power was found to increase by approximately $78 \%$ over this same temperature range. Thus, the resulting coefficient of performance
\end{abstract}


(COP) of the system was found to vary from 2.2 at an outdoor ambient temperature of $90^{\circ} \mathrm{F}\left(32^{\circ} \mathrm{C}\right)$ to 4.1 at an outdoor ambient temperature of $60^{\circ} \mathrm{F}\left(16^{\circ} \mathrm{C}\right)$. In addition, the coefficients of performance of both the transcritical $\mathrm{CO}_{2}$ booster and an HFC-based refrigeration systems were compared, and it was found that over the outdoor ambient temperature range of $60^{\circ} \mathrm{F}\left(16^{\circ} \mathrm{C}\right)$ to approximately $88^{\circ} \mathrm{F}\left(31^{\circ} \mathrm{C}\right)$, the $\mathrm{COP}$ of the transcritical $\mathrm{CO}_{2}$ booster system was on average $15 \%$ greater than that of the $\mathrm{HFC}$ system. Based on the laboratory evaluation, the transcritical $\mathrm{CO}_{2}$ booster refrigeration system demonstrates promise as a low emission, high efficiency alternative to the traditional multiplex DX systems currently in use.

Future efforts related to this project include completing a field evaluation of the transcritical $\mathrm{CO}_{2}$ booster refrigeration system in third-party supermarkets, as well as performing system modifications to enhance the efficiency of the $\mathrm{CO}_{2}$ refrigeration system, particularly in warm climates. The main objective of the field evaluation is to determine the energy consumption of a transcritical $\mathrm{CO}_{2}$ commercial refrigeration system in an actual, operating supermarket, thereby providing motivation to supermarket owners and operators to implement these low emission refrigeration systems. Hillphoenix and ORNL are currently negotiating the site selection and logistics for the field evaluation of the transcritical $\mathrm{CO}_{2}$ booster refrigeration system with two major food retailers. Installation of instrumented transcritical $\mathrm{CO}_{2}$ booster refrigeration systems at these test sites are planned for the Summer and Fall of 2016, with results to be published in 2017. Furthermore, at high ambient temperatures, the efficiency of the transcritical $\mathrm{CO}_{2}$ booster refrigeration system is low, compared to the traditional HFC-based multiplex DX system. To increase the efficiency of the $\mathrm{CO}_{2}$ refrigeration system, particularly in warm climates, a number of modifications will be made to the laboratory-scale refrigeration system, including the use of ejectors, parallel compression, adiabatic gas cooling and mechanical subcooling.

Motivated by the exceptional energy and environmental performance of the transcritical $\mathrm{CO}_{2}$ booster refrigeration system, the CRADA partner, Hillphoenix has commercialized the system for supermarket refrigeration applications. To date, Hillphoenix has over 130 installations of transcritical $\mathrm{CO}_{2}$ booster refrigeration system in the U.S. 


\section{INTRODUCTION}

According to the Food Marketing Institute, there were nearly 38,000 supermarkets in the United States in 2014, where a supermarket is defined to be a food retailer with annual sales of $\$ 2$ million or greater (Food Marketing Institute (FMI) 2016). The median size of these supermarkets is reported to be $46,000 \mathrm{ft}^{2}\left(4,300 \mathrm{~m}^{2}\right)$. Within the commercial buildings sector, supermarkets are one of the most energyintensive building types. Approximately half of the electrical energy consumption of a supermarket is devoted to the refrigeration system. In the US, the electrical energy consumption of a typical supermarket is in the range of 100,000 to 1.5 million $\mathrm{kWh}$ or more per year (ICF Consulting 2005).

The multiplex direct expansion (DX) refrigeration system is commonly used in supermarket applications. As shown in Fig. 1, this system consists of one or more compressor racks, which contain compressors in parallel, that are connected to the evaporators in refrigerated display cases and walk-in coolers/freezers. Long runs of refrigerant piping are required to connect the compressor racks to the display cases and walk-in coolers/freezers which are located throughout the supermarket. Due to the long length of piping and numerous connections and joints, the multiplex DX system is prone to significant refrigerant leakage, especially older existing systems. It has been estimated that the annual refrigerant emission rate can range between $3 \%$ to $35 \%$, with lower leak rates characteristic of new equipment and high leak rates characteristic of older equipment (ICF Consulting 2005).

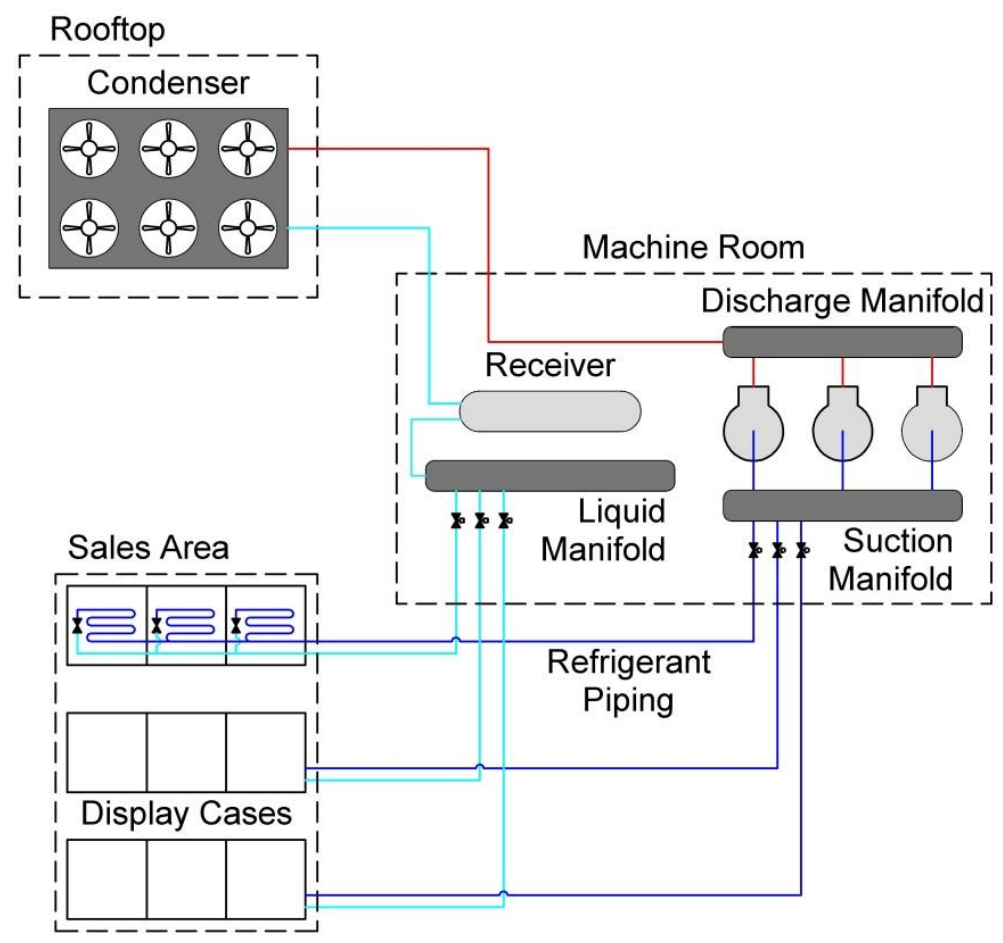

Fig. 1. Schematic of multiplex direct expansion (DX) supermarket refrigeration system.

The use of high Global Warming Potential (GWP) refrigerants in these systems, such as R-404A which has a GWP value of nearly 4000, combined with high refrigerant leakage, can result in considerable direct carbon dioxide equivalent $\left(\mathrm{CO}_{2 \mathrm{eq}}\right)$ emissions. In addition, commercial refrigeration systems consume a substantial amount of electrical energy, resulting in high indirect $\mathrm{CO}_{2 \mathrm{eq}}$ emissions. Thus, there are ongoing efforts to reduce both the direct and indirect environmental impacts of commercial refrigeration systems through the use of leak reduction measures, refrigerant charge minimization, low GWP refrigerants and energy efficiency measures. 


\subsection{PROJECT OBJECTIVES}

The objective of this Collaborative Research and Development Agreement (CRADA) between the Oak Ridge National Laboratory and Hill Phoenix is to develop a supermarket refrigeration system that reduces greenhouse gas emissions and has 25 to 30 percent lower energy consumption than existing systems. The challenges of this project will be to design a system that will achieve refrigerant leak rates of less than 5\% while significantly reducing energy consumption and refrigerant charge size. In addition, the refrigeration system design may include the safe use of a low Global Warming Potential (GWP) flammable refrigerant.

The outcomes of this project will include the design of a low emission, high efficiency commercial refrigeration system suitable for use in current U.S. supermarkets. In addition, a prototype low emission, high efficiency supermarket refrigeration system will be produced for laboratory and field testing. Laboratory and field testing will demonstrate the high energy efficiency and low environmental impact of the refrigeration system developed in this project.

\subsection{MOTIVATION}

The Department of Energy's (DOE) Building Technologies Office (BTO) has as its long term goal to create marketable technologies and design approaches that address energy consumption in existing and new buildings. The current vision that BTO has for achieving this goal involves reducing the energy and carbon emissions used by the energy service equipment (equipment providing space heating and cooling, refrigeration, etc.) by $50 \%$ compared to today's best common practice. Refrigeration systems in the supermarket sub-sector of commercial buildings account for approximately $50 \%$ of supermarket energy use, placing this class of equipment among the highest energy consumers in the commercial building domain. Technology areas of interest, such as secondary loop systems, waste heat reclaim, alternative refrigerants, advanced vapor compression, and hybrid ground source condensers have the potential to significantly reduce energy consumption for refrigeration equipment and aid progress towards DOE goals to improve energy performance.

The commonly used refrigeration system in supermarket applications is the multiplex direct expansion (DX) system, which is prone to refrigerant leaks due to its long lengths of refrigerant piping. This leakage reduces the efficiency of the system and increases the impact of the system on the environment. Methods for reducing refrigerant leakage and energy consumption are available, but underutilized. Further work needs to be done to reduce costs of advanced system designs to improve market utilization. In addition, refrigeration system retrofits that result in reduced energy consumption are needed since the majority of applications address retrofits rather than new stores. The retrofit market is also of most concern since it involves large-volume refrigerant systems with high leak rates. Finally, alternative refrigerants for new and retrofit applications are needed to reduce emissions and reduce the impact on the environment.

\subsection{CURRENT PRACTICE}

Supermarkets and other large food retail stores commonly utilize multiplex direct expansion (DX) refrigeration systems in conjunction with synthetic refrigerants such as R-22, R-404A and R-507. The annual refrigerant leakage from these systems is reported to be as high as 35\% (ICF Consulting 2005). The high Global Warming Potential (GWP) of the hydrofluorocarbon (HFC) refrigerants commonly used in these systems, coupled with the large refrigerant charge and the high refrigerant leakage rates leads to significant direct emissions of greenhouse gases into the atmosphere. Hence, these multiplex refrigeration systems can directly contribute to the increase in global warming.

Furthermore, the operation of multiplex DX refrigeration systems also contributes to global warming indirectly. For a typical supermarket in the US, the refrigeration system accounts for approximately 50\% of the supermarket's total energy consumption (Westphalen et al. 1996). On an annual basis, the 
refrigeration system of a typical supermarket may consume 1 million $\mathrm{kWh}$ or more (Zhang 2006). Thus, the indirect impact on the environment results from the release of greenhouse gases (mainly $\mathrm{CO}_{2}$ ) associated with the generation and transmission of the electrical energy used by the refrigeration system.

The direct environmental impact of the refrigeration system can be reduced by using refrigerants with lower GWP. Refrigerants such as R-32, R-134a, R-717, R-744, R-290, R-600a and R-1234yf could be potential alternative refrigerants. However, due to toxicity and/or flammability, some of these refrigerant options may not be permissible under various municipal safety codes. Cascade systems and secondary loop systems (discussed later in Chapters 2 and 3) using $\mathrm{CO}_{2}$ as a refrigerant can be used to reduce the direct impact on the environment due to their lower HFC refrigerant charge.

The indirect environmental impact of the refrigeration system can be reduced by increasing the energy efficiency of the system. One option for increasing energy efficiency is to reduce the load on the refrigeration system. This can be done by replacing open display cases with doored display cases.

Several studies have shown that doored display cases can reduce refrigeration system energy consumption by up to $50 \%$ when combined with high efficiency display case components such as LED lighting, demand defrost, electronically commutated evaporator fan motors and humidity controlled anti-sweat heaters (Rauss, Mitchell, and Faramarzi 2008; Fricke and Becker 2010). Other energy efficiency measures that can be utilized include variable speed drives for compressors and condenser fan motors, as well as floating condensing and suction pressure controls.

Carbon dioxide has recently received considerable attention as an alternative to the commonly used synthetic refrigerants in supermarket refrigeration systems, in an effort to develop systems with lower environmental impact (Bansal 2012; Getu and Bansal 2008). Although $\mathrm{CO}_{2}$ has a high critical pressure $(1070 \mathrm{psia}$ or $7.38 \mathrm{MPa})$ and a low critical temperature $\left(87.9^{\circ} \mathrm{F}\right.$ or $\left.31.1^{\circ} \mathrm{C}\right)$, its high operating pressure leads to a high vapor density and thus a high volumetric refrigerating capacity. The volumetric refrigerating capacity of $\mathrm{CO}_{2}\left(605.1 \mathrm{Btu} / \mathrm{ft}^{3}\right.$ at $32^{\circ} \mathrm{F}$ or $22,545 \mathrm{~kJ} / \mathrm{m}^{3}$ at $\left.0^{\circ} \mathrm{C}\right)$ is 3 to 10 times larger than chlorofluorocarbon (CFC), hydrochlorofluorocarbon (HCFC), hydrofluorocarbon (HFC) and hydrocarbon (HC) refrigerants (Kim, Pettersen, and Bullard 2004). In addition, carbon dioxide has no Ozone Depletion Potential (ODP); a GWP of one; and is nontoxic, nonflammable and inexpensive - all attractive characteristics when compared to synthetic refrigerants.

Carbon dioxide has successfully been used as a refrigerant in the low-temperature circuit of cascade systems, in secondary loop systems, and in transcritical systems (Bansal 2012; Girotto, Minetto, and Nekså 2004; Hinde and Zha 2009). However, transcritical $\mathrm{CO}_{2}$ systems tend to be more popular in moderate climates such as Northern Europe where the refrigeration system operates a majority of the time in the more efficient subcritical mode (Denecke et al. 2012; Sawalha and Palm 2003).

\subsection{OUTLINE OF THIS REPORT}

The structure of this report is as follows:

- Chapter 2 presents energy and emissions analyses performed for a variety of refrigeration system designs and refrigerant options, with the goal of identifying a system configuration and a refrigerant option which reduces both energy consumption and carbon dioxide equivalent emissions. Based on the analysis presented in Chapter 2, a transcritical $\mathrm{CO}_{2}$ booster refrigeration system was identified as having the potential to reduce energy consumption and emissions as compared to the baseline multiplex DX system.

- Chapter 3 presents further analysis of various configurations of $\mathrm{CO}_{2}$-based refrigeration systems. Based on this analysis, Hillphoenix and ORNL agreed that a transcritical $\mathrm{CO}_{2}$ booster refrigeration system warranted further investigation.

- Chapter 4 describes in detail the laboratory-scale transcritical $\mathrm{CO}_{2}$ booster refrigeration system which was developed for evaluation in ORNL's environmental chambers.

- Chapter 5 presents the results of the laboratory evaluation of the transcritical $\mathrm{CO}_{2}$ booster refrigeration system. 
- Chapter 6 describes future work to be performed, including field evaluations of the transcritical $\mathrm{CO}_{2}$ booster refrigeration system and the development of a system applicable to warm climates.

- Finally, Chapter 7 provides concluding remarks. 


\section{ANALYSIS OF REFRIGERATION SYSTEMS AND REFRIGERANT OPTIONS}

To meet the objective of developing a high efficiency, low emission commercial refrigeration system, an evaluation of various refrigeration system designs and refrigerant options was performed. Some of the key features in selecting an appropriate refrigeration system and/or refrigerant include the global warming potential (GWP) of the refrigerant, the energy consumption of the refrigeration system over its operating lifetime, and the refrigerant leakage over the system lifetime. Therefore, energy and life cycle climate performance (LCCP) analyses were performed on a variety of supermarket refrigeration systems to identify those designs and refrigerant selections which exhibit both low environmental impact and high energy efficiency. Based on the most promising system design and refrigerant selection, a high efficiency, low emission refrigeration system will be developed and evaluated.

The whole-building energy modeling tool, EnergyPlus, was used to model refrigeration systems in a variety of climate zones across the United States. The refrigeration systems that were modeled include the traditional multiplex direct expansion (DX) system, cascade systems with secondary loops and the transcritical $\mathrm{CO}_{2}$ system. Furthermore, a variety of refrigerants were investigated, including R-32, R134a, R-404A, R-1234yf, R-717, and R-744. LCCP analysis was used to determine the direct and indirect carbon dioxide emissions resulting from the operation of the various refrigeration systems over their lifetimes.

The following sections in Chapter 2 describe the details of the LCCP methodology, the energy modeling (including the specifications of a conceptual supermarket), and the various refrigeration systems which were investigated. Finally, the results of the LCCP and energy analyses are presented.

\subsection{LIFE CYCLE CLIMATE PERFORMANCE (LCCP)}

Life Cycle Climate Performance (LCCP) is a methodology used to determine the environmental impact of a refrigeration system design, its performance and use of a specific refrigerant. The environmental impact of a refrigeration system is measured by estimating the system's greenhouse gas emissions in terms of carbon dioxide equivalent emissions, i.e., the quantity of carbon dioxide that would have the same global warming potential (GWP) as the greenhouse gas emissions of the refrigeration system under consideration (Hafner, Nekså, and Pettersen 2004; Horie et al. 2010; Johnson 2004; Papasavva, Hill, and Andersen 2010; Spatz and Motta 2004; Zhang et al. 2011). LCCP represents the total carbon dioxide equivalent $\left(\mathrm{CO}_{2 \mathrm{eq}}\right)$ emissions, including both the direct and indirect emissions of the refrigeration system as follows:

$$
L C C P=\sum\left(E_{\text {direct }}+E_{\text {indirect }}\right)
$$

where $E_{\text {direct }}$ is the direct emissions and $E_{\text {indirect }}$ is the indirect emissions.

Direct emissions, $E_{\text {direct }}$, include those related to the direct release of refrigerant from the system, including annual leakage, loss at the end-of-life of the system and loss during service events, and can be calculated as follows:

$$
E_{\text {direct }}=E_{\text {leakage }}+E_{E O L}+E_{\text {service }}
$$

where $E_{\text {leakage }}$ is the $\mathrm{CO}_{2 \mathrm{eq}}$ of the total leakage of refrigerant from the system over its operating lifetime, $E_{E O L}$ is the $\mathrm{CO}_{2 \mathrm{eq}}$ of the refrigerant released at the end of the system life due to inefficiencies in refrigerant recovery, and $E_{\text {service }}$ is the $\mathrm{CO}_{2 \mathrm{eq}}$ of the total refrigerant release occurring during all refrigeration system service events over the system operating lifetime.

The indirect emissions, $E_{\text {indirect }}$, include those associated with the production and distribution of the energy required to operate the refrigeration system over its lifetime as well as emissions associated with 
the manufacturing, end-of-life decommissioning, and recycling of the refrigeration system, and can be calculated as follows:

$$
E_{\text {indirect }}=E_{\text {energy }}+E_{\text {manuf }}+E_{\text {recycle }}
$$

where $E_{\text {energy }}$ is the $\mathrm{CO}_{2 \mathrm{eq}}$ emissions associated with the production and distribution of the energy required to operate the refrigeration system over its lifetime, $E_{\text {manuf }}$ is the $\mathrm{CO}_{2 \mathrm{eq}}$ emissions associated with the energy required to manufacture both the refrigerant and the refrigeration system, and $E_{\text {recycle }}$ is the $\mathrm{CO}_{2 \mathrm{eq}}$ emissions associated with the energy of recycling of the refrigeration system at the end of its operating lifetime.

Emissions factors related to the production and distribution of electricity as well as for the production of the refrigerant and refrigerating equipment were obtained from Deru and Torcellini (2007) and Papasavva et al. (2010).

\subsection{ENERGY MODELING}

EnergyPlus was selected to model the hourly energy consumption of supermarket refrigeration systems in a variety of climate zones across the United States for a one-year period (US Department of Energy (DOE) 2012). This tool is capable of modeling the building envelope, heating and cooling loads, and HVAC and refrigeration system performance based on detailed weather data and building construction data. A conceptual supermarket design was developed for use in the EnergyPlus simulations. This design consists of a single-story supermarket with a floor area of approximately $38,600 \mathrm{ft}^{2}$ $\left(3,590 \mathrm{~m}^{2}\right)$, divided into four zones (vestibule, deli, main sales, and back room). The internal loads for each of these zones consist of lighting, people, electric and gas loads. Exterior wall construction for the conceptual design consists of stucco, concrete block, insulation, and gypsum board (from the exterior to the interior). HVAC is provided by packaged constant volume units with gas heat and electric cooling.

Using the conceptual supermarket design, energy simulations were performed for seven cities, shown in Table 1, which are representative of the seven climate zones in the continental United States (Pacific Northwest National Laboratory (PNNL) 2010). Hourly weather data from the seven cities was used in the simulations to determine refrigeration system performance in the seven climate zones.

Table 1. U.S. climate zones and cities used in energy simulations

\begin{tabular}{clcc}
\hline Climate zone & \multicolumn{1}{c}{ City } & $\begin{array}{c}\text { Annual average } \\
\text { temperature, }{ }^{\circ} \mathbf{F}\left({ }^{\circ} \mathbf{C}\right)\end{array}$ & $\begin{array}{c}\text { Standard deviation of } \\
\text { annual average } \\
\text { temperature, }{ }^{\circ} \mathbf{F}\left({ }^{\circ} \mathbf{C}\right)\end{array}$ \\
\hline 1 & Miami, FL & $76.1(24.5)$ & $8.1(4.5)$ \\
2 & San Antonio, TX & $68.7(20.4)$ & $15.3(8.5)$ \\
3 & San Francisco, CA & $56.8(13.8)$ & $6.9(3.8)$ \\
4 & Kansas City, MO & $53.7(12.1)$ & $21.6(12.0)$ \\
5 & Chicago, IL & $50.0(10.0)$ & $21.0(11.7)$ \\
6 & Billings, MT & $48.0(8.9)$ & $20.7(11.5)$ \\
7 & International Falls, MN & $38.1(3.4)$ & $26.0(14.4)$ \\
\hline
\end{tabular}

\subsection{REFRIGERATION SYSTEMS}

Standard-efficiency and high-efficiency refrigerated display cases as well as walk-in coolers and freezers were considered in the conceptual supermarket model. In addition, various refrigeration systems, including traditional multiplex direct expansion (DX) rack systems, cascade systems with secondary loops and transcritical $\mathrm{CO}_{2}$ systems, were incorporated into the conceptual supermarket model. The baseline conceptual supermarket consists of the traditional multiplex DX rack system coupled to 
standard-efficiency display cases and walk-ins. High-efficiency systems consist of the various refrigeration systems coupled to high-efficiency display cases and walk-ins.

\subsubsection{Refrigerated Display Cases and Walk-Ins}

The standard-efficiency refrigerated display cases in the baseline conceptual supermarket contain standard-efficiency components, such as fluorescent lighting, permanent split capacitor (PSC) fan motors, and constant-power anti-condensate heaters. In addition, most of the baseline medium-temperature display cases are of the open, vertical multi-deck design. The high-efficiency refrigerated display cases contain high-efficiency components, such as LED lighting, electronically commutated fan motors, and humidity-controlled anti-condensate heaters. In addition, many of the high-efficiency mediumtemperature display cases are of the doored, vertical multi-deck design. A summary of the standard- and high-efficiency, medium- and low-temperature display cases is given in Table 2.

For the conceptual supermarket, the total load of the standard-efficiency walk-in coolers was assumed to be $109,400 \mathrm{Btu} \cdot \mathrm{h}^{-1}(32,080 \mathrm{~W})$ while that for the standard-efficiency walk-in freezers was assumed to be $76,460 \mathrm{Btu} \cdot \mathrm{h}^{-1}(22,410 \mathrm{~W})$. The high-efficiency walk-in coolers and freezers were assumed to be $15 \%$ more energy efficient than their standard-efficiency counterparts.

Table 2. Rated load of standard- and high-efficiency refrigerated display cases

\begin{tabular}{|c|c|c|c|}
\hline Display case type & $\begin{array}{l}\text { Length, } \\
\text { ft (m) }\end{array}$ & $\begin{array}{c}\text { Standard efficiency } \\
\text { rated load, } \\
\text { Btu }^{-1} \mathbf{h}^{-1}(\mathrm{~W})\end{array}$ & $\begin{array}{l}\text { High efficiency } \\
\text { rated load, } \\
\text { Btu }^{-1}(\mathbf{W})\end{array}$ \\
\hline \multicolumn{4}{|l|}{ Medium-Temperature Cases } \\
\hline Service deli & $\begin{array}{r}40 \\
(12)\end{array}$ & $\begin{array}{r}11,270 \\
(3,303)\end{array}$ & $\begin{array}{l}13,323 \\
(3,905)\end{array}$ \\
\hline Multi-deck beverage, deli, dairy & $\begin{array}{r}124 \\
(37.8)\end{array}$ & $\begin{array}{r}181,420 \\
(53,174)\end{array}$ & $\begin{array}{r}35,360 \\
(10,364)\end{array}$ \\
\hline Multi-deck produce & $\begin{array}{r}12 \\
(3.7)\end{array}$ & $\begin{array}{l}13,236 \\
(3,879)\end{array}$ & $\begin{array}{r}10,920 \\
(3,201)\end{array}$ \\
\hline Single-deck produce & $\begin{array}{r}108 \\
(32.9)\end{array}$ & $\begin{array}{r}40,392 \\
(11,839)\end{array}$ & $\begin{array}{r}37,800 \\
(11,079)\end{array}$ \\
\hline Multi-deck meat & $\begin{array}{r}36 \\
(11)\end{array}$ & $\begin{array}{r}45,828 \\
(13,432)\end{array}$ & $\begin{array}{r}43,200 \\
(12,662)\end{array}$ \\
\hline Bakery & $\begin{array}{r}18 \\
(5.5)\end{array}$ & $\begin{array}{r}7,056 \\
(2,068)\end{array}$ & $\begin{array}{r}5,830 \\
(1,709)\end{array}$ \\
\hline Total & $\begin{array}{r}338 \\
(103)\end{array}$ & $\begin{array}{r}299,202 \\
(87,696)\end{array}$ & $\begin{array}{r}146,433 \\
(42,920)\end{array}$ \\
\hline \multicolumn{4}{|l|}{ Low-Temperature Cases } \\
\hline Dual temperature meat coffin & $\begin{array}{r}72 \\
(22)\end{array}$ & $\begin{array}{l}31,680 \\
(9,285)\end{array}$ & $\begin{array}{l}29,376 \\
(8,610)\end{array}$ \\
\hline Frozen food coffin & $\begin{array}{r}56 \\
(17)\end{array}$ & $\begin{array}{r}35,560 \\
(10,423)\end{array}$ & $\begin{array}{l}32,872 \\
(9,635)\end{array}$ \\
\hline Reach-in frozen food & $\begin{array}{r}140 \\
(42.7)\end{array}$ & $\begin{array}{r}80,360 \\
(23,554)\end{array}$ & $\begin{array}{r}61,600 \\
(18,055)\end{array}$ \\
\hline Total & $\begin{array}{r}268 \\
(81.7)\end{array}$ & $\begin{array}{r}147,600 \\
(43,262)\end{array}$ & $\begin{array}{r}123,848 \\
(36,300)\end{array}$ \\
\hline
\end{tabular}




\subsubsection{Refrigeration Systems}

The conceptual supermarket was modeled with the following refrigeration systems and their features are briefly described below:

- Multiplex DX system consisting of a medium-temperature (MT) compressor rack and a lowtemperature (LT) rack. The refrigerant modeled in each rack was R-404A. The R-404A multiplex DX system coupled to standard-efficiency display cases and walk-ins was considered to be the baseline system by which the other refrigeration systems would be compared.

- Cascade refrigeration system with a primary R-404A DX system, a LT CO $\mathrm{CO}_{2}$ DX system and a MT glycol secondary loop. The MT loads were cooled with a $30 \%$ propylene glycol secondary loop while the LT loads were cooled by the low-temperature $\mathrm{CO}_{2} \mathrm{DX}$ system.

- Cascade refrigeration system with a primary DX system (using a variety of refrigerants), a LT $\mathrm{CO}_{2}$ DX system and a MT $\mathrm{CO}_{2}$ secondary loop. The MT loads were cooled with a pumped $\mathrm{CO}_{2}$ secondary loop while the LT loads were cooled by the $\mathrm{LT} \mathrm{CO}_{2} \mathrm{DX}$ system. The primary refrigerants considered included R-404A, R-134a, R-32, R-1234yf and ammonia (R-717).

- Transcritical $\mathrm{CO}_{2}$ booster system. Both the MT and LT loads were served by direct expansion of $\mathrm{CO}_{2}$. The heat rejection from the system occurs either supercritically or subcritically, depending upon the outdoor ambient temperature.

Various refrigerants and their GWP values are shown in Table 3. The refrigerant charge for respective systems for the LCCP analysis was assumed as follows:

- Multiplex DX Systems: $1835 \mathrm{lb}(832 \mathrm{~kg})$ of R-404A

- Cascade Systems: $1100 \mathrm{lb}$ (499 kg) of primary refrigerant, and $430 \mathrm{lb}(195 \mathrm{~kg}$ ) of CO

- Transcritical $\mathrm{CO}_{2}$ Booster Systems: $920 \mathrm{lb}(417 \mathrm{~kg})$ of $\mathrm{CO}_{2}$

A $10 \%$ annual refrigerant leakage rate was assumed, with a $10 \%$ loss of refrigerant charge at the endof-life of the refrigeration system. Furthermore, a service leakage rate of 5\% was assumed, with a service interval of one service event every two years. Finally, the refrigeration system life was assumed to be 20 years.

Table 3. Global warming potential (GWP) values for selected refrigerants (ASHRAE, 2009; Spatz and Minor, 2008)

\begin{tabular}{lc}
\hline Refrigerant & GWP (100 year time horizon) \\
\hline R-32 & 675 \\
R-134a & 1430 \\
R-404A & 3900 \\
R-717 & $<1$ \\
R-744 & 1 \\
R-1234yf & 4 \\
\hline
\end{tabular}

\subsection{RESULTS AND DISCUSSION}

\subsubsection{Energy Consumption}

The EnergyPlus simulation results for the baseline and high-efficiency refrigeration systems are summarized in Fig. 2, where the annual electrical energy consumption of the various refrigeration systems is shown for the seven climates zones of the continental U.S., relative to the baseline R-404A multiplex DX system in Miami, FL. Recall that the high-efficiency refrigeration systems consist of the refrigeration systems coupled to the high-efficiency display cases and walk-ins, while the baseline system consists of the multiplex DX system coupled to the standard-efficiency display cases and walk-ins. 

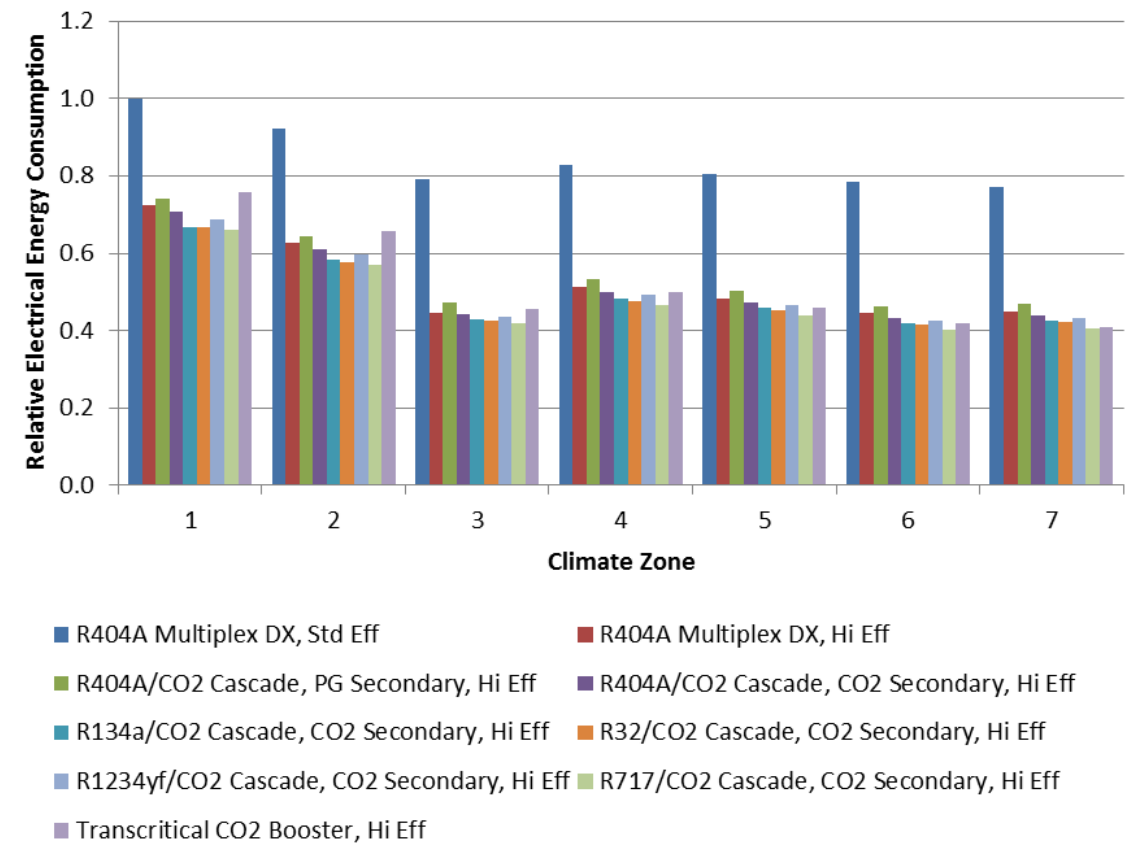

Fig. 2. Annual electrical energy consumption of the various refrigeration systems in the seven climate zones of the continental United States, relative to the baseline R-404A DX system in Miami, FL.

In general, the high-efficiency refrigeration systems performed well in the moderate and cold climate zones (Zones 3-7). In addition, the worst refrigeration system performance was noted in the warmest climate zones (Zones 1 and 2). On average, the energy consumption of the high-efficiency refrigeration systems was found to decrease by $38 \%$ from the hottest climate zone, Zone 1, to the coldest climate zone, Zone 7. It may be noted that the high-efficiency R-717/ $\mathrm{CO}_{2}$ cascade system with a $\mathrm{MT} \mathrm{CO}_{2}$ secondary loop performed the best in all of the climate zones. Across all the climate zones, this system consumed approximately $44 \%$ less energy than the baseline standard-efficiency R-404A multiplex DX refrigeration system. The R-32/CO $\mathrm{CO}_{2}$ and $\mathrm{R}-134 \mathrm{a} / \mathrm{CO}_{2}$ cascade systems produced similar results, consuming an average of $42 \%$ less energy than the baseline R-404A multiplex DX system. The high-efficiency R-404A/CO and $\mathrm{R}-1234 \mathrm{yf} / \mathrm{CO}_{2}$ cascade systems were comparable across the seven climate zones, each consuming approximately $40 \%$ less energy than the baseline R-404A multiplex DX system. The high-efficiency transcritical $\mathrm{CO}_{2}$ booster system appears to be highly sensitive to climate zone. As expected, this system performed relatively well in the colder climates (Zones 5-7) and consumed approximately $39 \%$ less energy on average than the standard-efficiency R-404A multiplex DX system. In addition, the transcritical $\mathrm{CO}_{2}$ booster system performed its worst in Climate Zones 1 and 2, where the booster system operates in the supercritical mode for a considerable portion of the year. The transcritical $\mathrm{CO}_{2}$ system was found to be up to $9 \%$ more efficient than the high-efficiency R-404A multiplex DX system for the colder climates (Zones 5-7) and up to 5\% less efficient than the high-efficiency R-404A multiplex DX system in the warm climates (Zones 1 and 2). On average, the high-efficiency R-404A multiplex DX system consumed 38\% less energy than the baseline R-404A multiplex DX system while the R-404A/CO cascade system with a MT glycol secondary loop consumed approximately $36 \%$ less energy than the baseline system. Finally, depending upon climate zone and refrigeration system configuration, it can be seen from Fig. 2 that by replacing standard-efficiency display cases and walk-ins with high-efficiency units, energy savings of between $24 \%$ to $49 \%$ can be achieved compared to the baseline standardefficiency R-404A multiplex DX system. 


\subsubsection{Life Cycle Climate Performance}

The $\mathrm{CO}_{2 \mathrm{eq}}$ emissions for the baseline and high-efficiency refrigeration systems in the seven climate zones of the continental U.S., relative to the baseline R-404A DX system in Miami, FL, are shown in Fig. 3. It can be seen that the baseline and high-efficiency R-404A multiplex DX systems produce considerably greater emissions than the other systems. In general, the $\mathrm{R}-717 / \mathrm{CO}_{2}$ cascade system with a MT CO${ }_{2}$ secondary loop produced the lowest emissions, followed closely by the R-1234yf $/ \mathrm{CO}_{2}$, R$32 / \mathrm{CO}_{2}$, and $\mathrm{R}-134 \mathrm{a} / \mathrm{CO}_{2}$ cascade systems, and the transcritical $\mathrm{CO}_{2}$ booster system. The R-404A/CO cascade systems, with either propylene glycol or $\mathrm{CO}_{2}$ secondary loops, produced approximately twice as much equivalent emissions than the aforementioned five systems.

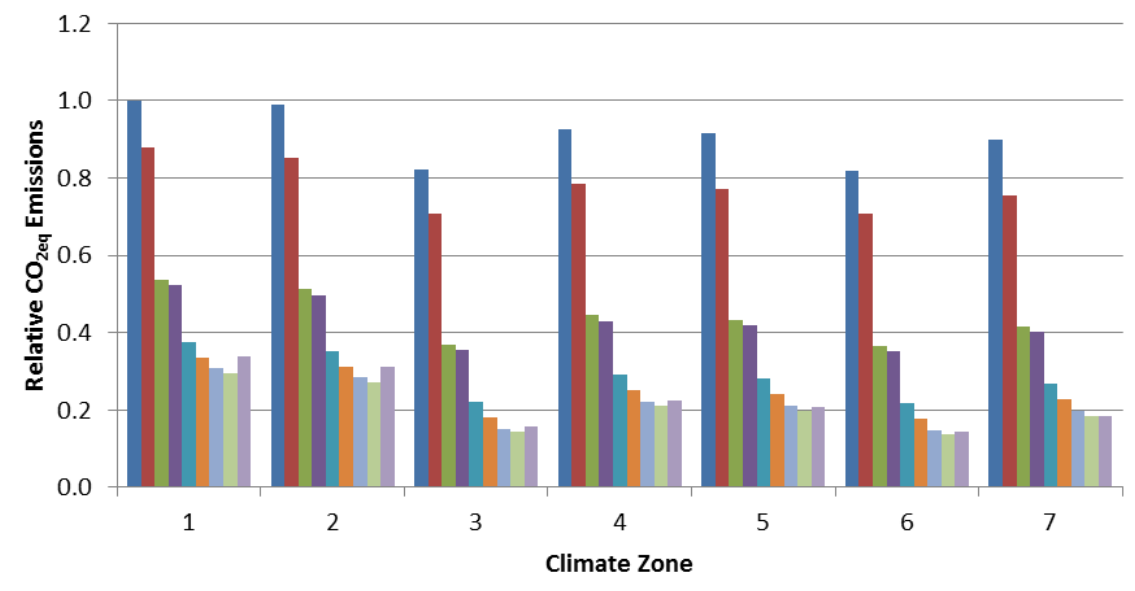

$$
\begin{array}{ll}
\text { R404A Multiplex DX, Std Eff } & \text { R404A Multiplex DX, Hi Eff } \\
\square \text { R404A/CO2 Cascade, PG Secondary, Hi Eff } & \text { R404A/CO2 Cascade, CO2 Secondary, Hi Eff } \\
\text { R134a/CO2 Cascade, CO2 Secondary, Hi Eff } & \text { R32/CO2 Cascade, CO2 Secondary, Hi Eff } \\
\text { R1234yf/CO2 Cascade, CO2 Secondary, Hi Eff } & \text { R717/CO2 Cascade, CO2 Secondary, Hi Eff } \\
\text { Transcritical CO2 Booster, Hi Eff } &
\end{array}
$$

Fig. 3. Carbon dioxide equivalent emissions of the various refrigeration systems in the seven climate zones of the continental United States, relative to the baseline R-404A DX system in Miami, FL.

For the various refrigeration systems, the average percentage reduction in $\mathrm{CO}_{2 \mathrm{eq}}$ emissions relative to the standard-efficiency R-404A multiplex DX system is shown in Table 4. The average percent reduction in $\mathrm{CO}_{2}$ emissions was determined by averaging the carbon dioxide emissions of each refrigeration system over the seven climate zones.

The R-717/ $\mathrm{CO}_{2}, \mathrm{R}-1234 \mathrm{yf} / \mathrm{CO}_{2}$ and $\mathrm{R}-32 / \mathrm{CO}_{2}$ cascade systems and the transcritical $\mathrm{CO}_{2}$ booster system all exhibited average reductions in $\mathrm{CO}_{2 \mathrm{eq}}$ emissions of greater than $73 \%$, relative to the standardefficiency R-404A multiplex DX system. The R-134a cascade system with $\mathrm{CO}_{2}$ secondary loop produced similar average reductions in $\mathrm{CO}_{2 \mathrm{eq}}$ emissions (69\%). The R-404A/CO $\mathrm{CO}_{2}$ cascade systems, with either propylene glycol or $\mathrm{CO}_{2}$ secondary loops, produced average reductions in $\mathrm{CO}_{2 \mathrm{eq}}$ emissions of $52 \%$ and $53 \%$, respectively, compared to the baseline R-404A multiplex DX system. Finally, the high-efficiency R-404A multiplex DX system had the lowest average emission reduction of $14 \%$ compared to the baseline system. 
Table 4. Average percent reduction in $\mathrm{CO}_{2 \mathrm{eq}}$ emissions relative to the baseline standard-efficiency R-404A multiplex DX system

\begin{tabular}{lc}
\hline \multicolumn{1}{c}{ Refrigeration system } & $\begin{array}{c}\text { Emissions reduction relative to baseline } \\
\text { R-404A multiplex DX system, \% }\end{array}$ \\
\hline R-404A Multiplex DX, Hi Eff & 14.4 \\
R-404A/CO $/ \mathrm{CO}_{2}$ Cascade, PG Secondary, Hi Eff & 51.9 \\
R-404A/CO $/ \mathrm{Ca}_{2}$ Cascade, $\mathrm{CO}_{2}$ Secondary, Hi Eff & 53.4 \\
R-134a/ $/ \mathrm{CO}_{2}$ Cascade, $\mathrm{CO}_{2}$ Secondary, Hi Eff & 68.7 \\
R-32/CO $\mathrm{Cascade}_{2} \mathrm{CO}_{2}$ Secondary, Hi Eff & 73.2 \\
R-1234yf/CO $/ \mathrm{Ca}_{2}$ Cascade, $\mathrm{CO}_{2}$ Secondary, Hi Eff & 76.5 \\
R-717/CO $\mathrm{Cascade}_{2} \mathrm{CO}_{2}$ Secondary, Hi Eff & 77.7 \\
Transcritical $\mathrm{CO}_{2}$ Booster, Hi Eff & 75.8 \\
\hline
\end{tabular}

The effect of refrigeration system design on the direct and indirect $\mathrm{CO}_{2 \mathrm{eq}}$ emissions is shown in Fig. 4 , averaged over the seven climate zones. It can be seen that $61 \%$ of the total emissions associated with the baseline R-404A multiplex DX system is attributed to direct emissions, while direct emissions account for $71 \%$ of the total for the high-efficiency R-404A multiplex system. Recall that direct emissions are associated with the direct release of refrigerant. Thus, those refrigeration systems with reduced refrigerant charge and/or low GWP refrigerants will exhibit significantly lower direct emissions. The direct emissions associated with the two R-404A/CO $\mathrm{CO}_{2}$ cascade systems are roughly $47 \%$ of the total $\mathrm{CO}_{2 \text { eq }}$ emissions. Replacing R-404A $(\mathrm{GWP}=3900)$ with $\mathrm{R}-134 \mathrm{a}(\mathrm{GWP}=1430)$ in the cascade systems results in direct emissions which are approximately $26 \%$ of the total $\mathrm{CO}_{2 \mathrm{eq}}$ emissions. Similarly, by replacing R-404A with R-32 in the cascade systems results in direct emissions which are approximately $14 \%$ of the total $\mathrm{CO}_{2 \mathrm{eq}}$ emissions. Finally, the direct emissions associated with the other three refrigeration systems ( $\mathrm{R}-1234 \mathrm{yf} / \mathrm{CO}_{2}$ cascade, $\mathrm{R}-717 / \mathrm{CO}_{2}$ cascade, and transcritical $\mathrm{CO}_{2}$ booster) were less than $0.1 \%$ of the total $\mathrm{CO}_{2 \mathrm{eq}}$ emissions. This is due to the very low GWP of R-1234yf, R-717 and R744.

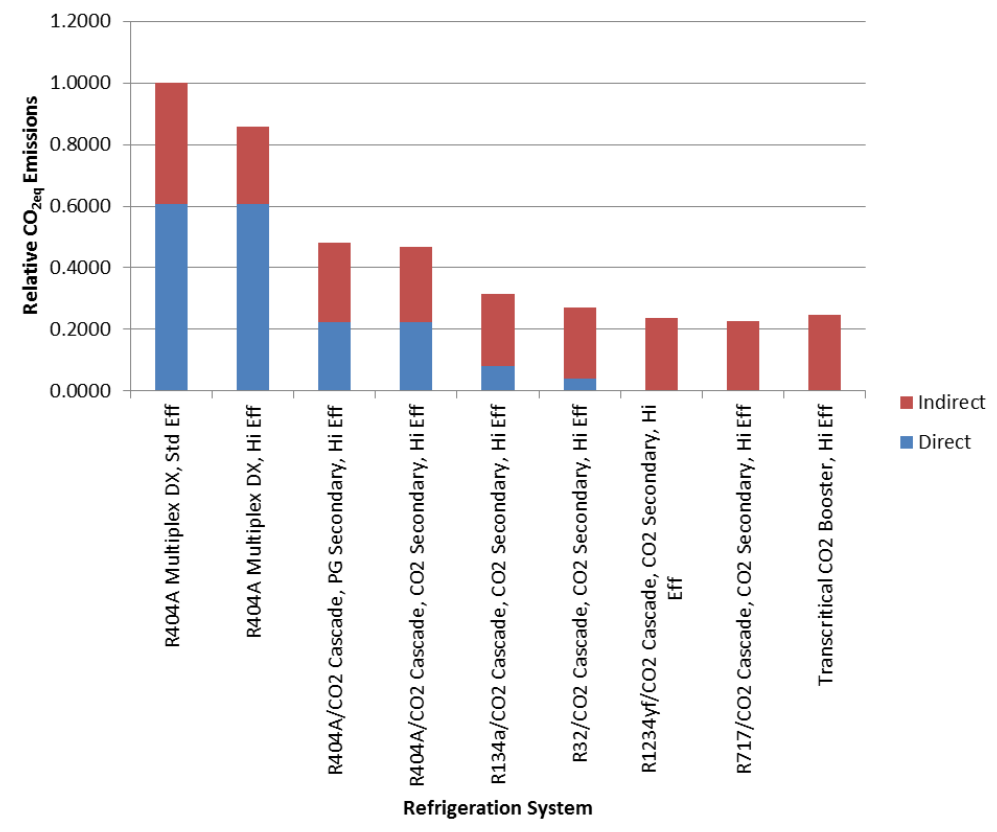

Fig. 4. Average direct and indirect carbon dioxide equivalent emissions for the various refrigeration systems. 


\subsection{SUMMARY}

In all the climate zones, the high-efficiency R-717/ $\mathrm{CO}_{2}$ cascade refrigeration system with a mediumtemperature $\mathrm{CO}_{2}$ secondary loop consumed the least amount of energy, using an average of $44 \%$ less energy compared to the baseline standard-efficiency R-404A multiplex DX system. In addition, the highefficiency R-134a/ $/ \mathrm{CO}_{2}, \mathrm{R}-32 / \mathrm{CO}_{2}$, and R-1234yf $/ \mathrm{CO}_{2}$ cascade refrigeration systems with mediumtemperature $\mathrm{CO}_{2}$ secondary loops performed well in each of the climate zones, using an average of $42 \%$ less energy compared to the baseline system. Finally, the high-efficiency transcritical $\mathrm{CO}_{2}$ booster system performed its best in the colder climate zones (Zones 5-7), and, overall, used an average of $39 \%$ less energy compared to the baseline system.

The energy consumption of the refrigeration systems could be reduced by $24 \%$ to $49 \%$ by replacing standard-efficiency display cases and walk-ins with high-efficiency units. These energy reduction measures can significantly reduce the refrigeration system's indirect carbon dioxide emissions associated with electrical energy use, thereby reducing the system's impact upon the environment.

The high-efficiency refrigeration systems utilizing low GWP refrigerants, including R-1234yf, R-717, and R-744, can drastically reduce carbon dioxide emissions as compared to the baseline R-404A multiplex DX refrigeration system. Emissions reductions of up to $78 \%$ are estimated for refrigeration systems that utilize low GWP refrigerants.

A transcritical $\mathrm{CO}_{2}$ booster refrigeration system, coupled with high-efficiency display cases and walkins, can achieve average energy reductions of $39 \%$ compared to the standard-efficiency R-404A multiplex DX system, with $76 \%$ lower emissions and hence is a potential low emission, high-efficiency alternative to the current baseline R-404A multiplex DX systems in use. 


\section{FURTHER ANALYSIS OF $\mathrm{CO}_{2}$ BASED REFRIGERATION SYSTEMS}

As shown in the analysis presented in Chapter 2, a transcritical $\mathrm{CO}_{2}$ booster refrigeration system, coupled with high-efficiency display cases and walk-ins, can achieve average energy reductions of up to $39 \%$ compared to the standard-efficiency R-404A multiplex DX system, with 76\% lower emissions and hence is a potential low emission, high-efficiency alternative to the current baseline R-404A multiplex DX systems currently in use. Thus, $\mathrm{CO}_{2}$-based refrigeration systems can potentially meet the project objectives of reduced energy consumption and reduced greenhouse gas emissions.

In order to optimize the operating parameters of $\mathrm{CO}_{2}$-based refrigeration systems, further analysis is presented in this chapter of various $\mathrm{CO}_{2}$ transcritical and cascade/secondary loop refrigeration systems for supermarket applications. In addition, the performance of selected $\mathrm{CO}_{2}$-based refrigeration systems is compared to the baseline R-404A multiplex direct expansion system using bin analyses in the eight climate zones of the United States.

In an effort to increase the efficiency of the transcritical $\mathrm{CO}_{2}$ system and to make it applicable to warmer climates, several researchers have investigated the energy efficiency of various configurations of the transcritical refrigeration system (Bell 2004; Ferrandi and Orlandi 2012; Ge and Tassou 2009, 2010; Mazzola, Toffolo, and Orlandi 2012; Sarkar and Agrawal 2010; Sawalha 2007; Winter and Murin 2012). However, these studies focused on a particular system only and lacked any system performance comparison with various other possible $\mathrm{CO}_{2}$ system configurations. Also, these studies did not optimize the design parameters such as the evaporator superheat $(\Delta T)$, the suction line heat exchanger (SLHX) effectiveness and the secondary loop circulation ratio $(C R)$, in order to maximize the system coefficient of performance (COP). A comprehensive analysis is presented of seven $\mathrm{CO}_{2}$-based refrigeration system configurations that are currently being used in the supermarket refrigeration industry and the performance of the more energy-efficient $\mathrm{CO}_{2}$-based refrigeration systems is compared with that of a baseline R-404A multiplex DX system using bin analyses in sixteen cities from eight climate zones of the United States.

\subsection{DESCRIPTION OF $\mathrm{CO}_{2}$ BASED REFRIGERATION SYSTEMS}

The $\mathrm{CO}_{2}$-based refrigeration systems investigated in this study include cascade and secondary loop systems as well as transcritical systems. These systems are briefly described in the following section, along with the performance comparison of the $\mathrm{CO}_{2}$-based refrigeration systems with the baseline R-404A multiplex direct expansion (DX) system (System 1), shown in Fig. 5.

\subsubsection{Secondary Loop and Cascade Systems}

A secondary loop system is comprised of two circuits, a primary DX circuit and a secondary pumped loop circuit, coupled through a secondary fluid heat exchanger. The primary DX circuit typically utilizes $\mathrm{R}-404 \mathrm{~A}$ while the secondary loop uses a pumped liquid such as propylene glycol (single-phase) or $\mathrm{CO}_{2}$ (two-phase).

A cascade system is comprised of separate high-temperature and low-temperature circuits, coupled through a heat exchanger called the cascade condenser. The cascade condenser functions as an evaporator for the high-temperature circuit and a condenser for the low-temperature circuit. Generally, the high-temperature circuit is a single-stage direct expansion system but the low-temperature circuit can either be a direct expansion system or a secondary loop system. The refrigerant in the high temperature circuit is typically an HFC (R-404A in this case), while $\mathrm{CO}_{2}$ is used in the low-temperature circuit. 


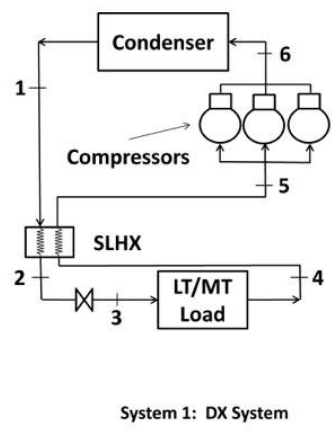

(a)

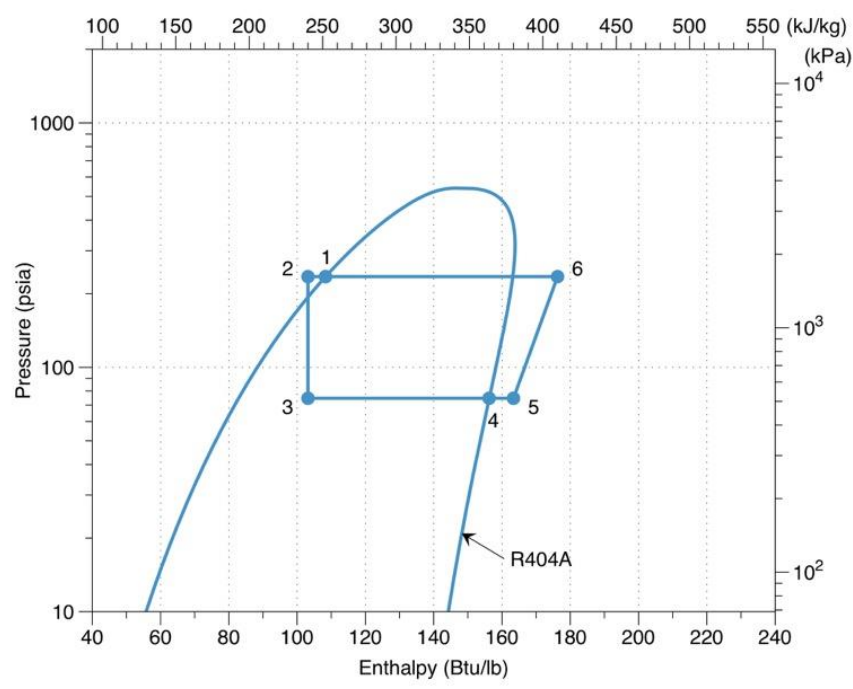

(b)

Fig. 5. Cycle schematic and pressure-enthalpy (p-h) diagram for the baseline multiplex direct expansion (DX) refrigeration system.

\subsubsection{1 $\mathrm{CO}_{2}$ Secondary Coolant (SC) System}

In the SC system (System 2), shown in Fig. 6, a high temperature R-404A circuit provides cooling to a low-temperature pumped $\mathrm{CO}_{2}$ secondary loop circuit. The pumped $\mathrm{CO}_{2}$ circuit in turn, provides cooling for the medium- or low-temperature loads. In the pressure-enthalpy $(P-h)$ diagram, the DX R-404A (1-23-4-5-6) and the pumped $\mathrm{CO}_{2}(7-8-9-10-11)$ circuits are represented by the inner and the outer domes, respectively.

Refrigeration systems with separate SC systems for the low- and medium-temperature loads are commonly used in supermarkets. In this report, such a paired SC system is called the Combined System 1.

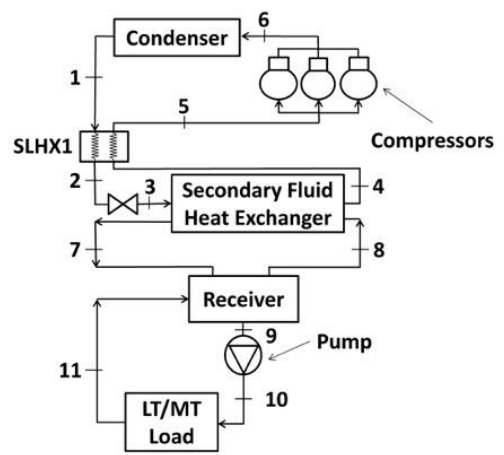

System 2: $\mathrm{CO}_{2}$ Secondary Coolant (SC) System

(a)

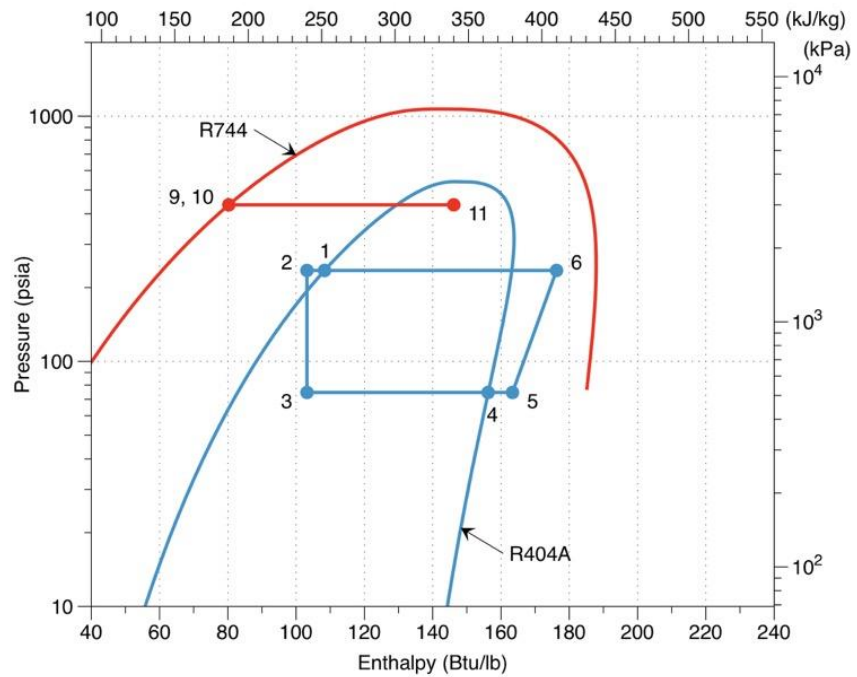

(b)

Fig. 6. Cycle schematic and pressure-enthalpy (p-h) diagram for the $\mathrm{CO}_{2}$ secondary coolant (SC) refrigeration system. 


\subsubsection{2 $\mathrm{CO}_{2}$ Direct Expansion Cascade (DEC) System}

In the DEC system (System 3), shown in Fig. 7, the low-temperature circuit and the high-temperature circuit are single-stage direct expansion systems, each having their own SLHXs (if necessary), coupled through the cascade condenser. In the $P$ - $h$ diagram, the DX R-404A (1-2-3-4-5-6) and the DX $\mathrm{CO}_{2}(7-8$ 9-10-11-12) circuits are represented by the inner and the outer domes, respectively.

A refrigeration system using a DEC system for the low-temperature (LT) circuit and a separate SC system for the medium-temperature (MT) circuit is also studied in this report. Such a refrigeration system will be called here the Combined System 2.

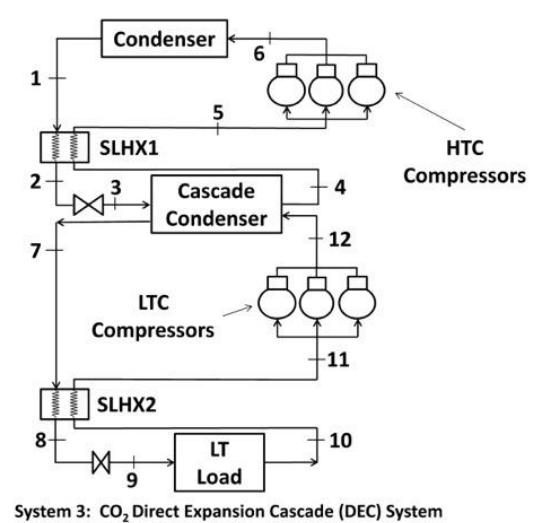

(a)

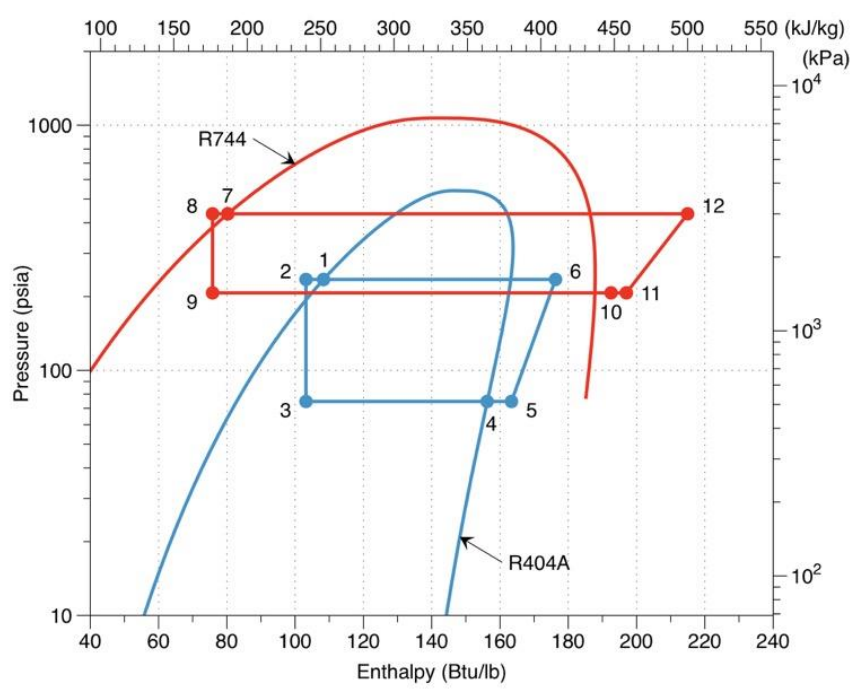

(b)

Fig. 7. Cycle schematic and pressure-enthalpy $(p-h)$ diagram for the $\mathrm{CO}_{2}$ direct expansion cascade (DEC) refrigeration system.

\subsubsection{Combined $\mathrm{CO}_{2}$ Secondary/Cascade (CSC) System}

In the CSC system (System 4), shown in Fig. 8, the low-temperature and medium-temperature loads are managed by a single-stage direct expansion system and a $\mathrm{CO}_{2}$ secondary loop system, respectively, coupled with the high-temperature circuit through the cascade condenser. In the $P$ - $h$ diagram, the DX $\mathrm{R}-404 \mathrm{~A}$ (1-2-3-4-5-6) and the $\mathrm{CO}_{2}$ (7-8-9-10-11-12-13-14-15-16-17-18) circuits are represented by the inner and the outer domes, respectively. 


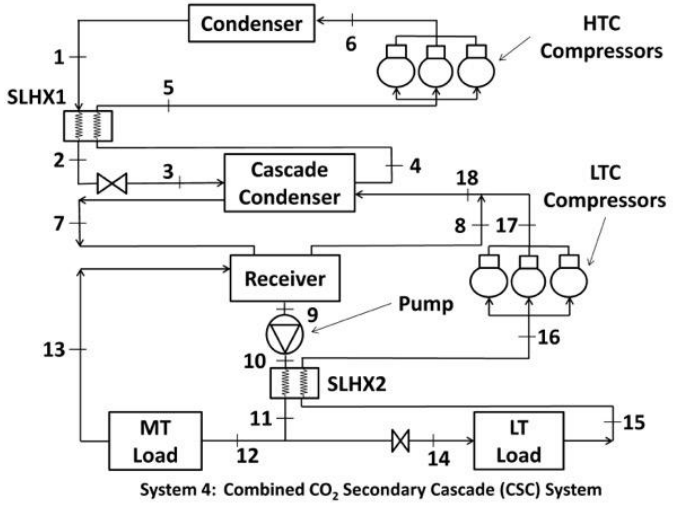

(a)

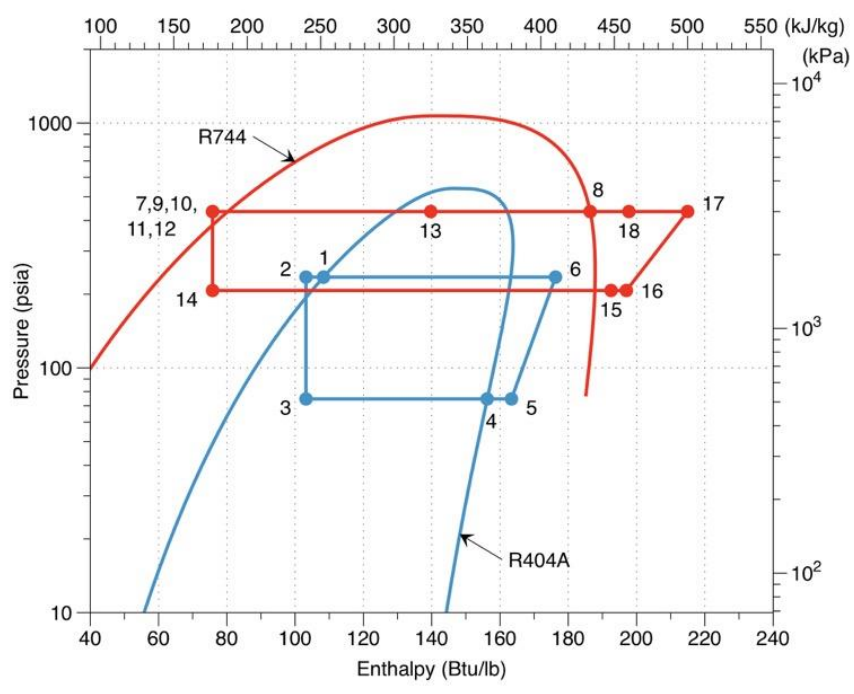

(b)

Fig. 8. Cycle schematic and pressure-enthalpy $(p-h)$ diagram for the combined $\mathrm{CO}_{2}$ secondary/cascade (CSC) refrigeration system.

\subsubsection{Combined Glycol Secondary/CO $\mathrm{CO}_{2}$ Cascade (CSC-G) System}

In the CSC-G System (System 5), shown in Fig. 9, the low-temperature loads are supplied with a single-stage direct expansion $\mathrm{CO}_{2}$ system coupled with the high-temperature circuit through the cascade condenser, while the medium-temperature loads are managed through a propylene glycol secondary loop (instead of liquid $\mathrm{CO}_{2}$ as in System 4). In the $P$ - $h$ diagram, the DX R-404A (1-2-3-4-5-6-7-8-9-10-11) and the $\mathrm{CO}_{2}$ (12-13-14-15-16-17) circuits are represented by the inner and the outer domes, respectively.

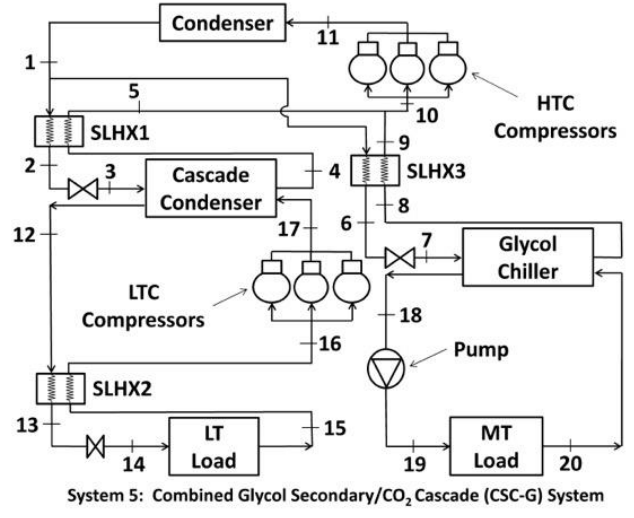

(a)

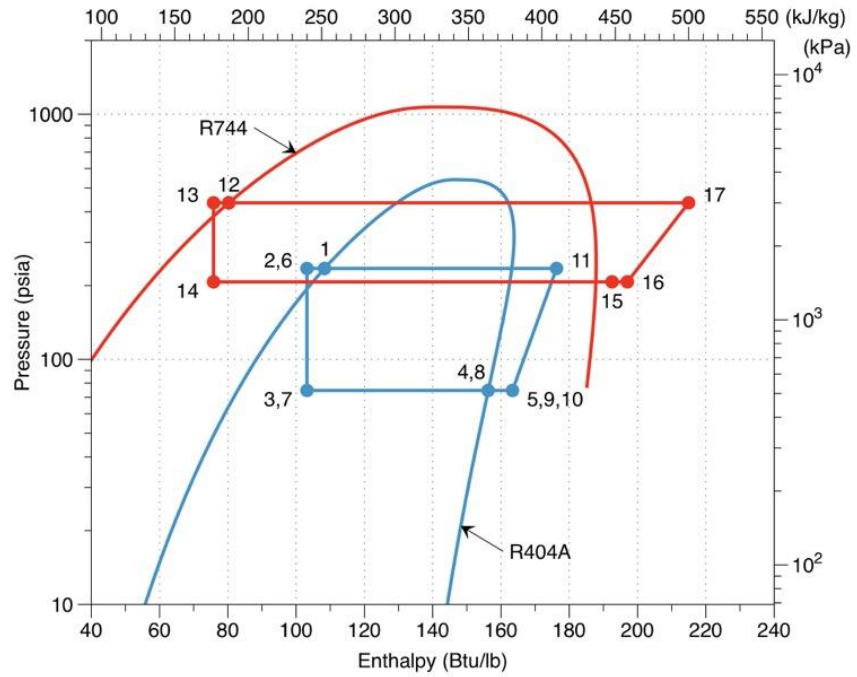

(b)

Fig. 9. Cycle schematic and pressure-enthalpy $(p-h)$ diagram for the combined glycol secondary/CO Cascade (CSC-G) refrigeration system. 


\subsubsection{Transcritical $\mathrm{CO}_{2}$ Booster Systems}

A transcritical $\mathrm{CO}_{2}$ booster system is divided into four pressure levels. At the highest pressure level, the refrigerant $\left(\mathrm{CO}_{2}\right)$ from the high pressure compressors enters a gas cooler/condenser and rejects heat to the surroundings. The high pressure $\mathrm{CO}_{2}$ is further cooled in a suction line heat exchanger (SLHX1) and expanded before being collected in the receiver. The saturated refrigerant liquid from the receiver is expanded to the saturation pressure corresponding to the medium-temperature and low-temperature loads, respectively. After absorbing heat from the low-temperature loads, the low-pressure refrigerant is further superheated in the SLHX2 and compressed in the low-pressure compressors. The discharge from the low-pressure compressors, the medium-temperature loads and the bypass valve combines before entering the high-pressure compressors.

\subsubsection{Standard Transcritical Booster System (STBS)}

In the STBS system (System 6), shown in Fig. 10, the high pressure refrigerant from the outlet of the gas cooler/condenser passes through the SLHX1 before expanding to an intermediate pressure level through the expansion device between locations 2 and 3 . In the $P$ - $h$ diagram, state points 1,2 and 17 are at the high pressure level, state points 3, 4, 6 and 9 are at the intermediate pressure level, state points 5, 7, $8,13,14,15$ and 16 are at the medium-temperature pressure level and state points 10,11 and 12 are at the low-temperature pressure level.

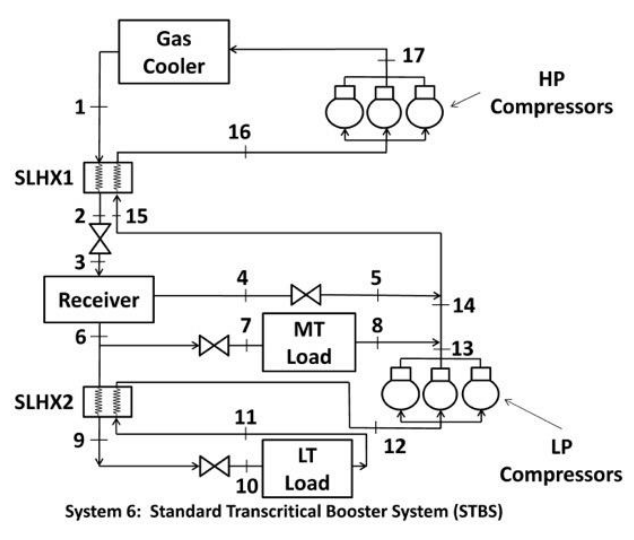

(a)

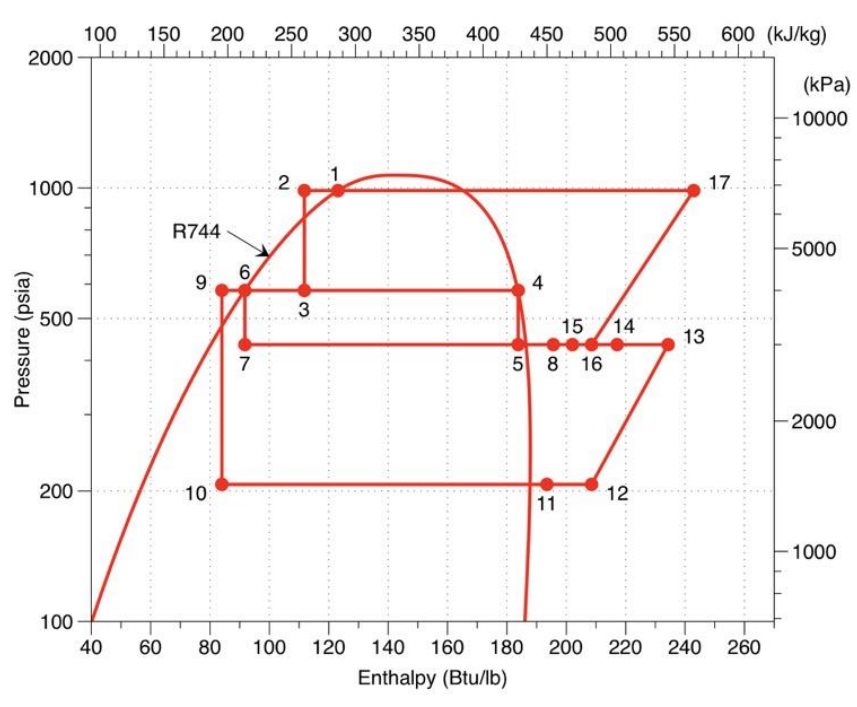

(b)

Fig. 10. Cycle schematic and pressure-enthalpy $(p-h)$ diagram for the standard transcritical $\mathrm{CO}_{2}$ booster refrigeration system (STBS).

\subsubsection{Transcritical Booster System with Bypass Compressor (TBS-BC)}

The TBS-BC system (System 7), shown in Fig. 11, is similar to the STBS, however, the refrigerant exiting the receiver bypass at location 4 is compressed by an additional set of compressors (bypass compressors), which then combines with the discharge of the high-pressure compressors at location 17 , before finally entering the gas cooler/condenser. In the $P$ - $h$ diagram, state points $1,2,5,16$ and 17 are at the high pressure level, state points 3, 4, 6 and 9 are at the intermediate pressure level, state points 7, 8, 13,14 , and 15 are at the medium-temperature pressure level and state points 10, 11 and 12 are at the lowtemperature pressure level. 


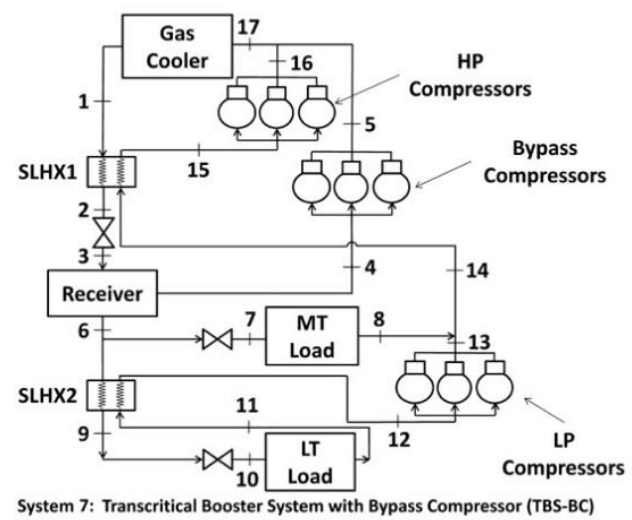

(a)

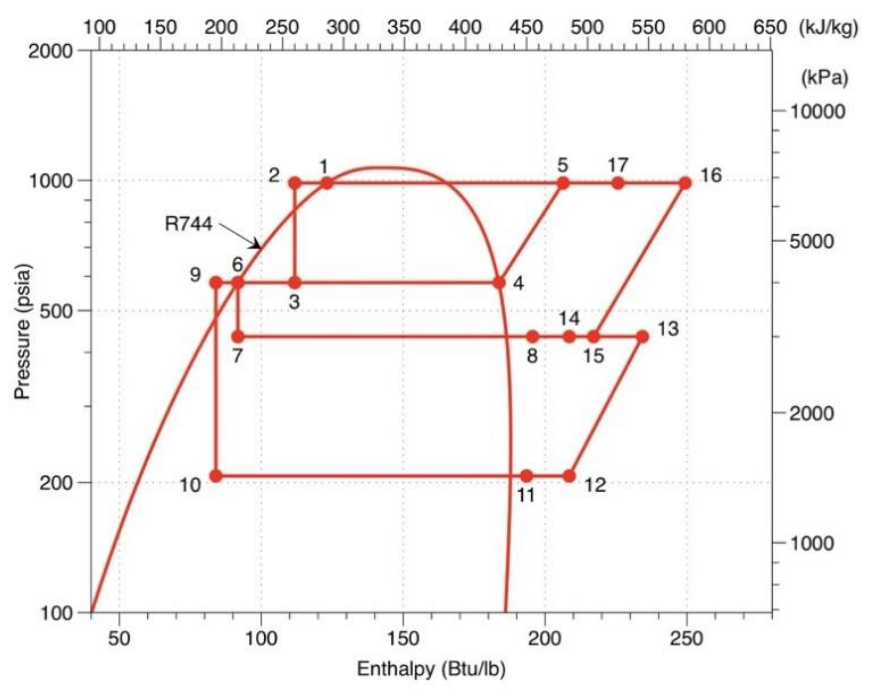

(b)

Fig. 11. Cycle schematic and pressure-enthalpy $(p-h)$ diagram for the transcritical $\mathrm{CO}_{2}$ booster refrigeration system with bypass compressor (TBS-BC).

\subsection{SYSTEM ANALYSIS}

The overall coefficient of performance, $C O P$, of a refrigeration system is determined by:

$$
C O P=\frac{\dot{Q}_{r e f}}{\dot{W}_{\text {total }}}
$$

where $\dot{Q}_{r e f}$ is the total refrigerating capacity of the system and $\dot{W}_{\text {total }}$ is the total power required by the compressors and pumps (the condenser/gas cooler fan power is excluded in these analyses). For the seven refrigeration systems discussed in Section 3.1, the corresponding equations for refrigerating capacity and total power input are given in Table 5. These equations were used with the definition of COP (Eqn. 4) to determine the performance of each of the seven refrigeration systems.

\subsection{METHODOLOGY}

\subsubsection{Baseline Parameters}

In order to assess the merits and the advantages offered by the $\mathrm{CO}_{2}$-based refrigeration systems, a parametric study was performed to determine the effect of various operating parameters on the energy efficiency of the systems. Ambient temperature ranging between $32^{\circ} \mathrm{F}$ and $104^{\circ} \mathrm{F}\left(0^{\circ} \mathrm{C}\right.$ and $\left.40^{\circ} \mathrm{C}\right)$ was used to determine the performance of the systems in all eight climate zones of the US. SLHX effectiveness values of $0,0.4$, and 0.7 were used to represent a system without a SLHX $(\varepsilon=0)$ or the upper range of a realistic heat exchanger (where 1.0 represents an ideal $100 \%$ efficient heat exchanger). Evaporator superheat is always required to ensure that no liquid enters the compressor. Thus, the performance of the systems was studied using an evaporator superheat of either $9 \mathrm{R}(5 \mathrm{~K})$ or $18 \mathrm{R}(10 \mathrm{~K})$ for both the low- and medium-temperature loads. The pump circulation ratio $(C R)$, the ratio of total refrigerant mass to the mass of vapor refrigerant, maintains wetted surface for effective heat transfer while minimizing pump work. The performance of secondary loop systems is studied with a $C R$ of 1.5 and 2.5. A summary of the parameters used in the analysis is given in Table 6 . The thermodynamic properties of the refrigerants were calculated using the National Institute of Standards and Technology 
(NIST) Reference Fluid Thermodynamic and Transport Properties Database (REFPROP) Version 9.1 (Lemmon et al., 2013).

Table 5. Refrigeration capacity and required power

\begin{tabular}{|c|c|c|}
\hline System & Total Refrigerating Capacity, $\dot{Q}_{\text {ref }}$ & Total Input Power, $\dot{W}_{\text {total }}$ \\
\hline DX & $\dot{Q}_{\text {ref }}=\dot{m}_{3}\left(h_{4}-h_{3}\right)$ & $\dot{W}_{\text {total }}=\dot{m}_{5}\left(h_{6}-h_{5}\right)$ \\
\hline $\mathrm{SC}$ & $\dot{Q}_{\mathrm{ref}}=\dot{m}_{10}\left(h_{11}-h_{10}\right)$ & $\begin{array}{l}\dot{W}_{\text {total }}=\dot{W}_{\text {pump }}+\dot{W}_{\text {comp }} \\
\dot{W}_{\text {comp }}=\dot{m}_{5}\left(h_{6}-h_{5}\right), \\
\dot{W}_{\text {pump }}=\dot{m}_{9}\left(h_{10}-h_{9}\right)\end{array}$ \\
\hline DEC & $\dot{Q}_{\mathrm{ref}}=\dot{m}_{9}\left(h_{10}-h_{9}\right)$ & $\begin{array}{c}\dot{W}_{\text {total }}=\dot{W}_{\mathrm{LP}}+\dot{W}_{\mathrm{HP}} \\
\dot{W}_{\mathrm{LP}}=\dot{m}_{11}\left(h_{12}-h_{11}\right) \\
\dot{W}_{\mathrm{HP}}=\dot{m}_{5}\left(h_{6}-h_{5}\right)\end{array}$ \\
\hline $\mathrm{CSC}$ & $\begin{array}{c}\dot{Q}_{\mathrm{ref}}=\dot{Q}_{\mathrm{LT}}+\dot{Q}_{\mathrm{MT}} \\
\dot{Q}_{\mathrm{LT}}=\dot{m}_{14}\left(h_{15}-h_{14}\right) \\
\dot{Q}_{\mathrm{MT}}=\dot{m}_{12}\left(h_{13}-h_{12}\right)\end{array}$ & $\begin{array}{c}\dot{W}_{\text {total }}=\dot{W}_{\mathrm{LP}}+\dot{W}_{\mathrm{HP}}+\dot{W}_{\text {pump }} \\
\dot{W}_{\mathrm{LP}}=\dot{m}_{16}\left(h_{17}-h_{16}\right) \\
\dot{W}_{\mathrm{HP}}=\dot{m}_{5}\left(h_{6}-h_{5}\right) \\
\dot{W}_{\text {pump }}=\dot{m}_{9}\left(h_{10}-h_{9}\right) \\
\end{array}$ \\
\hline CSC-G & $\begin{array}{c}\dot{Q}_{\mathrm{ref}}=\dot{Q}_{\mathrm{LT}}+\dot{Q}_{\mathrm{MT}} \\
\dot{Q}_{\mathrm{LT}}=\dot{m}_{14}\left(h_{15}-h_{14}\right) \\
\dot{Q}_{\mathrm{MT}}=\dot{m}_{19}\left(h_{20}-h_{19}\right)\end{array}$ & $\begin{array}{c}\dot{W}_{\text {total }}=\dot{W}_{\mathrm{LP}}+\dot{W}_{\mathrm{HP}}+\dot{W}_{\text {pump }} \\
\dot{W}_{\mathrm{LP}}=\dot{m}_{16}\left(h_{17}-h_{16}\right) \\
\dot{W}_{\mathrm{HP}}=\dot{m}_{10}\left(h_{11}-h_{10}\right) \\
\dot{W}_{\text {pump }}=\dot{m}_{18}\left(h_{19}-h_{18}\right)\end{array}$ \\
\hline STBS & $\begin{array}{c}\dot{Q}_{\mathrm{ref}}=\dot{Q}_{\mathrm{LT}}+\dot{Q}_{\mathrm{MT}} \\
\dot{Q}_{\mathrm{LT}}=\dot{m}_{10}\left(h_{11}-h_{10}\right) \\
\dot{Q}_{\mathrm{MT}}=\dot{m}_{7}\left(h_{8}-h_{7}\right)\end{array}$ & $\begin{array}{c}\dot{W}_{\text {total }}=\dot{W}_{\mathrm{LP}}+\dot{W}_{\mathrm{HP}} \\
\dot{W}_{\mathrm{LP}}=\dot{m}_{12}\left(h_{13}-h_{12}\right) \\
\dot{W}_{\mathrm{HP}}=\dot{m}_{16}\left(h_{17}-h_{16}\right)\end{array}$ \\
\hline TBS-BC & $\begin{array}{c}\dot{Q}_{\mathrm{ref}}=\dot{Q}_{\mathrm{LT}}+\dot{Q}_{\mathrm{MT}} \\
\dot{Q}_{\mathrm{LT}}=\dot{m}_{10}\left(h_{11}-h_{10}\right) \\
\dot{Q}_{\mathrm{MT}}=\dot{m}_{7}\left(h_{8}-h_{7}\right)\end{array}$ & $\begin{array}{c}\dot{W}_{\text {Total }}=\dot{W}_{\mathrm{LP}}+\dot{W}_{\mathrm{HP}}+\dot{W}_{\mathrm{BP}} \\
\dot{W}_{\mathrm{LP}}=\dot{m}_{12}\left(h_{13}-h_{12}\right) \\
\dot{W}_{\mathrm{HP}}=\dot{m}_{15}\left(h_{16}-h_{15}\right) \\
\dot{W}_{\mathrm{BP}}=\dot{m}_{4}\left(h_{5}-h_{4}\right)\end{array}$ \\
\hline
\end{tabular}

where $\dot{Q}_{L T}$ is the low-temperature refrigerating capacity, $\dot{Q}_{M T}$ is the medium-temperature refrigerating capacity, $\dot{W}_{\text {comp }}$ is the input power to the compressors, $\dot{W}_{\text {pump }}$ is the input power to the secondary coolant pumps, $\dot{W}_{L P}$ is the input power to the low-pressure compressors, $\dot{W}_{H P}$ is the input power to the high-pressure compressors, $\dot{W}_{B P}$ is the input power to the flash gas bypass compressors, $\dot{m}$ is the refrigerant mass flow rate, and $h$ is the refrigerant enthalpy.

Table 6. Parameters and their ranges

\begin{tabular}{lr}
\hline \multicolumn{1}{c}{ Parameter } & \multicolumn{1}{c}{ Range } \\
\hline Ambient temperature $\left(T_{a m b}\right)$ & $32-104^{\circ} \mathrm{F}\left(0-40^{\circ} \mathrm{C}\right)$ \\
Pump circulation ratio $(C R)$ & $1.5,2.5$ \\
Heat exchanger effectiveness $\left(\varepsilon_{s l h x}\right)$ & $0.0,0.4,0.7$ \\
Medium-temperature superheat $\left(\Delta T_{M T}\right)$ & $9,18 \mathrm{R}(5,10 \mathrm{~K})$ \\
Low-temperature superheat $\left(\Delta T_{L T}\right)$ & $9,18 \mathrm{R}(5,10 \mathrm{~K})$ \\
\hline
\end{tabular}

\subsubsection{System Operating Assumptions}

For an average supermarket $\left(45,000 \mathrm{ft}^{2}\right.$ or $\left.4,200 \mathrm{~m}^{2}\right)$, the typical refrigeration loads and temperatures of the low-temperature and the medium-temperature loads were assumed to be $222,000 \mathrm{Btu} / \mathrm{h}$ at a 
saturated evaporating temperature of $-22^{\circ} \mathrm{F}\left(65 \mathrm{~kW}\right.$ at $\left.-30^{\circ} \mathrm{C}\right)$ and $409,000 \mathrm{Btu} / \mathrm{h}$ at a saturated evaporating temperature of $23^{\circ} \mathrm{F}\left(120 \mathrm{~kW}\right.$ at $\left.-5^{\circ} \mathrm{C}\right)$, respectively.

For the proper operation of the expansion valves in the multiplex DX, SC, DEC, CSC and CSC-G systems, and for efficient heat transfer through the condenser in the cascade system options, the minimum condensing temperature is fixed at $T_{\text {cond }}=70^{\circ} \mathrm{F}\left(21^{\circ} \mathrm{C}\right)$ and the condensing temperature $\left(T_{\text {cond }}\right)$ is set to be $9 \mathrm{R}(5 \mathrm{~K})$ greater than the ambient temperature $\left(T_{a m b}\right)$. The approach temperature, which is the difference between the temperature at the outlet of the low-temperature circuit and the inlet of the high-temperature circuit of the cascade condenser, is $T_{a p p}=6^{\circ} \mathrm{F}\left(3.3^{\circ} \mathrm{C}\right)$.

Generally, in transcritical booster systems, the receiver pressure is approximately $70 \mathrm{psia}(0.5 \mathrm{MPa})$ higher than the saturated pressure of the medium-temperature loads, and thus, the intermediate pressure in the receiver is fixed at $P_{i n t}=510 \mathrm{psia}(3.5 \mathrm{MPa})$ for this study. The gas cooler/condenser temperature $\left(T_{G C}\right)$ is set to be $5^{\circ} \mathrm{F}\left(3^{\circ} \mathrm{C}\right)$ greater than the ambient temperature. Also, in transcritical operation, an optimum gas cooler pressure exists which maximizes the COP of the system (Kauf, 1999). These parameters, along with the equations for the optimum pressure of each transcritical booster system as functions of ambient temperature, are given in Table 7.

In addition, the following assumptions were made for the parametric analysis:

- $\quad$ The pressure drop and heat loss / gain in the suction lines are ignored.

- $\quad$ Only saturated liquid and saturated vapor exit the receiver.

- $\quad$ The isentropic efficiency of the low-pressure, high-pressure and bypass compressors is 0.65 .

- The expansion valves are isenthalpic.

- $\quad$ Condenser/gas cooler cooling fan power consumption is assumed to be roughly equal for all the systems given that the refrigeration loads are the same so fan power is not included in the COP computations.

Table 7. Baseline parameters of refrigeration systems

\begin{tabular}{|c|c|c|}
\hline System & Baseline Parameter & Value \\
\hline \multirow{2}{*}{ All } & \multirow{2}{*}{ Refrigeration Load } & $\dot{Q}_{M T}=409,000 \mathrm{Btu} / \mathrm{h}$ at $23^{\circ} \mathrm{F}\left(120 \mathrm{~kW}\right.$ at $\left.-5^{\circ} \mathrm{C}\right)$ \\
\hline & & $\dot{Q}_{L T}=222,000 \mathrm{Btu} / \mathrm{h}$ at $-22^{\circ} \mathrm{F}\left(65 \mathrm{~kW}\right.$ at $\left.-30^{\circ} \mathrm{C}\right)$ \\
\hline \multirow{2}{*}{$\begin{array}{l}\text { Baseline } \\
\text { System }\end{array}$} & \multirow{2}{*}{ Condensing Temperature } & $\begin{array}{l}T_{\text {cond }}=70^{\circ} \mathrm{F} \text { for } T_{a m b} \leq 61^{\circ} \mathrm{F} \\
\left(T_{\text {cond }}=21^{\circ} \mathrm{C} \text { for } T_{a m b} \leq 16^{\circ} \mathrm{C}\right)\end{array}$ \\
\hline & & $\begin{array}{l}T_{\text {cond }}=T_{a m b}+9^{\circ} \mathrm{F} \text { for } T_{a m b}>61^{\circ} \mathrm{F} \\
\left(T_{\text {cond }}=T_{a m b}+5^{\circ} \mathrm{C} \text { for } T_{a m b}>16^{\circ} \mathrm{C}\right)\end{array}$ \\
\hline \multirow{3}{*}{$\begin{array}{l}\text { Cascade } \\
\text { Systems }\end{array}$} & \multirow{2}{*}{ Condensing Temperature } & $\begin{array}{l}T_{\text {cond }}=70^{\circ} \mathrm{F} \text { for } T_{a m b} \leq 61^{\circ} \mathrm{F} \\
\left(T_{\text {cond }}=21^{\circ} \mathrm{C} \text { for } T_{a m b} \leq 16^{\circ} \mathrm{C}\right)\end{array}$ \\
\hline & & $\begin{array}{l}T_{\text {cond }}=T_{a m b}+9^{\circ} \mathrm{F} \text { for } T_{a m b}>61^{\circ} \mathrm{F} \\
\left(T_{\text {cond }}=T_{a m b}+5^{\circ} \mathrm{C} \text { for } T_{a m b}>16^{\circ} \mathrm{C}\right)\end{array}$ \\
\hline & $\begin{array}{l}\text { Cascade Condenser } \\
\text { Approach Temperature }\end{array}$ & $T_{a p p}=6^{\circ} \mathrm{F}\left(3.3^{\circ} \mathrm{C}\right)$ \\
\hline \multirow{5}{*}{$\begin{array}{l}\text { Booster } \\
\text { Systems }\end{array}$} & $\begin{array}{l}\text { Intermediate Pressure in } \\
\text { Receiver }\end{array}$ & $P_{\text {int }}=510 \mathrm{psia}(3.5 \mathrm{MPa})$ \\
\hline & \multirow{2}{*}{$\begin{array}{l}\text { Condenser/Gas Cooler } \\
\text { Outlet Temperature }\end{array}$} & $\begin{array}{l}T_{G C}=45^{\circ} \mathrm{F} \text { for } T_{a m b} \leq 40^{\circ} \mathrm{F} \\
\left(T_{G C}=7.2^{\circ} \mathrm{C} \text { for } T_{a m b} \leq 4.2^{\circ} \mathrm{C}\right)\end{array}$ \\
\hline & & $\begin{array}{l}T_{G C}=T_{a m b}+5^{\circ} \mathrm{F} \text { for } T_{a m b}>40^{\circ} \mathrm{F} \\
\left(T_{G C}=T_{a m b}+3^{\circ} \mathrm{C} \text { for } T_{a m b}>4.2^{\circ} \mathrm{C}\right)\end{array}$ \\
\hline & \multirow{2}{*}{$\begin{array}{l}\text { Condenser/Gas Cooler } \\
\text { Pressure for } T_{a m b} \geq 81^{\circ} \mathrm{F} \\
\left(27^{\circ} \mathrm{C}\right)\end{array}$} & $\begin{array}{l}P_{\text {STBS }}=0.114 T_{a m b}^{2}+0.780 T_{a m b}+282\left[\mathrm{psia}, T_{a m b} \text { in }{ }^{\circ} \mathrm{F}\right] \\
\left(P_{S T B S}=2.54 \times 10^{-3} T_{a m b}^{2}+0.100 T_{a m b}+2.92\left[\mathrm{MPa}, T_{a m b} \text { in }{ }^{\circ} \mathrm{C}\right]\right)\end{array}$ \\
\hline & & $\begin{array}{l}P_{T B S-B C}=0.0177 T_{a m b}^{2}+19.2 T_{a m b}+580\left[\mathrm{psia}, T_{a m b} \text { in }{ }^{\circ} \mathrm{F}\right] \\
\left(P_{T B S-B C}=4.00 \times 10^{-4} T_{a m b}^{2}+0.252 T_{a m b}+0.362\left[\mathrm{MPa}, T_{a m b} \text { in }{ }^{\circ} \mathrm{C}\right]\right)\end{array}$ \\
\hline
\end{tabular}




\subsection{RESULTS AND DISCUSSION}

The effects of ambient temperature, evaporator superheat and SLHX effectiveness on the performance of each of the seven refrigeration system configurations were investigated. Altogether, six $\mathrm{CO}_{2}$-based refrigeration system configurations were analyzed and compared, including the Combined System 1, Combined System 2, CSC system (System 4), CSC-G system (System 5), STBS (System 6), and TBS-BC (System 7). In addition, the performance of the six $\mathrm{CO}_{2}$-based refrigeration systems was compared to the baseline R-404A multiplex DX system (System 1).

\subsubsection{Cascade and Secondary Loop Systems}

In general, for the cascade and secondary loop systems, an increase in the ambient temperature leads to an increase in the work required by the high-temperature circuit with no impact on the work required by the low-temperature circuit. This is due to the fact that the high-temperature circuit compressors experience changes in the ambient temperature through the condenser, while the low-temperature circuit compressors and pumps are decoupled from the ambient conditions through the cascade condenser. Thus, the system COP decreases with an increase in the ambient temperature.

\subsubsection{Combined System 1}

The system COP and the work ratio $(W R)$ vs. ambient temperature for a given pump circulation ratio of 1.5 for the Combined System $1\left(\mathrm{CO}_{2}\right.$ Secondary Coolant System for low- and medium-temperature applications) is shown in Fig. 12. The work ratio of the compressors, $W R$, is defined to be the ratio of the compressor power, $\dot{W}$, to the total power required by the system, $\dot{W}+\dot{W}_{\text {pump }}$, as follows:

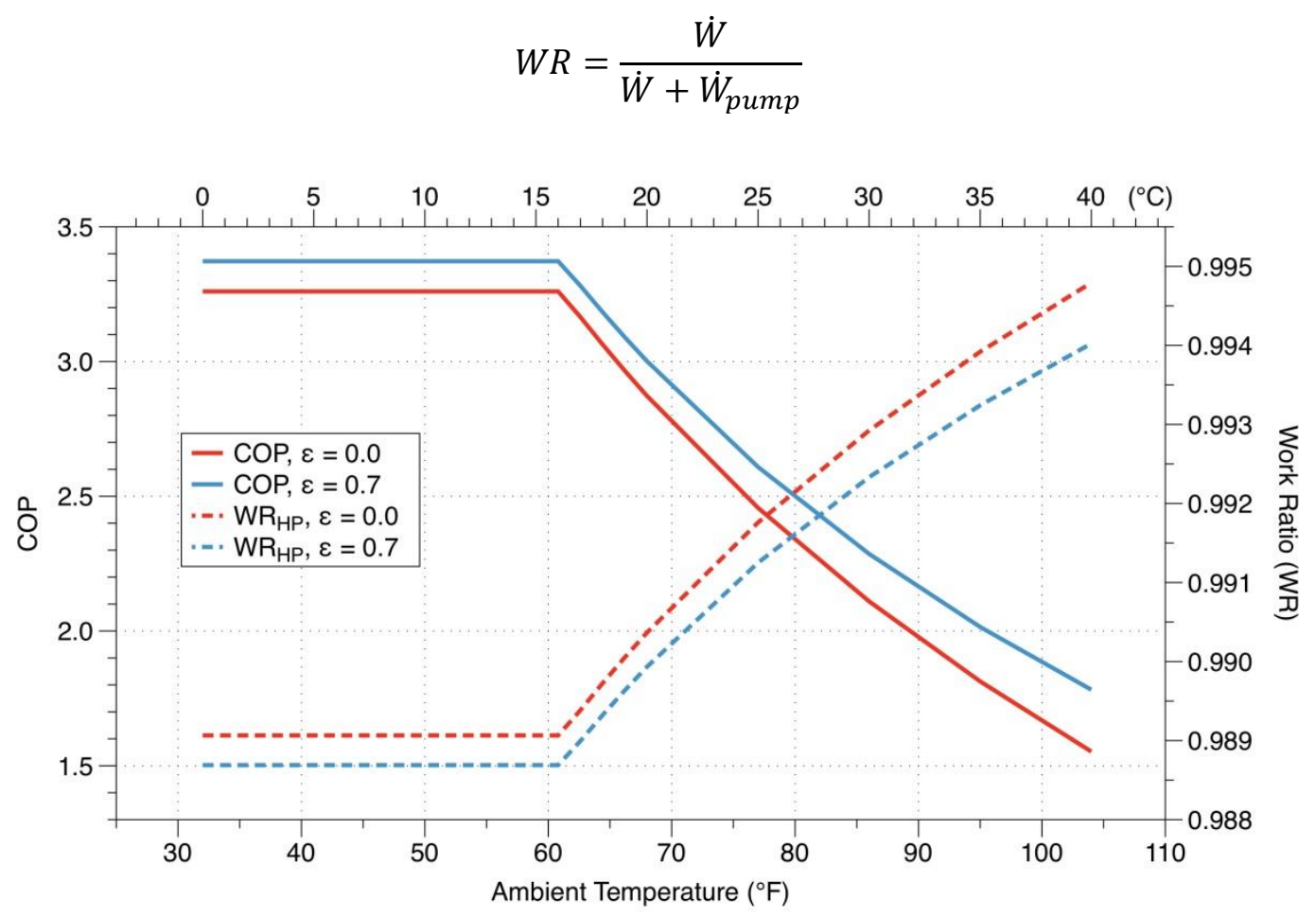

Fig. 12. COP and work ratio vs. ambient temperature with $\mathrm{CR}=1.5$ for Combined System 1 .

Since the SLHX is in the high-temperature circuit, it has no impact on the performance of the lowtemperature circuit. However, with an increase in the effectiveness of the SLHX, the work required by 
the compressors decreases, as illustrated by a decrease in the compressor work ratio shown in Fig. 12, resulting in an increase in the system COP. For example, at an ambient temperature of $68^{\circ} \mathrm{F}\left(20^{\circ} \mathrm{C}\right)$, the system COP increases by $4.5 \%$ with an increase in SLHX effectiveness from 0 to 0.7 .

The work required by the secondary loop refrigerant pump increases with an increase in the circulation ratio. However, the ratio of the work input to the compressors to the total work input to the system is generally greater than $99 \%$, while the pump work is typically less than $1 \%$. Thus, a change in the circulation ratio has an insignificant impact on the system COP.

\subsubsection{Combined System 2}

Similarly, in the Combined System 2 (DEC for low-temperature, SC for medium-temperature), an increase in the effectiveness of all the suction line heat exchangers leads to a decrease in the work required by the low- and the high-pressure compressors, resulting in an increase in the system COP. For example, at an ambient temperature of $68^{\circ} \mathrm{F}\left(20^{\circ} \mathrm{C}\right)$, the system COP increases by $2.2 \%$ with an increase in SLHX effectiveness from 0 to 0.7. The effect of increasing the LT superheat by $9 \mathrm{R}(5 \mathrm{~K})$ from $9 \mathrm{R}$ to $18 \mathrm{R}(5 \mathrm{~K}$ to $10 \mathrm{~K})$ is insignificant, resulting in a decrease in COP of only $0.14 \%$.

\subsubsection{Combined $\mathrm{CO}_{2}$ Secondary/Cascade (CSC)}

For the Combined $\mathrm{CO}_{2}$ Secondary/Cascade System (CSC), Fig. 13 shows the system COP vs. ambient temperature for a $\mathrm{LT}$ evaporator superheat of $9 \mathrm{R}(5 \mathrm{~K})$.

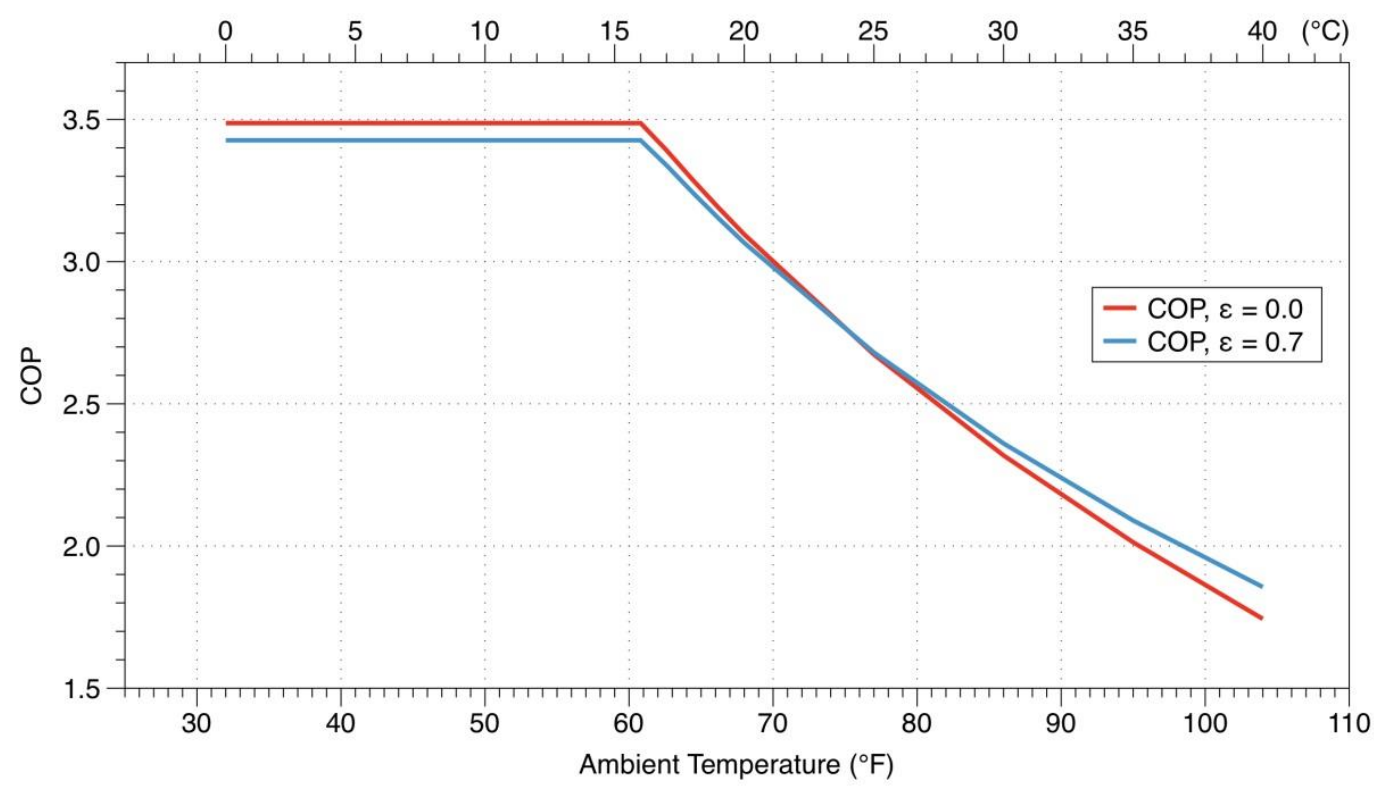

Fig. 13. COP vs. ambient temperature with $\Delta T_{L T}=9 \mathrm{R}(5 \mathrm{~K})$ for the CSC system (System 4).

With an increase in the effectiveness of SLHX1 and SLHX2, the mass flow through the system decreases and the enthalpy at the inlet of compressors increases. In comparison to the rate of increase in enthalpy change across the compressors, the rate of decrease in the refrigerant mass flow rate is greater in the high-temperature circuit than in the low-temperature circuit. This leads to an increase in the work required by the low-pressure compressors and a decrease in the work required by the high-pressure compressors. As the SLHX effectiveness increases at low ambient temperature, the increase in work required by the low-pressure compressors dominates the decrease in that of the high-pressure compressors, thereby, increasing the total work required by the system and decreasing the system COP. 
However, as the SLHX effectiveness increases at high ambient temperatures, the total work required by the system decreases and the COP increases. At an ambient temperature of $41^{\circ} \mathrm{F}\left(5^{\circ} \mathrm{C}\right)$, an increase in effectiveness of the SLHX from 0 to 0.7 leads to the system COP decreasing by about $1.7 \%$. On the other hand, at an ambient temperature of $95^{\circ} \mathrm{F}\left(35^{\circ} \mathrm{C}\right)$, with a change in the effectiveness of the SLHX from 0 to 0.7, the system COP increases by $3.8 \%$. The effect of increasing the LT superheat by $9 \mathrm{R}(5 \mathrm{~K})$ from $9 \mathrm{R}$ to $18 \mathrm{R}(5 \mathrm{~K}$ to $10 \mathrm{~K})$ is insignificant.

\subsubsection{Combined Glycol Secondary/CO $\mathrm{CO}_{2}$ Cascade System (CSC-G)}

As with the CSC System, low-temperature evaporator superheat has a negligible impact on the COP of the CSC-G System. Furthermore, the SLHX in the high-temperature circuit of the system was found to be beneficial to system performance while the SLHX in the low-temperature circuit was found to have a negative effect on performance. With an increase in effectiveness from 0 to 0.7 for the high-temperature circuit SLHX, the COP of the system increased by $2.2 \%$. However, for the low-temperature circuit, an increase in the SLHX effectiveness from 0 to 0.7 resulted in a decrease in system COP by $0.5 \%$.

\subsubsection{Transcritical Booster Systems}

For the Standard Transcritical Booster System (STBS), Fig. 14 shows the system COP, the work ratios $\left(W R_{L P}, W R_{H P}\right)$ and the mass flow ratios $\left(M R_{L T}, M R_{M T}, M R_{B P}\right)$ vs. ambient temperature at constant SLHX effectiveness $\left(\varepsilon_{S L H X}=0.4\right)$. The mass flow ratio, $M R$, of a circuit (low-temperature, mediumtemperature, and bypass) is the ratio of the circuit flow rate to the total system mass flow rate:

$$
M R_{c i r c}=\frac{\dot{m}_{c i r c}}{\dot{m}_{L T}+\dot{m}_{M T}+\dot{m}_{B P}}
$$

where $\dot{m}_{c i r c}, \dot{m}_{L T}, \dot{m}_{M T}$, and $\dot{m}_{B P}$ are the refrigerant mass flow rates of the circuit of interest, the lowtemperature circuit, the medium-temperature circuit and the flash gas bypass, respectively.

As shown in Fig. 14(b), for a given SLHX effectiveness and superheat, an increase in ambient temperature leads to an increase in the bypass mass flow rate and the bypass mass flow ratio $\left(M R_{B P}\right)$. The effect of this can be seen in Fig. 14(a) where the work required by the high-pressure compressor increases and consequently, the system COP decreases.

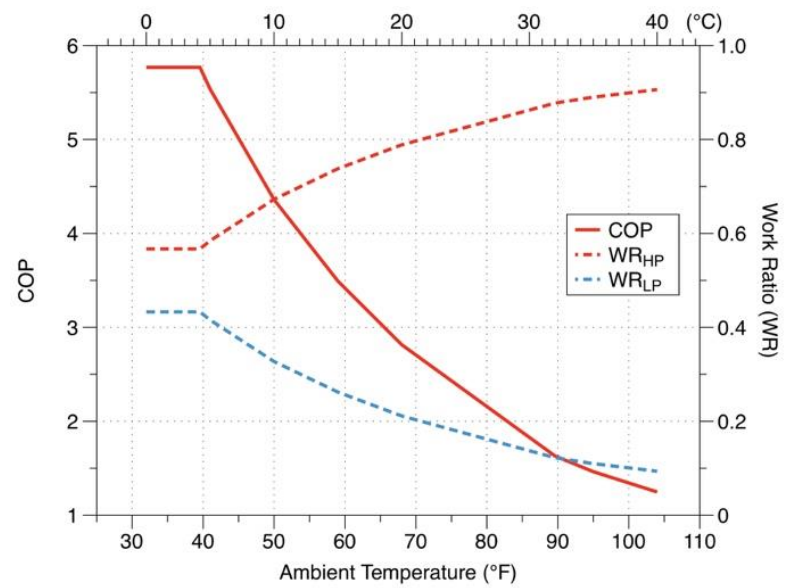

(a)

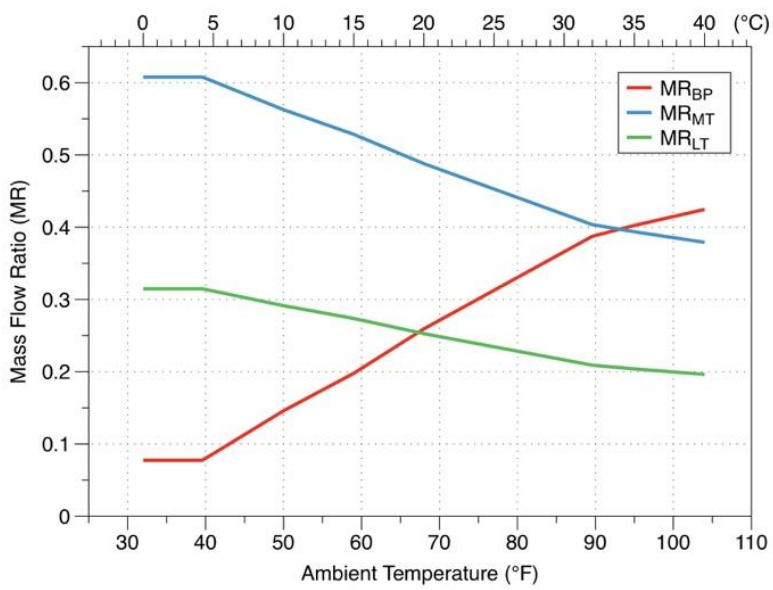

(b)

Fig. 14. Performance of the STBS system (System 6) for $\varepsilon_{\mathrm{SLHX}}=0.4$ and $\Delta T=9 \mathrm{R}$ (5 K). (a) System COP and work ratios, (b) Mass flow ratio. 
An increase in evaporator superheat results in a decrease in the total refrigerant mass flow rate. In general, increasing the evaporator superheat leads to an increase in the refrigerant enthalpy throughout the system between the low-pressure compressor and the gas cooler inlet. However, the increase in enthalpy associated with superheat is nearly counterbalanced by the decrease in the total refrigerant flow rate. As a result, the rate of change of COP with an increase in superheat is insignificant $(<0.75 \%)$. Similarly, for the Transcritical Booster System with Bypass Compressor (TBS-BC), the evaporator superheat has insignificant impact on the system COP.

The mass flow ratio $\left(M R_{L T}, M R_{M T}, M R_{B P}\right)$ vs. ambient temperature for a given $\mathrm{LT}$ and $\mathrm{MT}$ evaporator superheat of $9 \mathrm{R}(5 \mathrm{~K})$ for the STBS (System 6) is shown in Fig. 15. With an increase in the effectiveness of SLHX1 and SLHX2, the quality of refrigerant at the inlet of both the receiver and the low-temperature evaporator decreases, thereby decreasing the bypass mass flow ratio $\left(M R_{B P}\right)$ and the low-temperature mass flow ratio $\left(M R_{L T}\right)$. Since the bypass mass flow rate increases with ambient temperature but decreases with SLHX effectiveness above $66^{\circ} \mathrm{F}\left(19^{\circ} \mathrm{C}\right)$, the first effect is more pronounced than the latter, leading to an increase in $M R_{L T}$.

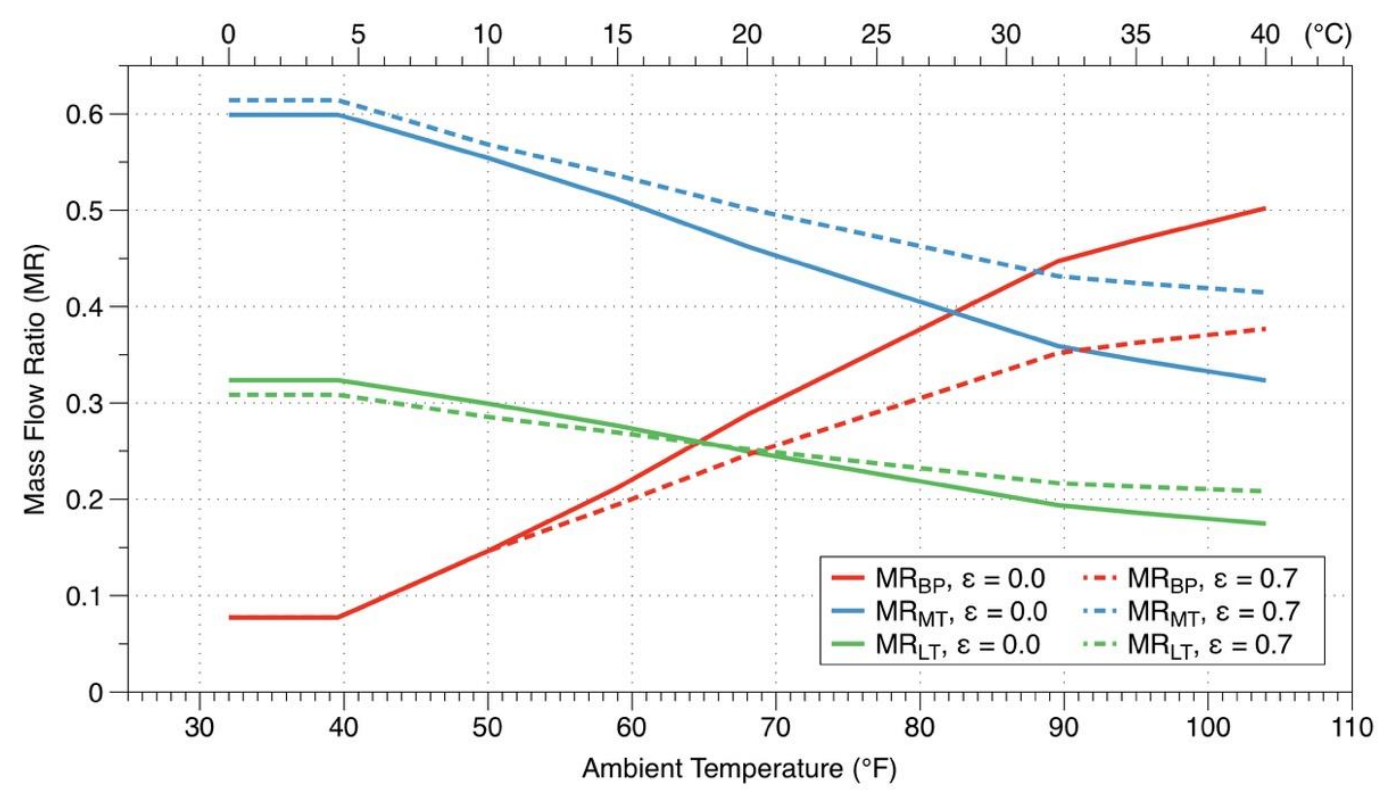

Fig. 15. Mass flow ratio vs. ambient temperature with $\Delta T=9 \mathrm{R}(5 \mathrm{~K})$ for the STBS (System 6).

In addition, for the STBS (System 6), an increase in the SLHX effectiveness increases the enthalpy of the refrigerant at the inlet of the low- and high-pressure compressors. In subcritical operation, the rate of increase in the enthalpy difference across the compressors and the rate of decrease in the mass flow through the low-temperature evaporator and the bypass, leads to changes in the relative work input to the low-pressure and high-pressure compressors. This results in a decrease in the system COP during subcritical operation but an increase during transcritical operation. With a change in effectiveness of SLHX1 (upstream of the receiver) from 0 to 0.7 , the COP was found to decrease by $0.02 \%$ at an ambient temperature of $50^{\circ} \mathrm{F}\left(10^{\circ} \mathrm{C}\right)$ while the COP increased by $2.3 \%$ at an ambient temperature of $95^{\circ} \mathrm{F}\left(35^{\circ} \mathrm{C}\right)$. A increase in effectiveness of SLHX2 (at the low temperature load) leads to a decrease in COP, where the impact of the increase in effectiveness is higher at lower ambient temperatures as compared to higher ambient temperatures. For example, with an increase in effectiveness of SLHX2 from 0 to 0.7 at an ambient temperature of $50^{\circ} \mathrm{F}\left(10^{\circ} \mathrm{C}\right)$, the COP decreased by $1.7 \%$. However, at an ambient temperature of $95^{\circ} \mathrm{F}\left(35^{\circ} \mathrm{C}\right)$, an increase in effectiveness of SLHX2 from 0 to 0.7 decreased the COP by only $0.41 \%$.

In the TBS-BC (System 7), SLHX1 (upstream of receiver) should not operate at lower ambient conditions (less than $57^{\circ} \mathrm{F}$ or $14^{\circ} \mathrm{C}$ ) as the temperature of the hot stream coming from the refrigerated 
display cases is warmer than the refrigerant at the gas cooler outlet. At $T_{a m b}=57^{\circ} \mathrm{F}\left(14^{\circ} \mathrm{C}\right)$, the decrease in COP is negligible $(<0.04 \%)$ with an increase in effectiveness of SLHX1 from 0 to 0.7 . However, at $T_{a m b}=95^{\circ} \mathrm{F}\left(35^{\circ} \mathrm{C}\right)$, the system COP increases by $3.7 \%$ with an increase in effectiveness of SLHX1 from 0 to 0.7 .

Similar to the STBS, an increase in effectiveness of SLHX2 (at the low temperature load) of the TBS$\mathrm{BC}$ leads to a decrease in COP. With change in effectiveness of SLHX2 from 0 to 0.7, the COP decreases by $1.9 \%$ and $1.0 \%$ at $T_{a m b}=50^{\circ} \mathrm{F}\left(10^{\circ} \mathrm{C}\right)$ and $95^{\circ} \mathrm{F}\left(35^{\circ} \mathrm{C}\right)$, respectively.

\subsubsection{Comparison of $\mathrm{CO}_{2}$-based Refrigeration Systems with the Baseline System}

Figure 16 shows the system COP vs. ambient temperature for the two Transcritical Booster Systems and the Combined Cascade/Secondary Loop Systems for a constant SLHX effectiveness $\left(\varepsilon_{S L H X}=0.4\right)$, evaporator superheat $(\Delta T=9 \mathrm{R}=5 \mathrm{~K})$ and pump circulation ratio $(C R=1.5)$. It can be seen that the Transcritical Booster System with Bypass Compressor (TBS-BC) and the Combined Secondary Cascade (CSC) System are the most efficient systems among the transcritical booster and the cascade/secondary loop systems, respectively.

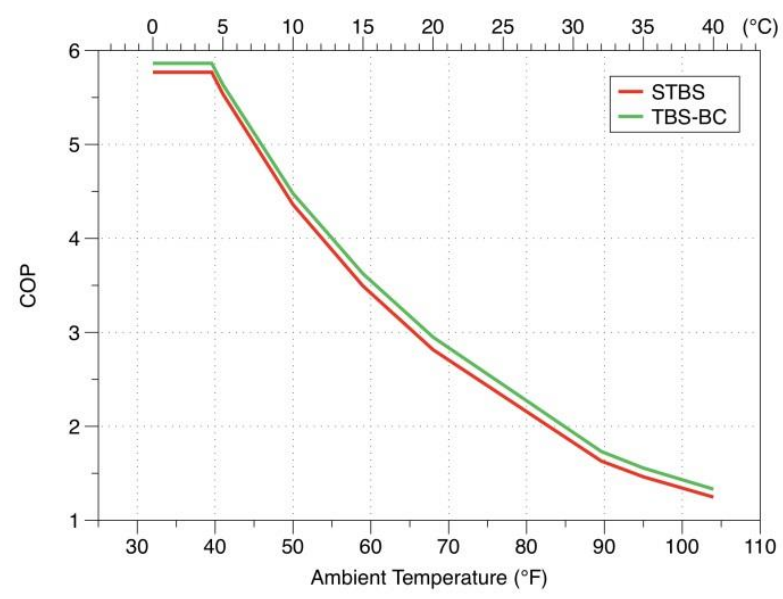

(a)

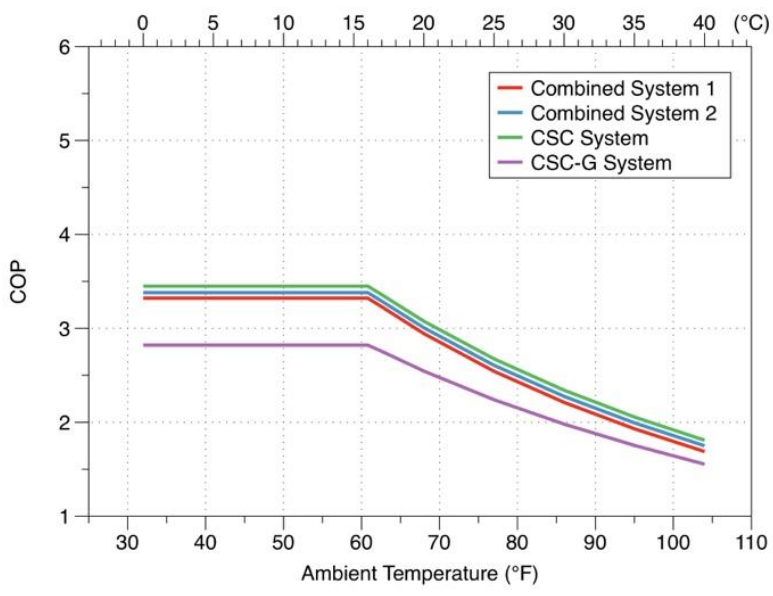

(b)

Fig. 16. System COP vs. ambient temperature at $\varepsilon_{\mathrm{SLHX}}=0.4, \Delta T=9 \mathrm{R}(5 \mathrm{~K})$ and $C R=1.5$. (a) Transcritical booster systems, (b) Cascade/secondary systems.

\subsubsection{Climate Zones}

Bin analyses were performed to determine the annual average COP of the TBS-BC (System 7), the CSC (System 4) and the R-404A multiplex DX system (System 1) in sixteen cities selected from the eight climate zones of the United States (ICC, 2009). Note that the evaporating temperatures for the CSC (System 4) and TBS-BC (System 7) were set at $27^{\circ} \mathrm{F}\left(-3^{\circ} \mathrm{C}\right)$ and $-18^{\circ} \mathrm{F}\left(-28^{\circ} \mathrm{C}\right)$ for the mediumtemperature and low-temperature loads, respectively, to account for the more favorable heat transfer characteristics of $\mathrm{CO}_{2}$ as compared to R-404A. The 16 cities selected for the bin analyses are shown in Table 8, along with their annual average temperature and annual average COP of System 1, System 4 and System 7. The hourly weather data from these sixteen cities were used to determine the annual average $\mathrm{COP}$ for the three refrigeration systems. It can be seen that the transcritical $\mathrm{CO}_{2}$ booster system (TBSBC) performs as well as, or better than, the baseline R-404A multiplex DX system for all eight climate zones in the U.S. In the warm climate zones (Zones 1 and 2), the annual performance of the TBS-BC and multiplex DX systems are nearly identical. In the colder climates (Zones 6,7 and 8), the annual average COP of the TBS-BC is approximately $40 \%$ greater than that of the R-404A multiplex DX system. 
Table 8. U.S. climate zones, cities and annual average $\mathrm{COP}$ for several $\mathrm{CO}_{2}$-based refrigeration systems

\begin{tabular}{clcccc}
\hline $\begin{array}{c}\text { Climate } \\
\text { Zone }\end{array}$ & \multicolumn{1}{c}{ City } & $\begin{array}{c}\text { Annual Average } \\
\text { Temperature, } \\
\left({ }^{\circ} \mathbf{F}\right)\end{array}$ & $\begin{array}{c}\text { Annual } \\
\text { Average } \\
\mathbf{C O P}_{\mathbf{D X}}\end{array}$ & $\begin{array}{c}\text { Annual } \\
\text { Average } \\
\text { COP }_{\text {CSC }}\end{array}$ & $\begin{array}{c}\text { Annual } \\
\text { Average } \\
\text { COP }_{\text {TBS-BC }}\end{array}$ \\
\hline 1 & Miami, FL & $76.8(24.9)$ & 2.62 & 2.75 & 2.64 \\
\hline 2A & Houston, TX & $69.3(20.7)$ & 3.00 & 2.94 & 3.26 \\
2B & Phoenix, AZ & $74.8(23.8)$ & 2.77 & 2.76 & 2.89 \\
\hline 3A & Atlanta, GA & $62.6(17.0)$ & 3.30 & 3.10 & 3.82 \\
3B & Los Angeles, CA & $63.1(17.3)$ & 3.61 & 3.28 & 3.64 \\
3B & Las Vegas, NV & $68.4(20.2)$ & 3.07 & 2.94 & 3.48 \\
3C & San Francisco, CA & $57.9(14.4)$ & 4.00 & 3.38 & 4.17 \\
\hline 4A & Baltimore, MD & $55.9(13.3)$ & 3.47 & 3.20 & 4.33 \\
4B & Albuquerque, NM & $57.6(14.2)$ & 3.45 & 3.19 & 4.32 \\
4C & Seattle, WA & $52.5(11.4)$ & 3.89 & 3.38 & 4.73 \\
\hline 5A & Chicago, IL & $50.0(10.0)$ & 3.54 & 3.25 & 4.70 \\
5B & Boulder, CO & $50.5(10.3)$ & 3.61 & 3.27 & 4.74 \\
\hline 6A & Minneapolis, MN & $46.4(8.0)$ & 3.57 & 3.27 & 4.91 \\
6B & Helena, MN & $45.0(7.2)$ & 3.71 & 3.34 & 5.13 \\
\hline 7 & Duluth, MN & $39.7(4.3)$ & 3.76 & 3.38 & 5.30 \\
\hline 8 & Fairbanks, AK & $28.2(-2.1)$ & 3.81 & 3.41 & 5.56 \\
\hline
\end{tabular}

\subsection{SUMMARY}

The comparative analysis of the $\mathrm{CO}_{2}$-based refrigeration systems with the baseline R-404A system was performed. For the transcritical booster systems (STBS and TBS-BC), the system COP decreases with an increase in ambient temperature, while the SLHX effectiveness and the evaporator superheat have minimal impact on system performance. The secondary loop pump circulation ratio and the evaporator superheat have negligible impact on the performance of the combined cascade/secondary loop systems (Combined Systems 1 and 2, CSC and CSC-G). An increase in SLHX effectiveness leads to an increase in the performance of the Combined Systems 1 and 2. For the CSC-G, the SLHX in the high-temperature circuit of the system was found to be beneficial to system performance while the SLHX in the lowtemperature circuit was found to have a negative effect on performance. Also, an increase in the SLHX effectiveness in the CSC system leads to an increase in the system performance for $T_{a m b}<75^{\circ} \mathrm{F}\left(24^{\circ} \mathrm{C}\right)$ but a decrease in performance for $T_{a m b}>75^{\circ} \mathrm{F}\left(24^{\circ} \mathrm{C}\right)$. The TBS-BC and the CSC systems are the most efficient systems among the transcritical booster and cascade/secondary loop systems, respectively. Based on a bin analysis, it was found that the TBS-BC performed as well or better than the R-404A multiplex DX system in all eight climate zones of the US. Implementation of transcritical booster systems or cascade/secondary loop systems using optimized operating conditions will lead to reduced direct greenhouse gas emissions while achieving comparable energy consumption as compared to current HFCbased multiplex DX systems. 


\section{LABORATORY-SCALE HIGH-EFFICIENCY, LOW-EMISSION REFRIGERATION SYSTEM}

Based on the energy and life cycle climate performance (LCCP) analyses discussed in Chapters 2 and 3 , it was determined that a transcritical $\mathrm{CO}_{2}$ booster refrigeration system for supermarket applications would meet the requirements of reduced carbon emissions and increased energy efficiency. To that end, the research team designed and fabricated a laboratory-scale transcritical $\mathrm{CO}_{2}$ booster refrigeration system for further evaluation.

The high-efficiency, low-emission commercial refrigeration system installed in the large environmental test chambers at the Oak Ridge National Laboratory (ORNL) consisted of a transcritical $\mathrm{CO}_{2}$ compressor rack, an air-cooled gas cooler/condenser, medium-temperature (MT) and lowtemperature (LT) refrigerated display cases, and MT and LT "false" loads.

A piping diagram for the transcritical $\mathrm{CO}_{2}$ compressor rack and gas cooler is shown in Fig. 17. The liquid line at the exit of the flash tank supplies liquid $\mathrm{CO}_{2}$ to the MT and LT display cases and false loads. The superheated $\mathrm{CO}_{2}$ from the exit of the LT display case and false load returns to the compressor rack at the LT suction header, which feeds the LT compressors. The superheated $\mathrm{CO}_{2}$ from the MT display case and false load returns to the compressor rack at the MT suction header and mixes with the LT compressor discharge and the flash gas from the flash tank. This vapor is then compressed in the MT compressors and the discharge is cooled via the air-cooled gas cooler/condenser.

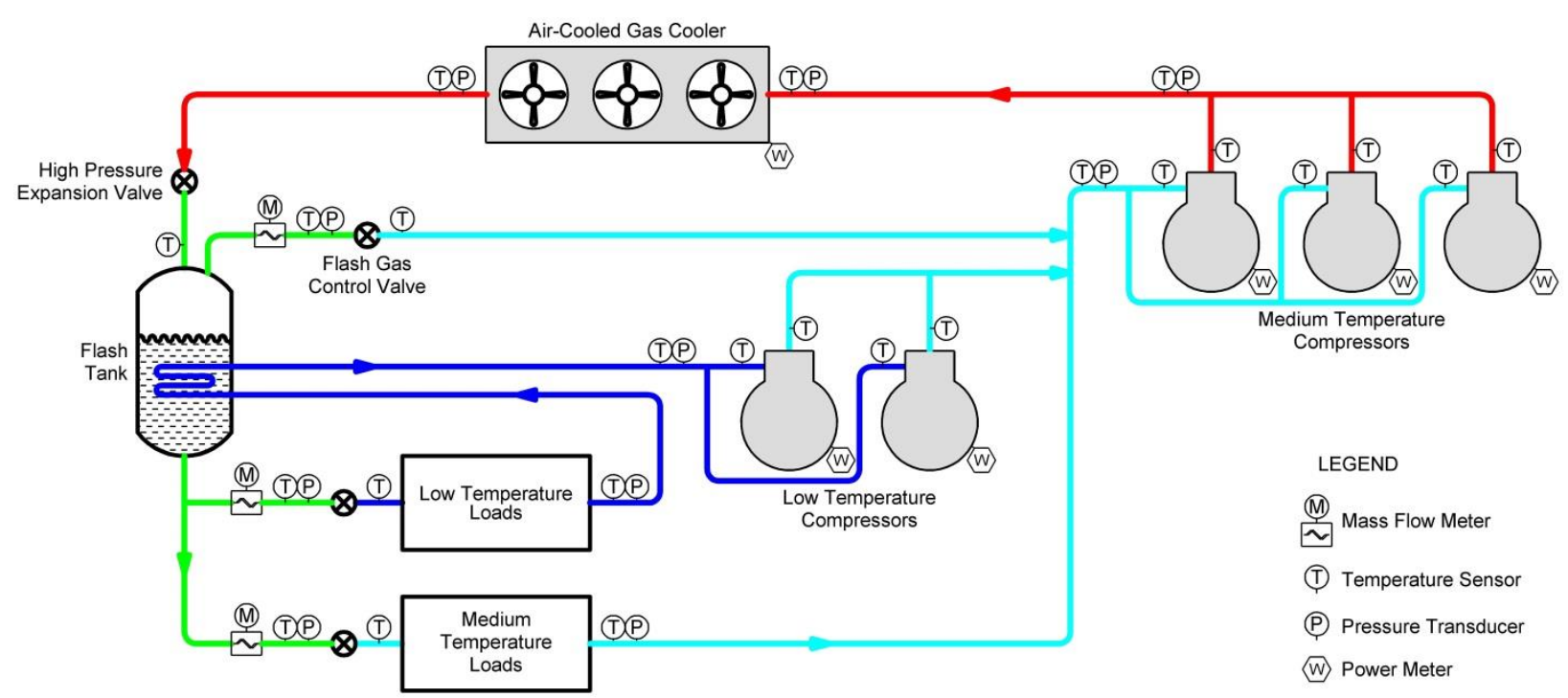

Fig. 17. Schematic of the laboratory-scale transcritical $\mathrm{CO}_{2}$ booster refrigeration system.

The laboratory-scale refrigeration system has a low-temperature cooling capacity of approximately 2.5 tons at a saturated evaporating temperature of $-22^{\circ} \mathrm{F}\left(9.1 \mathrm{~kW}\right.$ at $\left.-30^{\circ} \mathrm{C}\right)$ and a medium-temperature cooling capacity of approximately 9.6 tons at a saturated evaporating temperature of $20^{\circ} \mathrm{F}(34 \mathrm{~kW}$ at $\left.-6.7^{\circ} \mathrm{C}\right)$. One 4-door vertical display case, $10 \mathrm{ft}(3.0 \mathrm{~m})$ in length, as well as a "false" load provided by a plate heat exchanger and a glycol loop, constitutes the low-temperature load. The medium-temperature load consists of one open vertical display case, $8 \mathrm{ft}(2.4 \mathrm{~m})$ in length, as well as a "false" load provided by a plate heat exchanger and glycol loop.

The air-cooled gas cooler/condenser is installed in a temperature and humidity controlled "outdoor" environmental chamber while the compressor rack and refrigerated display cases are installed in a separate temperature and humidity controlled "indoor" environmental chamber. For both chambers, the temperature can be controlled between 0 to $150^{\circ} \mathrm{F}\left(-18\right.$ to $\left.66^{\circ} \mathrm{C}\right)$ and the humidity can be controlled 
between 30 to $90 \%$. Thus, the air-cooled condenser can be exposed to typical outdoor ambient conditions while the refrigerated display cases operate in an environment typical of that found in the sales area of a supermarket.

\subsection{COMPRESSOR RACK}

The compressor rack consists of several refrigerant compressors and the associated piping and valving which forms the liquid headers and low-temperature and medium-temperature suction headers as well as the discharge header. The refrigeration loads (i.e., the refrigerated display cases) are connected to the liquid and suction headers of the compressor rack and the gas cooler/condenser is connected to the discharge header of the compressor rack.

The compressor rack contains two low-temperature reciprocating compressors and three mediumtemperature reciprocating compressors. The low-temperature compressors operate sub-critically, while the medium-temperature compressors can operate either sub-critically or super-critically, depending upon the ambient conditions. In addition, for each temperature level (i.e., LT or MT), the compressor rack contains a primary compressor that is variable capacity (via a variable frequency drive), and one or two secondary compressors that are fixed capacity. The primary compressor is used first to satisfy the refrigeration load, and it can modulate its capacity to match the applied load. If the primary compressor is not sufficient to satisfy the load, then the secondary compressor(s) operate as well, with the primary compressor modulating its capacity to match the load.

The manufacturer's model, evaporator capacity and power requirements for the reciprocating $\mathrm{CO}_{2}$ compressors are given in Table 9.

Table 9. Compressor specifications

\begin{tabular}{cccccr}
\hline $\begin{array}{c}\text { Compressor } \\
\text { Type }\end{array}$ & $\begin{array}{c}\text { Temperature } \\
\text { Level }\end{array}$ & Model & $\begin{array}{c}\text { Capacity } \\
\text { Control }\end{array}$ & $\begin{array}{c}\text { Evaporator } \\
\text { Capacity*, Btu/h (W) }\end{array}$ & $\begin{array}{c}\text { Power*, } \\
\text { W }\end{array}$ \\
\hline Reciprocating & LT & 2KSL-1K & Variable & $19,000(5,570)$ & 1,340 \\
Reciprocating & LT & 2MSL-07K & Fixed & $12,000(3,520)$ & 820 \\
Reciprocating & MT & 4MTC-10K & Variable & $38,000(11,100)$ & 9,660 \\
Reciprocating & MT & 4MTC-10K & Fixed & $39,000(11,400)$ & 9,720 \\
Reciprocating & MT & 4MTC-7K & Fixed & $38,500(11,300)$ & 9,400 \\
\hline
\end{tabular}

*Evaporator capacity and power are given for the following operating conditions using $\mathrm{R}-744\left(\mathrm{CO}_{2}\right)$ :

LT: $-22^{\circ} \mathrm{F}\left(-30^{\circ} \mathrm{C}\right)$ evaporating temperature, $20^{\circ} \mathrm{F}\left(-6.7^{\circ} \mathrm{C}\right)$ condensing temperature

MT: $20^{\circ} \mathrm{F}\left(-6.7^{\circ} \mathrm{C}\right)$ evaporating temperature, $100^{\circ} \mathrm{F}\left(38^{\circ} \mathrm{C}\right)$ gas cooling temperature

The total refrigerating capacity of the compressor rack is given in Table 10.

Table 10. Compressor rack capacity

\begin{tabular}{cc}
\hline Temperature Level & Compressor Rack Capacity, Btu/h (W) \\
\hline LT & $31,000(9,090)$ \\
MT & $116,000(34,000)$ \\
\hline
\end{tabular}

\subsection{REFRIGERATED DISPLAY CASES AND FALSE LOADS}

The low-temperature display case is a 4-door model with a length of $10 \mathrm{ft}(3.0 \mathrm{~m})$, and a rated capacity of $5,700 \mathrm{Btu} / \mathrm{h}(1.67 \mathrm{~kW})$. The medium-temperature display case is an open, vertical multi-deck model, $8 \mathrm{ft}(2.4 \mathrm{~m})$ in length, with a rated capacity of 9,600 Btu/h $(2.81 \mathrm{~kW})$. The rated capacities of the display cases are determined by the manufacturer at the standard rating conditions of $75^{\circ} \mathrm{F}, 55 \% \mathrm{RH}$, according to ASHRAE Standard 72 (2005). 
Each display case contains one evaporator and one electronic expansion valve (EEV). Furthermore, each display case is controlled by its own case controller (EEV, temperature set-point, defrost, etc.). The LT and MT display cases utilize LED lighting and electronically commutated (EC) evaporator fan motors. In addition, the LT display case contains anti-sweat heaters to prevent condensation from forming around the exterior surfaces of the case. Finally, the LT display case utilizes electric defrost heaters while the MT display case utilizes off-cycle defrost. The specifications for the low-temperature and medium-temperature display cases are shown in Table 11.

Table 11. Refrigerated display case specifications

\begin{tabular}{lcc}
\hline Case Parameter & $\begin{array}{c}\text { Low-Temperature Display } \\
\text { Case }\end{array}$ & $\begin{array}{c}\text { Medium-Temperature } \\
\text { Display Case }\end{array}$ \\
\hline Model Number & 6RZLH & O5DM-NRG \\
Type & 4-door, vertical multi-deck & Open, vertical multi-deck \\
Length & $10 \mathrm{ft}(3.0 \mathrm{~m})$ & $8 \mathrm{ft}(2.4 \mathrm{~m})$ \\
Rated Capacity & $5,700 \mathrm{Btu} / \mathrm{h}(1,670 \mathrm{~W})$ & $9,600 \mathrm{Btu} / \mathrm{h}(2,810 \mathrm{~W})$ \\
Fan Amperage & $0.93 \mathrm{amps}$ & $0.75 \mathrm{amps}$ \\
Lighting Amperage & $0.90 \mathrm{amps}$ & $0.40 \mathrm{amps}$ \\
Anti-Sweat Heater Amperage & $7.99 \mathrm{amps}$ & -- \\
Defrost Type & Electric & Off-cycle \\
Defrost Amperage & $16.29 \mathrm{amps}$ & -- \\
\hline
\end{tabular}

In addition to the refrigerated display cases, low-temperature and medium-temperature "false" loads are also incorporated into the refrigeration system. The false loads consist of plate heat exchangers with a refrigerant circuit on one side of the heat exchanger and a glycol circuit on the other side. The LT false load can provide an additional load of up to approximately $22,000 \mathrm{Btu} / \mathrm{h}(6.4 \mathrm{~kW})$ to the low -temperature side of the refrigeration system, while the MT false load can provide an additional load of up to approximately $92,000 \mathrm{Btu} / \mathrm{h}(27.0 \mathrm{~kW})$ to the medium-temperature side of the refrigeration system.

\subsection{AIR-COOLED GAS COOLER/CONDENSER}

As shown in the system schematic in Fig. 17, an air-cooled gas cooler/condenser is used to reject heat from the refrigeration system. The gas cooler/condenser accepts the discharge refrigerant vapor from the compressor rack, cools or condenses the refrigerant, and discharges the cooled refrigerant into a flash tank. The air-cooled gas cooler/condenser, Luvata model LGV8812, has two variable speed fans and its rated heat rejection capacity, with R-744, is $268,000 \mathrm{Btu} / \mathrm{h}(78.5 \mathrm{~kW})$ at an entering gas temperature of $242^{\circ} \mathrm{F}\left(117^{\circ} \mathrm{C}\right)$ and a leaving gas temperature of $97.5^{\circ} \mathrm{F}\left(36.4^{\circ} \mathrm{C}\right)$.

\subsection{REFRIGERATION SYSTEM CONROLS}

The refrigeration system is controlled with a Danfoss AK-SC 355 system controller. This controller provides the following control for the system:

- Compressor control to maintain suction pressure setpoints for the LT and MT circuits

- High pressure expansion valve control to maintain optimum high-side pressure

- Condenser fan speed control to maintain condensing pressure

In addition to the system controller, each display case has an individual case controller (Danfoss AKCC 550A). These case controllers communicate with the system controller and regulate expansion valve opening, display case air temperature, defrost operation, and lighting and fan operation. Also, since the 
false loads utilize electronic expansion valves, electronic controllers are required for the two false loads (Carel EVO evolution).

\subsection{INSTRUMENTATION}

The laboratory-scale commercial refrigeration system was fully instrumented to monitor its performance. Refrigerant temperature and pressure were measured at the inlet and outlet of each major system component (gas cooler/condenser, display cases and false loads, compressors), and refrigerant flow rate to each load was measured. Power consumption of the compressor, gas cooler fans and display case fans/lighting and defrost heater were also measured. In addition, display case discharge and return air temperatures were measured. Specific measurement points for the compressor rack are indicated on the schematic shown in Fig. 17, while a detailed list of the measurement points in the commercial refrigeration system is provided in Appendix A.

The specifications of the instrumentation used in the laboratory-scale commercial refrigeration system are given in Table 12.

Table 12. Specifications of instrumentation

\begin{tabular}{|c|c|c|c|}
\hline Instrument & Measurement & Measurement Range & Accuracy \\
\hline Watt transducer & $\begin{array}{l}\text { Compressor power, } \\
\text { gas cooler fan power }\end{array}$ & $\begin{array}{c}0 \text { to } 4,000 \mathrm{~W} \\
0 \text { to } 8,000 \mathrm{~W} \\
0 \text { to } 80,000 \mathrm{~W}\end{array}$ & $\pm 0.5 \%$ of reading \\
\hline Type-T thermocouple & $\begin{array}{l}\text { Refrigerant } \\
\text { temperature, display } \\
\text { case discharge and } \\
\text { return air temperature }\end{array}$ & $\begin{array}{c}-454 \text { to } 752^{\circ} \mathrm{F} \\
\left(-270 \text { to } 400^{\circ} \mathrm{C}\right)\end{array}$ & $\begin{array}{l}\text { Greater of } 1.8^{\circ} \mathrm{F} \text { or } 0.75 \% \text { for } \\
32 \text { to } 662^{\circ} \mathrm{F} \\
\left(\text { Greater of } 1.0^{\circ} \mathrm{C} \text { or } 0.75 \%\right. \\
\text { for } 0 \text { to } 350^{\circ} \mathrm{C} \text { ) } \\
\end{array}$ \\
\hline $\begin{array}{l}\text { Temperature/humidity } \\
\text { sensor }\end{array}$ & $\begin{array}{l}\text { "Indoor" and } \\
\text { "outdoor" chamber } \\
\text { temperature and } \\
\text { humidity }\end{array}$ & $\begin{array}{l}\text { Humidity: } 0 \text { to } 100 \% \mathrm{RH} \\
\text { Temperature: }-40 \text { to } 176^{\circ} \mathrm{F} \\
\left(-40 \text { to } 80^{\circ} \mathrm{C}\right)\end{array}$ & $\begin{array}{c} \pm 1.7 \% \mathrm{RH} \text { for } 0 \text { to } 90 \% \mathrm{RH} \\
\pm 0.36^{\circ} \mathrm{F} \text { for } 59 \text { to } 77^{\circ} \mathrm{F} \\
\left( \pm 0.2^{\circ} \mathrm{C} \text { for } 15 \text { to } 25^{\circ} \mathrm{C}\right)\end{array}$ \\
\hline Pressure transducer & Refrigerant pressure & $\begin{array}{l}0 \text { to } 1000 \mathrm{psig} \\
(0 \text { to } 7 \mathrm{MPa}) \\
0 \text { to } 2000 \mathrm{psig} \\
(0 \text { to } 14 \mathrm{MPa})\end{array}$ & $\pm 0.25 \%$ full scale \\
\hline $\begin{array}{l}\text { Coriolis mass flow } \\
\text { meter }\end{array}$ & Refrigerant mass flow & $\begin{array}{l}0 \text { to } 22 \mathrm{lb} / \mathrm{min} \\
\text { (0 to } 10 \mathrm{~kg} / \mathrm{min} \text { ) }\end{array}$ & $\pm 0.05 \%$ \\
\hline $\begin{array}{l}\text { Positive displacement } \\
\text { flow meter }\end{array}$ & $\begin{array}{l}\text { Refrigerant mass } \\
\text { flow, glycol mass } \\
\text { flow }\end{array}$ & $\begin{array}{c}0.03 \text { to } 7.0 \mathrm{GPM} \\
(0.11 \text { to } 26.4 \mathrm{~L} / \mathrm{min})\end{array}$ & $\pm 0.5 \%$ of reading \\
\hline
\end{tabular}




\section{EVALUATION OF HIGH EFFICIENCY, LOW EMISSION REFRIGERATION SYSTEM}

The performance of the transcritical $\mathrm{CO}_{2}$ booster refrigeration system was determined at four ambient temperature conditions, nominally $60^{\circ} \mathrm{F}\left(16^{\circ} \mathrm{C}\right), 70^{\circ} \mathrm{F}\left(21^{\circ} \mathrm{C}\right), 80^{\circ} \mathrm{F}\left(27^{\circ} \mathrm{C}\right)$ and $90^{\circ} \mathrm{F}\left(32^{\circ} \mathrm{C}\right)$. After the refrigeration system achieved steady-state operation at each of the four ambient temperature conditions, system performance data was collected for a 24-hour period, with a sampling rate of 1 second.

Subsequently, 30-second averaged data was used for the calculation of thermodynamic properties and performance metrics.

The collected performance data was analyzed to determine the following average performance parameters for the 24-hour hour test periods:

- Average LT Suction Header Pressure (psig)

- Average LT Suction Header Temperature $\left({ }^{\circ} \mathrm{F}\right)$

- Average LT Suction Header Superheat $\left({ }^{\circ} \mathrm{F}\right)$

- Average MT Suction Header Pressure (psig)

- Average MT Suction Header Temperature $\left({ }^{\circ} \mathrm{F}\right)$

- Average MT Suction Header Superheat $\left({ }^{\circ} \mathrm{F}\right)$

- Average LT Load Superheat $\left({ }^{\circ} \mathrm{F}\right)$

- Average MT Load Superheat $\left({ }^{\circ} \mathrm{F}\right)$

- Average LT Load (Btu/h)

- Average MT Load (Btu/h)

- Average Compressor Power (W)

- Average COP

- Average LT Refrigerant Mass Flow (lb/min)

- Average MT Refrigerant Mass Flow (lb/min)

- Average Gas Cooler Inlet Temperature $\left({ }^{\circ} \mathrm{F}\right)$

- Average Gas Cooler Outlet Temperature $\left({ }^{\circ} \mathrm{F}\right)$

- Average Gas Cooler Inlet Air Temperature $\left({ }^{\circ} \mathrm{F}\right)$

- Average Gas Cooler Outlet Air Temperature $\left({ }^{\circ} \mathrm{F}\right)$

- Average Heat Rejection (Btu/h)

A summary of the performance of the transcritical $\mathrm{CO}_{2}$ booster refrigeration system is presented in the following sections.

\subsection{LABORATORY PERFORMANCE DATA}

The average medium-temperature and low-temperature refrigeration loads for the transcritical $\mathrm{CO}_{2}$ refrigeration system, as a function of outdoor ambient temperature, are shown in Fig. 18. Each refrigeration load data point shown in Fig. 18 represents the sum of the either the LT or MT display case load and the false load. For each display case and false load, the refrigeration load was determined from the inlet and outlet enthalpies and refrigerant mass flow rate through the load as follows:

$$
\dot{Q}_{i}=\dot{m}_{i}\left(h_{i, o u t}-h_{i, i n}\right)
$$

where $\dot{Q}_{i}$ is the average refrigeration load of load $i, \dot{m}_{i}$ is the average refrigerant mass flow rate through load $i, h_{i, \text { out }}$ is the average enthalpy of the refrigerant exiting load $i$, and $h_{i, i n}$ is the average enthalpy of the refrigerant entering load $i$. The enthalpies of the refrigerant were determined from the NIST Reference Fluid Thermodynamic and Transport Properties Database (REFPROP) Version 9.1 (Lemmon, McLinden, and Huber 2013), using the measured refrigerant pressures and temperatures at the corresponding locations. Note that for the refrigerated display cases, the average values of the thermodynamic properties and refrigerant mass flow exclude those periods during which the display cases 
were undergoing defrost. Also, the experimental uncertainty associated with the calculated refrigeration load was estimated to be $\pm 1.1 \%$ of the calculated value.

It can be seen that the MT and LT refrigeration loads remain fairly constant over the outdoor temperature range from $60^{\circ} \mathrm{F}$ to $90^{\circ} \mathrm{F}\left(16^{\circ} \mathrm{C}\right.$ to $\left.32^{\circ} \mathrm{C}\right)$. This is not unexpected, since the "indoor" conditions surrounding the display cases were fixed at $75^{\circ} \mathrm{F}\left(24^{\circ} \mathrm{F}\right)$ and $55 \% \mathrm{RH}$, and thus, the load on the display cases did not vary. On average, the total LT load was approximately $26,000 \mathrm{Btu} / \mathrm{h}(7.6 \mathrm{~kW})$ while the total MT load was approximately $62,000 \mathrm{Btu} / \mathrm{h}(18 \mathrm{~kW})$.

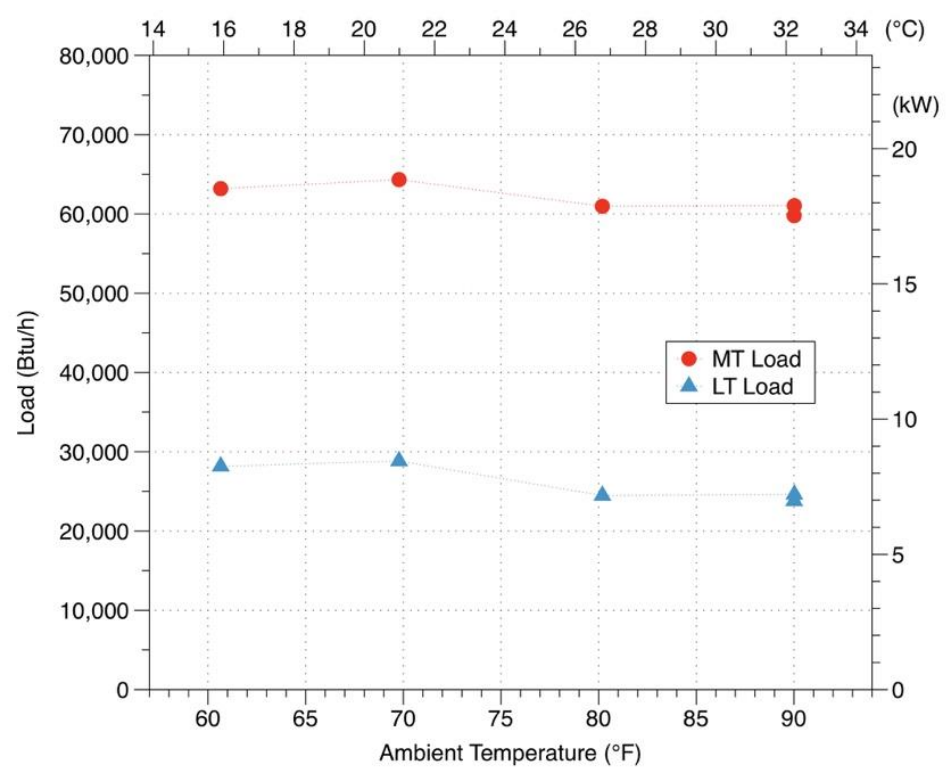

Fig. 18. Average medium-temperature (MT) and low-temperature (LT) refrigeration loads for the transcritical $\mathrm{CO}_{2}$ refrigeration system.

The average total compressor power for the transcritical $\mathrm{CO}_{2}$ refrigeration system, as a function of outdoor ambient temperature, is shown in Fig. 19. The total compressor power is the sum of the power supplied to the MT and LT compressors, as measured by the individual power transducers on each compressor, and this performance data corresponds to the combination of LT and MT display cases and false loads shown in Fig. 18. It can be seen that as the outdoor ambient temperature increases, the total compressor power increases. Over the outdoor ambient temperature range from $60^{\circ} \mathrm{F}$ to $90^{\circ} \mathrm{F}\left(16^{\circ} \mathrm{C}\right.$ to $32^{\circ} \mathrm{C}$ ), the total compressor power increased from approximately $6,500 \mathrm{~W}$ to $11,500 \mathrm{~W}$, representing an increase of approximately $76 \%$. 


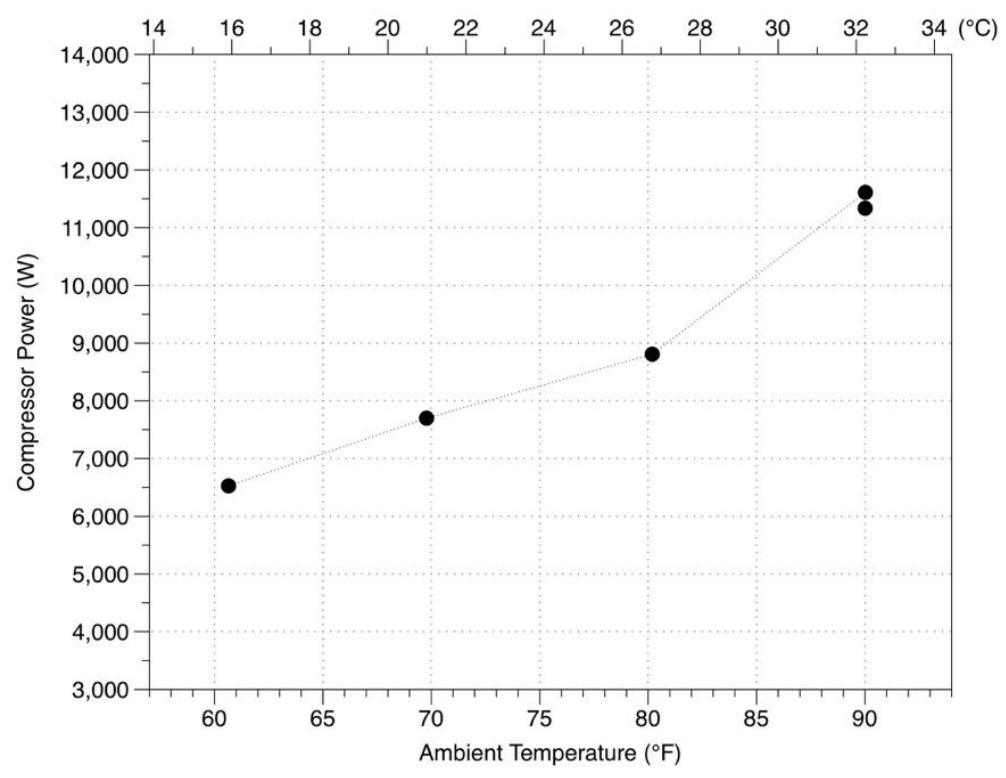

Fig. 19. Average total compressor power for the transcritical $\mathrm{CO}_{2}$ refrigeration system.

Combining the refrigeration loads and compressor power, the coefficient of performance (COP) of the transcritical $\mathrm{CO}_{2}$ booster refrigeration system can be calculated as a function of outdoor ambient temperature, according to Eqn. (4). As shown in Fig. 20, the COP, or efficiency, of the system is greatest at lower outdoor ambient temperatures, and the COP was found to vary from 4.1 to 2.1 over the outdoor ambient temperature range from $60^{\circ} \mathrm{F}$ to $90^{\circ} \mathrm{F}\left(16^{\circ} \mathrm{C}\right.$ to $\left.32^{\circ} \mathrm{C}\right)$. The experimental uncertainty associated with the calculated COP was estimated to be $\pm 5.0 \%$ of the calculated value.

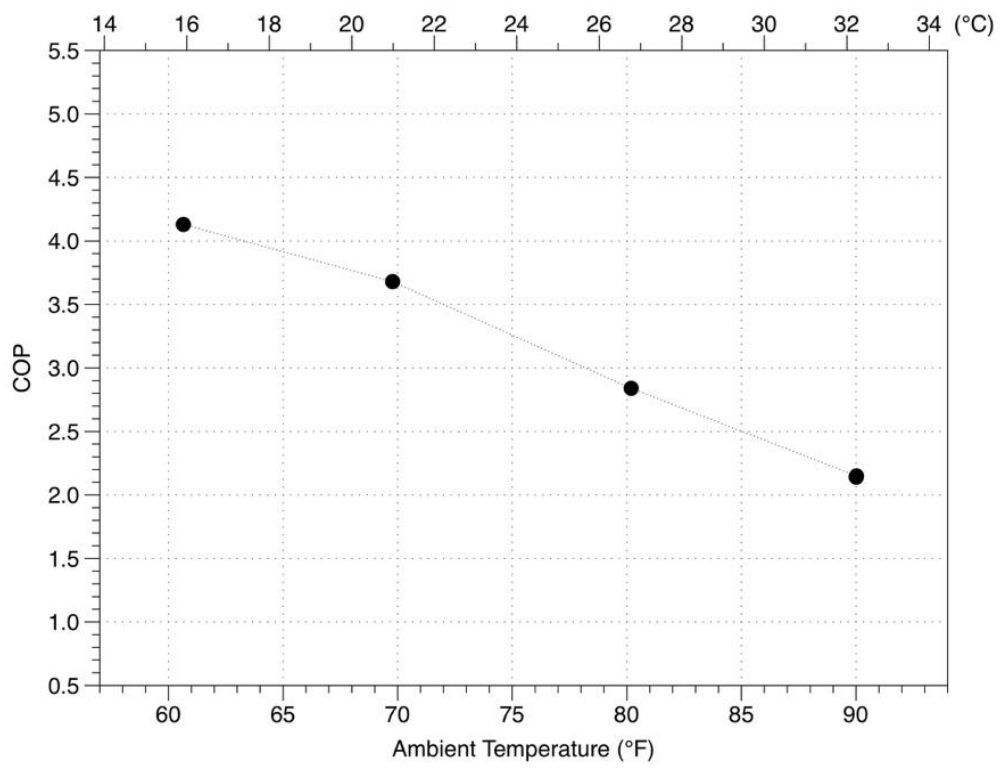

Fig. 20. Coefficient of performance (COP) for the transcritical $\mathrm{CO}_{2}$ refrigeration system.

The refrigeration system controller maintains the gas cooler pressure at a value which optimizes the $\mathrm{COP}$ of the system for a given outdoor ambient temperature. The variation in gas cooler pressure versus ambient temperature is shown in Fig. 21 . At an ambient temperature of $90^{\circ} \mathrm{F}\left(32^{\circ} \mathrm{C}\right)$, the gas cooler pressure is approximately $1300 \mathrm{psig}(9.1 \mathrm{MPa})$, while at an ambient temperature of $60^{\circ} \mathrm{F}\left(16^{\circ} \mathrm{C}\right)$, the gas 
cooler pressure is $860 \mathrm{psig}(6.0 \mathrm{MPa})$. Contrast these high operating pressures with that of a typical HFC multiplex DX system using R-404A, which would have a condensing pressure of approximately $250 \mathrm{psig}$ $(1.8 \mathrm{MPa})$ at an ambient temperature of $90^{\circ} \mathrm{F}\left(32^{\circ} \mathrm{C}\right)$.

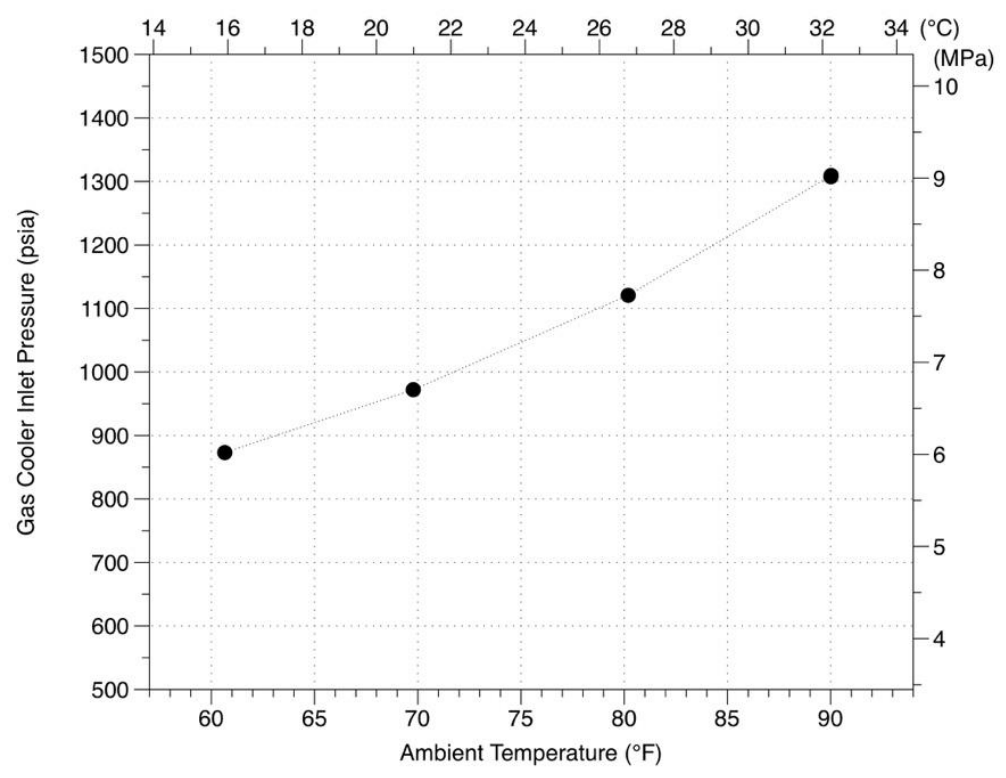

Fig. 21. Gas cooler inlet pressure for the transcritical $\mathrm{CO}_{2}$ refrigeration system.

The refrigerant temperatures at the discharge of the MT compressors, as well as at the inlet and outlet of the gas cooler are shown in Fig. 22 as a function of outdoor ambient temperature. As expected, these temperatures increase as the outdoor ambient temperature increases. The gas cooler inlet temperature was found to range from 160 to $210^{\circ} \mathrm{F}\left(71\right.$ to $\left.99^{\circ} \mathrm{C}\right)$, while the gas cooler outlet temperature ranged from 66 to $94^{\circ} \mathrm{F}\left(19\right.$ to $\left.34^{\circ} \mathrm{C}\right)$, over the ambient temperature range of $60^{\circ} \mathrm{F}$ to $90^{\circ} \mathrm{F}\left(16^{\circ} \mathrm{C}\right.$ to $\left.32^{\circ} \mathrm{C}\right)$. The high discharge temperature (or gas cooler inlet temperature) during supercritical operation indicates an opportunity for utilizing the rejected heat to offset some or all of the water heating or space heating needs of a supermarket. 


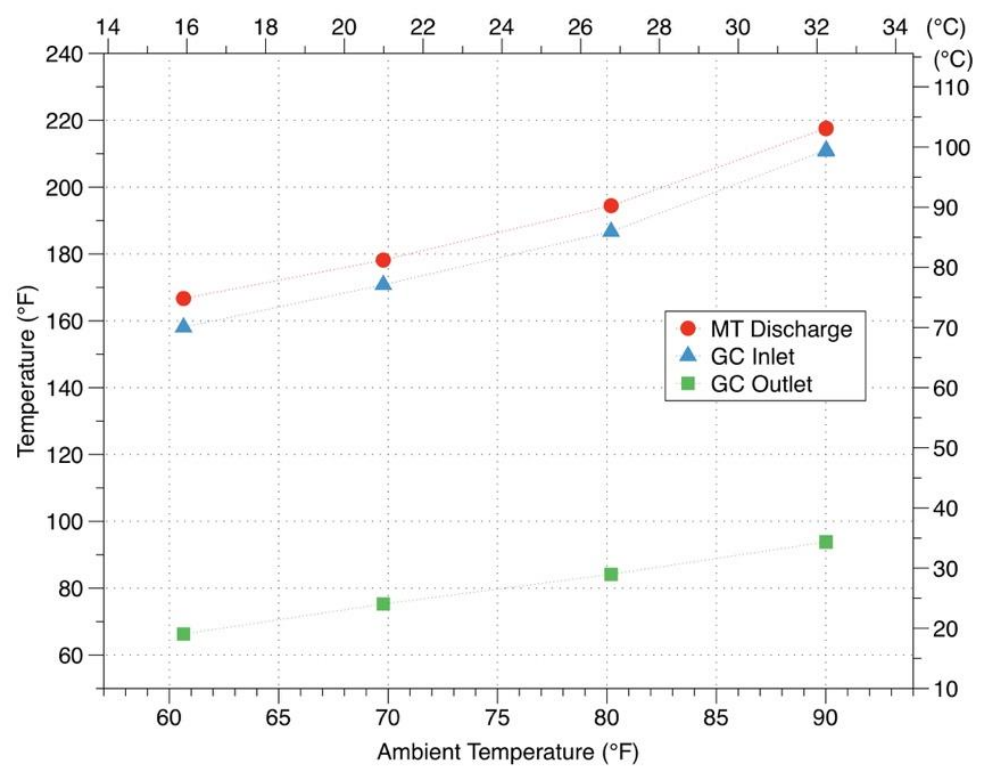

Fig. 22. Medium-temperature (MT) compressor discharge temperature, and gas cooler inlet and outlet temperatures.

Several system parameters were found to remain relatively constant during operation, regardless of outdoor ambient temperature. These parameters include flash tank pressure, LT compressor suction temperature and pressure, LT compressor discharge temperature and pressure, and MT compressor suction pressure. The refrigeration system controller maintains these parameters at constant values in order to provide the required display case temperature set points. The measured values for these parameters are shown in Table 13.

Table 13. Refrigeration system parameters

\begin{tabular}{lr}
\hline System Parameter & \multicolumn{1}{c}{ Value } \\
\hline Flash tank pressure & $502 \mathrm{psig}(3.56 \mathrm{MPa})$ \\
LT compressor suction temperature & $36^{\circ} \mathrm{F}\left(2.2^{\circ} \mathrm{C}\right)$ \\
LT compressor suction pressure & $180 \mathrm{psig}(1.34 \mathrm{MPa})$ \\
LT compressor discharge temperature & $157^{\circ} \mathrm{F}\left(69.4^{\circ} \mathrm{C}\right)$ \\
LT compressor discharge pressure & $383 \mathrm{psig}(2.74 \mathrm{MPa})$ \\
MT compressor suction pressure & $383 \mathrm{psig}(2.74 \mathrm{MPa})$ \\
\hline
\end{tabular}

The high pressure expansion valve located after the gas cooler expands the $\mathrm{CO}_{2}$ into the flash tank to a pressure of approximately $500 \mathrm{psig}(3.56 \mathrm{MPa})$, corresponding to a saturation pressure of about $33^{\circ} \mathrm{F}$ $\left(0.6^{\circ} \mathrm{C}\right)$. Thus, liquid $\mathrm{CO}_{2}$ at approximately $33^{\circ} \mathrm{F}\left(0.6^{\circ} \mathrm{C}\right)$ is fed from the flash tank to the refrigerated display cases and false loads. Since the LT loads remained fixed regardless of outdoor ambient temperature, the LT compressor suction and discharge temperatures and pressures remained relatively constant, as shown in Table 13. Also, since the LT compressor discharge, suction lines from the MT loads and the vapor from the flash tank all feed into the MT compressor suction, the MT compressor suction pressure remained constant at approximately $383 \mathrm{psig}(2.74 \mathrm{MPa})$. However, the MT compressor discharge pressure and temperature are affected by the outdoor ambient temperature, and these quantities varied accordingly. 


\subsection{DISCUSSION}

The transcritical $\mathrm{CO}_{2}$ booster refrigeration system performed as expected under the controlled laboratory conditions. Since the display cases were exposed to fixed conditions $\left(75^{\circ} \mathrm{F}, 55 \% \mathrm{RH}\right)$ throughout testing, the refrigeration loads remained fixed over the "outdoor" ambient temperature range. In addition, the compressor power, the gas cooler pressure, the MT discharge temperature, the gas cooler inlet temperature and gas cooler outlet temperature increased with increasing "outdoor" ambient temperature. This results in decreasing COP with increasing ambient temperature.

The performance of the transcritical $\mathrm{CO}_{2}$ booster refrigeration system was compared to that of a laboratory-scale HFC-based multiplex DX system using R-404A as the refrigerant. The HFC-based refrigeration system has a low-temperature cooling capacity of approximately 5 tons at a saturated evaporating temperature of $-20^{\circ} \mathrm{F}\left(18 \mathrm{~kW}\right.$ at $\left.-29^{\circ} \mathrm{C}\right)$ and a medium-temperature cooling capacity of approximately 10 to 15 tons at a saturated evaporating temperature of $25^{\circ} \mathrm{F}$ ( 35 to $53 \mathrm{~kW}$ at $-4^{\circ} \mathrm{C}$ ). Three open vertical display cases, each $12 \mathrm{ft}(3.7 \mathrm{~m})$ in length, constitute the low-temperature load. The medium-temperature load consists of two open vertical display cases, each $12 \mathrm{ft}(3.7 \mathrm{~m})$ in length, as well as a "false" load provided by a plate heat exchanger and glycol loop. The system contains two LT and two MT reciprocating compressors as well as an air-cooled condenser. Furthermore, this HFC-based refrigeration system is similarly instrumented to determine its performance.

The coefficients of performance of both the transcritical $\mathrm{CO}_{2}$ booster and the HFC-based refrigeration systems are shown in Fig. 23, as a function of ambient temperature. It can be seen that over the temperature range of $60^{\circ} \mathrm{F}\left(16^{\circ} \mathrm{C}\right)$ to approximately $88^{\circ} \mathrm{F}\left(31^{\circ} \mathrm{C}\right)$, the $\mathrm{COP}$ of the transcritical $\mathrm{CO}_{2}$ booster system is greater than that of the $\mathrm{HFC}$ system. At $60^{\circ} \mathrm{F}\left(16^{\circ} \mathrm{C}\right)$, the $\mathrm{COP}$ of the transcritical $\mathrm{CO}_{2}$ booster system was $25 \%$ higher than that of the HFC system, and on average between $60^{\circ} \mathrm{F}\left(16^{\circ} \mathrm{C}\right)$ and $88^{\circ} \mathrm{F}$ $\left(31^{\circ} \mathrm{C}\right)$, the $\mathrm{COP}$ of the the $\mathrm{CO}_{2}$ booster system was $15 \%$ greater than the HFC system. Extrapolating the trends above $88^{\circ} \mathrm{F}\left(31^{\circ} \mathrm{C}\right)$, it is expected that the HFC-based refrigeration system will have a greater COP than the transcritical $\mathrm{CO}_{2}$ booster system.

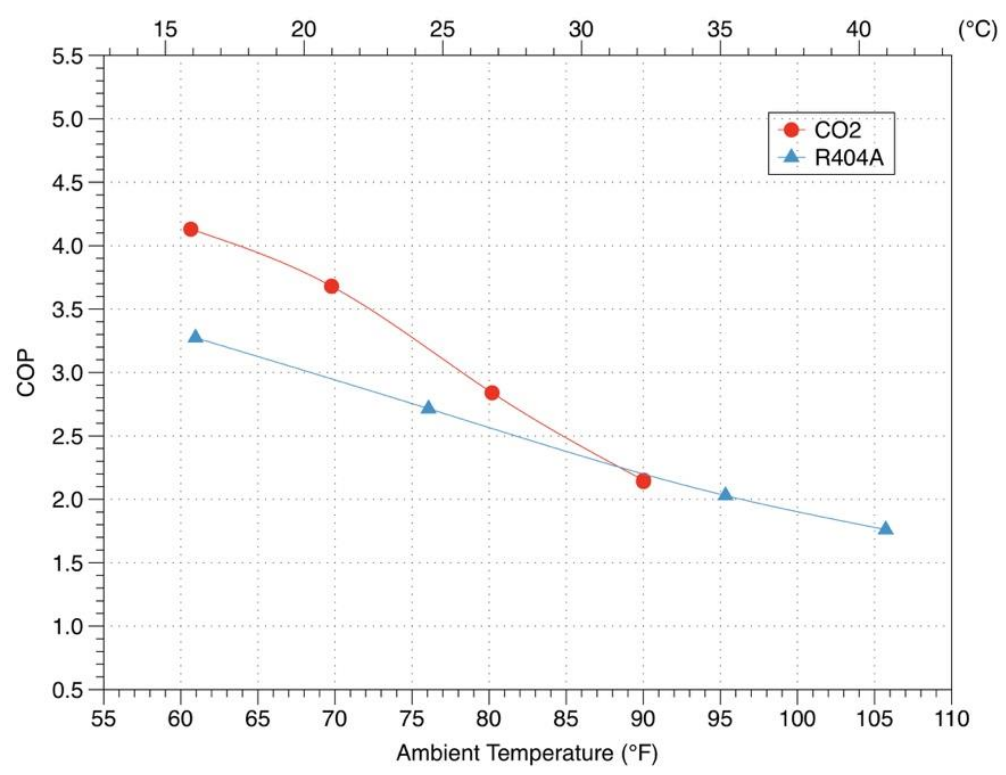

Fig. 23. Comparison of COP for R-404A multiplex DX and transcritical $\mathrm{CO}_{2}$ booster refrigeration systems.

For those climate zones with temperatures that fall mainly below $88^{\circ} \mathrm{F}\left(31^{\circ} \mathrm{C}\right)$, the transcritical $\mathrm{CO}_{2}$ booster refrigeration system would offer an energy benefit compared to the traditional HFC-based multiplex DX system. 


\section{FUTURE WORK}

Future efforts related to this project include completing a field evaluation of the transcritical $\mathrm{CO}_{2}$ booster refrigeration system in a third-party supermarket, as well as performing system modifications to enhance the efficiency of the $\mathrm{CO}_{2}$ refrigeration system, particularly in warm climates.

\subsection{FIELD EVALUATION}

Due to concerns related to ozone depletion and global climate change, refrigerants such as R-22 and $\mathrm{R}-404 \mathrm{~A}$, which are commonly used in commercial refrigeration systems, have been, or may potentially be, phased out due to their detrimental environmental effects. As noted previously, a transcritical carbon dioxide booster refrigeration system has been designed and developed for commercial refrigeration applications, which uses $\mathrm{CO}_{2}$ as the sole refrigerant. $\mathrm{CO}_{2}$ has a very low global warming potential ( GWP = 1), and thus the environmental impact of this system is estimated to be over $75 \%$ less than that of a traditional multiplex direct expansion system utilizing R-404A. The main objective of this field evaluation is to determine the energy consumption of a transcritical $\mathrm{CO}_{2}$ commercial refrigeration system in an actual, operating supermarket, thereby providing motivation to supermarket owners and operators to implement these low emission refrigeration systems.

\subsubsection{General Plan}

With the assistance of CRADA partner, Hillphoenix, a suitable supermarket will be identified for installation of a transcritical $\mathrm{CO}_{2}$ refrigeration system. Details of the refrigeration system to be installed will be collected, such as:

- Basic system layout

- MT and LT compressor specifications (capacity, power, quantity)

- Gas cooler/condenser specifications (capacity, fan power, quantity)

- Connected loads: display case and walk-in specifications (capacity, power, length/size)

- System control strategy (pressure and temperature setpoints, gas cooler/evaporator pressures, etc.)

The measured performance of the transcritical $\mathrm{CO}_{2}$ booster refrigeration system will be compared to that of a similarly configured HFC-based multiplex DX system. The performance of the multiplex DX refrigeration system will either be measured directly using a system operating in a similar location as the $\mathrm{CO}_{2}$ system or be determined with a calibrated energy model. The comparison of system performance between the baseline refrigeration system and the transcritical $\mathrm{CO}_{2}$ refrigeration system will be normalized to ambient conditions, operating conditions, and normalized to system capacity. Other operating parameters such as suction and discharge pressures, refrigeration-side and case temperatures, refrigerant level and system parameters setpoints will be compared.

It is anticipated that the performance of the refrigeration system will be determined for a period of no less than six months, with an effort to ensure that the system performance data is collected for both a cold and warm season.

\subsubsection{Data Acquisition}

The state of the existing data acquisition system connected to the refrigeration system, which could be accessed through the refrigeration system controller, will be assessed to determine the following:

- Type of quantities measured

- Location and number of quantities measured

- Frequency of measurements

- Suitability of measured quantities to assess effect of refrigerant retrofit 
It will be assumed that at a minimum, the following quantities should be measured to ensure that meaningful comparisons can be made between the baseline system and the $\mathrm{CO}_{2}$ system:

- Compressor and gas cooler/condenser fan power

- Gas cooler/condenser pressure and temperature

- MT (medium-temperature) suction pressure and temperature

- LT (low-temperature) suction pressure and temperature

- Display case discharge air temperatures

- MT and LT liquid flow rate

- Outdoor ambient temperature and relative humidity

- Store indoor temperature and relative humidity

Instrumentation and data acquisition equipment will be added to the refrigeration system for those quantities which are not sufficiently measured or recorded by the refrigeration system controller.

\subsubsection{Field Evaluation Report}

A detailed final report will be written to describe the results of the field evaluation of the transcritical $\mathrm{CO}_{2}$ refrigeration system. This report will include the following:

High Level Objectives

Description of Test System

- Clear description of the new refrigeration technology

- Clear description of the benchmark. Whenever possible, this baseline system should use reasonable-cost and up-to-date refrigeration technologies and fluids

Performance

○ Overall assumptions that should include operating conditions.

- Identification of sources of differences using both theoretical and well documented field measurement based arguments

○ Energy measurements including both annualized energy and peak summer energy consumption, and a "bin-hour" ambient temperature graph for typical year for the location of the test store

Economics

- Inclusion of any reliability considerations

○ Main assumptions that could affect return-on-investment (ROI)

Conclusions

- Realistic maintenance costs

\subsubsection{Progress-to-Date}

Hillphoenix and ORNL have negotiated the site selection and logistics for the field evaluation of the transcritical $\mathrm{CO}_{2}$ booster refrigeration system with two major food retailers. Installations are planned for the Summer and Fall of 2016, with results to be published in 2017.

\subsection{SYSTEM MODIFICATIONS}

At high ambient temperatures, the efficiency of the transcritical $\mathrm{CO}_{2}$ booster refrigeration system is low, compared to the traditional HFC-based multiplex DX system. To increase the efficiency of the $\mathrm{CO}_{2}$ refrigeration system, particularly in warm climates, a number of modifications can be made to the laboratory-scale system described in Chapter 4. These modifications include the use of ejectors, parallel compression, adiabatic gas cooling and mechanical subcooling. 


\subsubsection{Ejectors}

Carbon dioxide vapor compression refrigeration systems have a much larger pressure difference between the high- and low-pressure sides of the system than other refrigerant systems. An ejector can recover the large pressure drop to drive mass flow from the evaporator, and thus elevate the suction pressure entering the compressor. The pressure ratio across the compressor is reduced, leading to increased compressor efficiency. In addition, an ejector, in place of a conventional throttling device, recovers useful momentum during the expansion process, leading to higher system efficiency.

\subsubsection{Parallel Compression}

In the transcritical $\mathrm{CO}_{2}$ booster refrigeration system, the $\mathrm{CO}_{2}$ exiting the gas cooler is expanded through a high-pressure expansion valve to a flash tank at an intermediate pressure. This intermediate pressure is greater than that required for the MT and LT loads, and thus, the $\mathrm{CO}_{2}$ must be further expanded at the MT and LT loads. In the laboratory scale $\mathrm{CO}_{2}$ refrigeration system evaluated in this study, the flash gas which subsequently exits the flash tank is further expanded to the suction pressure of the MT loads. The expanded flash gas mixes with the suction gas from the MT loads and the discharge of the LT compressors to be compressed to the high pressure in the gas cooler. The technique of separately compressing the flash gas and the MT suction gas, known as parallel compression, can be used to increase system efficiency. Separate compressors are used to compress the flash gas directly from the flash tank to the high pressure in the gas cooler. Rather than expanding and then compressing the flash gas, it is compressed directly, and since the pressure ratio associated with compressing the flash gas directly is lower than that associated with compressing expanded flash gas, overall compressor energy use is be decreased.

\subsubsection{Adiabatic Gas Cooler}

The transcritical $\mathrm{CO}_{2}$ booster refrigeration system operates most efficiently when the $\mathrm{CO}_{2}$ remains subcritical. During warm ambient conditions, the $\mathrm{CO}_{2}$ refrigeration system will operate supercritically, and its efficiency will be degraded. The use of an adiabatic gas cooler can extend the transition from subcritical to supercritical operation by keeping the temperature and pressure of the $\mathrm{CO}_{2}$ below the critical point at higher ambient temperatures as compared to a simple air-cooled gas cooler, and thereby increase system efficiency. In an air-cooled gas cooler, the temperature of the $\mathrm{CO}_{2}$ at the outlet of the gas cooler approaches the dry-bulb ambient temperature. On the other hand, in an adiabatic gas cooler, the temperature of the $\mathrm{CO}_{2}$ at the exit of the gas cooler approaches the ambient wet-bulb temperature, which in warm dry climates, is significantly lower than that of the dry-bulb temperature. This effect is achieved by passing the ambient air first through a media saturated with moisture, which cools the ambient air, and then passing the cooled air over the coils of the gas cooler. Thus, the $\mathrm{CO}_{2}$ exiting the adiabatic gas cooler is lower than it would be if it had passed through an air-cooled gas cooler.

\subsubsection{Mechanical Subcooler}

A subcooler is a separate, smaller refrigeration cycle that is used to reduce the temperature of the $\mathrm{CO}_{2}$ exiting the gas cooler o below the ambient temperature, without affecting the discharge pressure. This may be achieved with another vapor compression cycle, a thermoelectric cooler, or other means. As a result, less flash gas is produced by the high-pressure expansion valve, and an increased refrigerating effect is created in the evaporator. The subcooling device typically can be operated at a much smaller temperature differential than that at which the refrigeration cycle is operating, so the efficiency of the subcooler itself may be comparably very high. The resulting lower compressor energy consumption, due to the reduced amount of flash gas and increased refrigerating effect, increases the overall cycle efficiency. 


\subsection{SUMMARY}

A field investigation of the transcritical $\mathrm{CO}_{2}$ booster refrigeration system is planned, in which a system will be installed in an actual, operating supermarket. A field testing plan has been developed with the CRADA partner, with the main objective to determine the energy consumption of a transcritical $\mathrm{CO}_{2}$ commercial refrigeration system in an actual, operating supermarket. It is hoped that the results of this field evaluation will provide the motivation for supermarket owners and operators to deploy these low emission refrigeration systems in their stores.

Future work will also include modification of the basic transcritical $\mathrm{CO}_{2}$ booster refrigeration system to enhance its performance, particularly in warm climates. These modifications include the use of ejectors, parallel compression, adiabatic gas cooling and mechanical subcooling. 


\section{CONCLUSIONS}

The objective of the Cooperative Research and Development Agreement (CRADA) between Oak Ridge National Laboratory (ORNL) and Hillphoenix, Inc., as described in this report, was to conduct research and development on a supermarket refrigeration system that reduces greenhouse gas emissions and has 25 to 30 percent lower energy consumption than existing systems.

Initially, energy and life cycle climate performance (LCCP) analyses were performed on a variety of supermarket refrigeration systems to identify those designs and refrigerant selections which exhibit both low environmental impact and high energy efficiency. The whole-building energy modeling tool, EnergyPlus, was used to model traditional multiplex direct expansion (DX) system, cascade systems with secondary loops and the transcritical $\mathrm{CO}_{2}$ system in a variety of climate zones across the United States. Furthermore, a variety of refrigerants were investigated, including R-32, R-134a, R-404A, R-1234yf, R717, and R-744. LCCP analysis was used to determine the direct and indirect carbon dioxide emissions resulting from the operation of the various refrigeration systems over their lifetimes. This analysis showed that a transcritical $\mathrm{CO}_{2}$ booster refrigeration system, coupled with high-efficiency display cases and walk-ins, can achieve average energy reductions of 39\% compared to the standard-efficiency R-404A multiplex DX system, with $76 \%$ lower emissions and hence is a potential low emission, high-efficiency alternative to the current baseline R-404A multiplex DX systems in use.

In order to optimize the operating parameters of $\mathrm{CO}_{2}$-based refrigeration systems, further analysis was presented of various $\mathrm{CO}_{2}$ transcritical and cascade/secondary loop refrigeration systems for supermarket applications. In addition, the performance of selected $\mathrm{CO}_{2}$-based refrigeration systems is compared to the baseline R-404A multiplex direct expansion system using bin analyses in the eight climate zones of the United States. It was found that the transcritical $\mathrm{CO}_{2}$ booster system (TBS-BC) performs as well as, or better than, the baseline R-404A multiplex DX system for all eight climate zones in the U.S. In the warm climate zones (Zones 1 and 2), the annual performance of the TBS-BC and multiplex DX systems are nearly identical. In the colder climates (Zones 6, 7 and 8), the annual average COP of the TBS-BC is approximately $40 \%$ greater than that of the R-404A multiplex DX system. Implementation of transcritical booster systems or cascade/secondary loop systems using optimized operating conditions will lead to reduced direct greenhouse gas emissions while achieving comparable energy consumption as compared to current HFC-based multiplex DX systems.

Based on the energy and life cycle climate performance (LCCP) analyses, it was determined that a transcritical $\mathrm{CO}_{2}$ booster refrigeration system for supermarket applications would meet the requirements of reduced carbon emissions and increased energy efficiency. To that end, the research team evaluated a laboratory-scale transcritical $\mathrm{CO}_{2}$ booster refrigeration system to be evaluated in ORNL's environmental chambers. The high-efficiency, low-emission commercial refrigeration system consists of a transcritical $\mathrm{CO}_{2}$ compressor rack, an air-cooled gas cooler/condenser, medium-temperature (MT) and lowtemperature (LT) refrigerated display cases, and MT and LT "false" loads. The laboratory-scale refrigeration system has a low-temperature cooling capacity of approximately 2.5 tons at a saturated evaporating temperature of $-22^{\circ} \mathrm{F}\left(9.1 \mathrm{~kW}\right.$ at $\left.-30^{\circ} \mathrm{C}\right)$ and a medium-temperature cooling capacity of approximately 9.6 tons at a saturated evaporating temperature of $20^{\circ} \mathrm{F}\left(34 \mathrm{~kW}\right.$ at $\left.-6.7^{\circ} \mathrm{C}\right)$. One 4 -door vertical display case, $10 \mathrm{ft}(3.0 \mathrm{~m})$ in length, as well as a "false" load provided by a plate heat exchanger and a glycol loop, constitutes the low-temperature load. The medium-temperature load consists of one open vertical display case, $8 \mathrm{ft}(2.4 \mathrm{~m})$ in length, as well as a "false" load provided by a plate heat exchanger and glycol loop. The laboratory-scale commercial refrigeration system was fully instrumented to monitor its performance. Refrigerant temperature and pressure were measured at the inlet and outlet of each major system component (gas cooler/condenser, display cases and false loads, compressors), and refrigerant flow rate to each load was measured. Power consumption of the compressor, gas cooler fans and display case fans/lighting and defrost heater were also measured. In addition, display case discharge and return air temperatures were measured. 
The performance of the transcritical $\mathrm{CO}_{2}$ booster refrigeration system was determined at four outdoor ambient temperature conditions, nominally $60^{\circ} \mathrm{F}\left(16^{\circ} \mathrm{C}\right), 70^{\circ} \mathrm{F}\left(21^{\circ} \mathrm{C}\right), 80^{\circ} \mathrm{F}\left(27^{\circ} \mathrm{C}\right)$ and $90^{\circ} \mathrm{F}\left(32^{\circ} \mathrm{C}\right)$. After the refrigeration system achieved steady-state operation at each of the four outdoor ambient temperature conditions, system performance data was collected for a 24-hour period. Over the outdoor ambient temperature range from $60^{\circ} \mathrm{F}$ to $90^{\circ} \mathrm{F}\left(16^{\circ} \mathrm{C}\right.$ to $\left.32^{\circ} \mathrm{C}\right)$, the coefficient of performance (COP) of the system was found to vary from 4.1 to 2.1. On average between ambient temperatures of $60^{\circ} \mathrm{F}$ and $88^{\circ} \mathrm{F}\left(16^{\circ} \mathrm{C}\right.$ and $\left.31^{\circ} \mathrm{C}\right)$, the $\mathrm{COP}$ of the the $\mathrm{CO}_{2}$ booster system was $15 \%$ greater than that of a laboratoryscale HFC refrigeration system. Extrapolating the trends for ambient temperatures above $88^{\circ} \mathrm{F}\left(31^{\circ} \mathrm{C}\right)$, it is expected that the HFC-based refrigeration system will have a greater $\mathrm{COP}$ than the transcritical $\mathrm{CO}_{2}$ booster system.

Based on the exceptional energy and environmental performance of the transcritical $\mathrm{CO}_{2}$ booster refrigeration system, the CRADA partner, Hillphoenix, has commercialized the system for supermarket refrigeration applications. To date, Hillphoenix has over 130 installations of transcritical $\mathrm{CO}_{2}$ booster refrigeration system in the U.S. 


\section{REFERENCES}

American Society of Heating, Refrigerating and Air-Conditioning Engineers (ASHRAE). 2005. ASHRAE Standard 72-2005, Method of Testing Commercial Refrigerators and Freezers. Atlanta, GA: American Society of Heating, Refrigerating and Air Conditioning Engineers.

Bansal, P.K. 2012. "A Review - Status of $\mathrm{CO}_{2}$ as a Low Temperature Refrigerant: Fundamentals and R\&D Opportunities." Applied Thermal Engineering 41:18-29.

Bell, I. 2004. "Performance Increase of Carbon Dioxide Refrigeration Cycle with the Addition of Parallel Compression Economization." 6th IIR Gustav Lorentzen Conference on Natural Working Fluids, Glasgow, UK, 29 August - 1 September 2004.

Denecke, J., A. Hafner, T. Eikevik, and Y. Ladam. 2012. "Heat Recovery Solutions for R744 Booster Commercial Refrigeration Systems." 10th IIR Gustav Lorentzen Conference on Natural Working Fluids, Delft, The Netherlands, 25-27 June 2012.

Deru, M., and P. Torcellini. 2007. Source Energy and Emission Factors for Energy Use in Buildings. NREL/TP-550-38617. Golden, CO: National Renewable Energy Laboratory.

Ferrandi, C., and M. Orlandi. 2012. "Theoretical Analysis of Cold Storage Device Effects on the Performance and Regulation of a $\mathrm{CO}_{2}$ Supermarket Refrigeration Plant." 10th IIR Gustav Lorentzen Conference on Natural Working Fluids, Delft, The Netherlands, 25-27 June 2012.

Food Marketing Institute (FMI). 2016. "Supermarket Facts." Accessed 1 February 2016. http://www.fmi.org/research-resources/supermarket-facts.

Fricke, B.A., and B.R. Becker. 2010. "Energy Use of Doored and Open Vertical Refrigerated Display Cases." 13th International Refrigeration and Air Conditioning Conference, Purdue University, West Lafayette, IN, 12-15 July 2010.

Ge, Y.T., and S.A. Tassou. 2009. "Control Optimization of $\mathrm{CO}_{2}$ Cycles for Medium-Temperature Retail Food Refrigeration Systems." International Journal of Refrigeration 32 (6):1376-1388.

Ge, Y.T., and S.A. Tassou. 2010. "Performance Evaluation and Control Optimization of a $\mathrm{CO}_{2} \mathrm{Booster}$ Refrigeration System in Supermarket." 1st IIR International Conference on Sustainability and the Cold Chain, Cambridge, UK, 29-31 March 2010.

Getu, H.M., and P.K. Bansal. 2008. "Thermodynamic Analysis of an R744-R717 Cascade Refrigeration System." International Journal of Refrigeration 31 (1):45-54.

Girotto, S., S. Minetto, and P. Nekså. 2004. "Commercial Refrigeration System using $\mathrm{CO}_{2}$ as the Refrigerant." International Journal of Refrigeration 27 (7):717-723.

Hafner, A., P. Nekså, and J. Pettersen. 2004. "Life Cycle Climate Performance (LCCP) of Mobile AirConditioning Systems with HFC-134a, HFC-152a and R-744." Mobile Air Conditioning Summit, Washington, D.C., 14-15 April 2004.

Hinde, D., and S. Zha. 2009. "Natural Refrigerant Applications in North American Supermarkets." IIAR Industrial Refrigeration Conference and Exhibition, Dallas, TX, 22-25 March 2009.

Horie, H., T. Kamiaka, C. Dang, and E. Hihara. 2010. "Study on Cycle Property and LCCP Evaluation of Heat Pump using HFO-1234yf, HFC-32, and HFC-410A as Refrigerant." 2010 International Symposium on Next-Generation Air Conditioning and Refrigeration Technology, Tokyo, Japan, 1719 February 2010.

ICF Consulting. 2005. Revised Draft Analysis of U.S. Commercial Supermarket Refrigeration Systems. Washington, D.C.: US Environmental Protection Agency (EPA).

Johnson, C. 2004. "The Embodied Greenhouse Gas Emissions of Carbon Dioxide Refrigerant (R-744) as an Adjustment to Global Warming Potential." 15th Annual Earth Technologies Forum and Mobile Air Conditioning Summit, Washington, D.C., 13-15 April 2004.

Kim, M., J. Pettersen, and C.W. Bullard. 2004. "Fundamental Process and System Design Issues in $\mathrm{CO}_{2}$ Vapor Compression Systems." Progress in Energy and Combustion Science 30 (2):119-174. 
Lemmon, E., M. McLinden, and M. Huber. NIST Standard Reference Database 23: Reference Fluid Thermodynamic and Transport Properties-REFPROP, Version 9.1, Standard Reference Data Program. Gaithersburg, MD: National Institute of Standards and Technology (NIST).

Mazzola, D., A. Toffolo, and M. Orlandi. 2012. "Supermarket Application. $\mathrm{CO}_{2}$ System with Groundwater Sink. Model Simulation." 10th IIR Gustav Lorentzen Conference on Natural Working Fluids, Delft, The Netherlands, 25-27 June 2012.

Pacific Northwest National Laboratory (PNNL). 2010. Volume 7.1, High-Performance Home Technologies: Guide to Determining Climate Regions by County. Wasthington, D.C.: U.S. Department of Energy (DOE).

Papasavva, S., W. Hill, and S. Andersen. 2010. "GREEN-MAC-LCCP: A Tool for Assessing the Life Cycle Climate Performance of MAC Systems." Environmental Science and Technology 44 (19):7666-7672.

Rauss, D., S. Mitchell, and R. Faramarzi. 2008. "Cool Retrofit Solutions in Refrigerated Display Cases." 2008 ACEEE Summer Study on Energy Efficiency in Buildings, Pacific Grove, CA, 17-22 August 2008.

Sarkar, J., and N. Agrawal. 2010. "Performance Optimization of Transcritical $\mathrm{CO}_{2}$ Cycle with Parallel Compression Economization." International Journal of Thermal Sciences 49 (5):838-843.

Sawalha, S. 2007. "Theoretical Evaluation of Trans-Critical $\mathrm{CO}_{2}$ Systems in Supermarket Refrigeration. Part 1: Modeling, Simulation and Optimization of Two System Solutions." International Journal of Refrigeration 31 (3):516-524.

Sawalha, S., and B. Palm. 2003. "Energy Consumption Evaluation of Indirect Systems with $\mathrm{CO}_{2}$ as Secondary Refrigerant in Supermarket Refrigeration." 21st IIR International Congress of Refrigeration, Washington, D.C., 17-22 August 2003.

Spatz, M., and S. Motta. 2004. "An Evaluation of Options for Replacing HCFC-22 in Medium Temperature Refrigeration Systems." International Journal of Refrigeration 27 (5):475-483.

US Department of Energy (DOE). EnergyPlus. Washington, D.C.: Energy Efficiency \& Renewable Energy, U.S. Department of Energy.

Westphalen, D., R.A. Zogg, A.F. Varone, and M.A. Foran. 1996. Energy Savings Potential for Commercial Refrigeration Equipment. Washington, D.C.: US Department of Energy (DOE).

Winter, J., and S. Murin. 2012. "Energy Saving and Increasing Reliability at $\mathrm{CO}_{2}$ Transcritical Boosters. A Case Study." 10th IIR Gustav Lorentzen Conference on Natural Working Fluids, Delft, The Netherlands, 25-27 June 2012.

Zhang, M. 2006. "Energy analysis of various supermarket refrigeration systems." 11 th International Refrigeration and Air Conditioning Conference, Purdue University, West Lafayette, IN, 17-20 July 2006.

Zhang, M., J. Muehlbauer, V. Aute, and R. Radermacher. 2011. Life Cycle Climate Performance Model for Residential Heat Pump Systems. Arlington, VA: Air-Conditioning Heating and Refrigeration Technology Institute (AHRTI). 
APPENDIX A. MEASUREMENT POINTS FOR LABORATORY-SCALE TRANSCRITICAL $\mathrm{CO}_{2}$ REFRIGERATION SYSTEM 



\section{APPENDIX A. MEASUREMENT POINTS FOR LABORATORY-SCALE TRANSCRITICAL $\mathrm{CO}_{2}$ REFRIGERATION SYSTEM}

A list of measurement points for the laboratory-scale transcritical $\mathrm{CO}_{2}$ booster refrigeration system is provided below. During the performance evaluation of the laboratory-scale transcritical $\mathrm{CO}_{2}$ booster refrigeration system, these system parameters were sampled and recorded once per second and subsequently, 30-second averaged data was used for the calculation of the system performance metrics.

- Mass flow of flash gas (lb/min)

- Mass flow of liquid refrigerant to LT display case (lb/min)

- Mass flow of liquid refrigerant to MT display case (lb/min)

- Mass flow of liquid refrigerant to LT false load (GPM)

- Mass flow of liquid refrigerant to MT false load (GPM)

- Mass flow of glycol to LT false load (GPM)

- Mass flow of glycol to MT false load (GPM)

- Pressure, flash tank (psig)

- Pressure, gas cooler refrigerant inlet (psig)

- Pressure, gas cooler refrigerant outlet (psig)

- Pressure, liquid to LT display case (psig)

- Pressure, suction of LT display case (psig)

- Pressure, liquid to LT false load (psig)

- Pressure, suction of LT false load (psig)

- Pressure, liquid to MT display case (psig)

- Pressure, suction of MT display case (psig)

- Pressure, liquid to MT false load (psig)

- Pressure, suction of MT false load (psig)

- Pressure, LT suction header (psig)

- Pressure, MT suction header (psig)

- Pressure, MT compressor discharge (psig)

- Relative humidity, indoor chamber air (\%)

- Relative humidity, outdoor chamber air (\%)

- Temperature, flash gas bypass expansion valve inlet $\left({ }^{\circ} \mathrm{F}\right)$

- Temperature, flash gas bypass expansion valve outlet $\left({ }^{\circ} \mathrm{F}\right)$

- Temperature, gas cooler fan \#1 inlet air $\left({ }^{\circ} \mathrm{F}\right)$

- Temperature, gas cooler fan \#2 inlet air $\left({ }^{\circ} \mathrm{F}\right)$

- Temperature, gas cooler fan \#1 outlet air $\left({ }^{\circ} \mathrm{F}\right)$

- Temperature, gas cooler fan \#2 outlet air $\left({ }^{\circ} \mathrm{F}\right)$

- Temperature, gas cooler refrigerant inlet $\left({ }^{\circ} \mathrm{F}\right)$

- Temperature, gas cooler refrigerant outlet $\left({ }^{\circ} \mathrm{F}\right)$

- Temperature, indoor chamber air $\left({ }^{\circ} \mathrm{F}\right)$

- Temperature, outdoor chamber air $\left({ }^{\circ} \mathrm{F}\right)$

- Temperature, liquid to LT display case $\left({ }^{\circ} \mathrm{F}\right)$

- Temperature, LT display case expansion valve outlet $\left({ }^{\circ} \mathrm{F}\right)$

- Temperature, suction of LT display case $\left({ }^{\circ} \mathrm{F}\right)$

- Temperature, LT display case return air $\left({ }^{\circ} \mathrm{F}\right)$

- Temperature, LT display case discharge air $\left({ }^{\circ} \mathrm{F}\right)$

- Temperature, liquid to LT false load $\left({ }^{\circ} \mathrm{F}\right)$

- Temperature, LT false load expansion valve outlet $\left({ }^{\circ} \mathrm{F}\right)$

- Temperature, suction of LT false load $\left({ }^{\circ} \mathrm{F}\right)$ 
- Temperature, LT false load glycol inlet $\left({ }^{\circ} \mathrm{F}\right)$

- Temperature, LT false load glycol outlet $\left({ }^{\circ} \mathrm{F}\right)$

- Temperature, LT compressor \#1 discharge $\left({ }^{\circ} \mathrm{F}\right)$

- Temperature, LT compressor \#1 suction $\left({ }^{\circ} \mathrm{F}\right)$

- Temperature, LT compressor \#2 discharge $\left({ }^{\circ} \mathrm{F}\right)$

- Temperature, LT compressor \#2 suction $\left({ }^{\circ} \mathrm{F}\right)$

- Temperature, LT suction header $\left({ }^{\circ} \mathrm{F}\right)$

- Temperature, LT discharge header $\left({ }^{\circ} \mathrm{F}\right)$

- Temperature, liquid to MT display case $\left({ }^{\circ} \mathrm{F}\right)$

- Temperature, MT display case expansion valve outlet $\left({ }^{\circ} \mathrm{F}\right)$

- Temperature, suction of MT display case $\left({ }^{\circ} \mathrm{F}\right)$

- Temperature, MT display case return air $\left({ }^{\circ} \mathrm{F}\right)$

- Temperature, MT display case discharge air $\left({ }^{\circ} \mathrm{F}\right)$

- Temperature, liquid to MT false load $\left({ }^{\circ} \mathrm{F}\right)$

- Temperature, MT false load expansion valve outlet $\left({ }^{\circ} \mathrm{F}\right)$

- Temperature, suction of MT false load $\left({ }^{\circ} \mathrm{F}\right)$

- Temperature, MT false load glycol inlet $\left({ }^{\circ} \mathrm{F}\right)$

- Temperature, MT false load glycol outlet $\left({ }^{\circ} \mathrm{F}\right)$

- Temperature, MT compressor \#1 discharge $\left({ }^{\circ} \mathrm{F}\right)$

- Temperature, MT compressor \# 1 suction $\left({ }^{\circ} \mathrm{F}\right)$

- Temperature, MT compressor \#2 discharge $\left({ }^{\circ} \mathrm{F}\right)$

- Temperature, MT compressor \#2 suction $\left({ }^{\circ} \mathrm{F}\right)$

- Temperature, MT compressor \#3 discharge $\left({ }^{\circ} \mathrm{F}\right)$

- Temperature, MT compressor \#3 suction $\left({ }^{\circ} \mathrm{F}\right)$

- Temperature, MT suction header $\left({ }^{\circ} \mathrm{F}\right)$

- Temperature, MT discharge header $\left({ }^{\circ} \mathrm{F}\right)$

- Temperature, compressor rack inlet, from gas cooler $\left({ }^{\circ} \mathrm{F}\right)$

- Temperature, compressor rack outlet, to gas cooler $\left({ }^{\circ} \mathrm{F}\right)$

- Temperature, compressor rack outlet, liquid to display cases $\left({ }^{\circ} \mathrm{F}\right)$

- Temperature, compressor rack outlet, liquid to false loads $\left({ }^{\circ} \mathrm{F}\right)$

- Temperature, compressor rack inlet, LT display case suction $\left({ }^{\circ} \mathrm{F}\right)$

- Temperature, compressor rack inlet, LT false load suction $\left({ }^{\circ} \mathrm{F}\right)$

- Temperature, compressor rack inlet, MT display case suction $\left({ }^{\circ} \mathrm{F}\right)$

- Temperature, compressor rack inlet, MT false load suction $\left({ }^{\circ} \mathrm{F}\right)$

- Power, gas cooler fans (W)

- Power, LT compressor \#1 (W)

- Power, LT compressor \#2 (W)

- Power, MT compressor \#1 (W)

- Power, MT compressor \#2 (W)

- Power, MT compressor \#3 (W) 